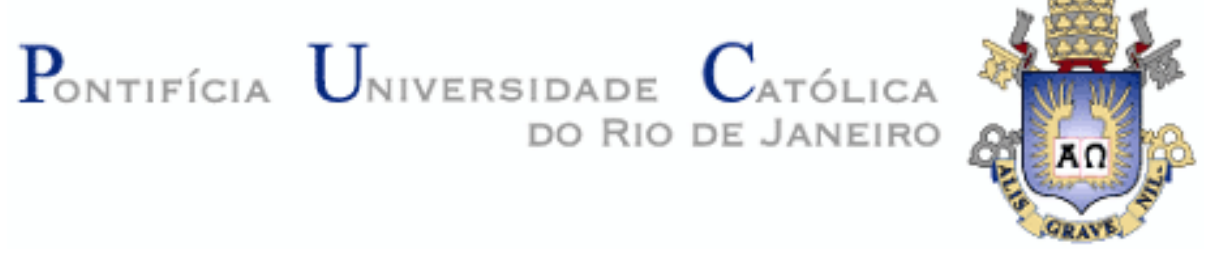

Marco Vinicio Guamán Alarcón

Short fatigue cracks departing from elongated notched specimens and their effect on fatigue limit

Tese de Doutorado

Thesis presented to the Programa de PósGraduação em Engenharia Mecânica of PUC-Rio in partial fulfillment of the requirements for the degree of Doutor em Ciências - Engenharia Mecânica.

Advisor: Prof. Jaime Tupiassú Pinho de Castro

Rio de Janeiro

June 2017 
Marco Vinicio Guamán Alarcón

\section{Short fatigue cracks departing from elongated notched specimens and their effect on fatigue limit}

Thesis presented to the Programa de Pós-graduação em Engenharia Mecânica of PUC-Rio in partial fulfillment of the requirements for the degree of Doutor em Ciências Engenharia Mecânica. Approved by the undersigned Examination Committee.

Prof. Jaime Tupiassú Pinho de Castro Advisor

Departamento de Engenharia Mecânica - PUC-Rio

Prof. José Luiz de França Freire Departamento de Engenharia Mecânica - PUC-Rio

Prof. Marco Antonio Meggiolaro Departamento de Engenharia Mecânica - PUC-Rio

Prof. Antonio Carlos de Oliveira Miranda Universidade de Brasília - UNB

Prof. Paulo Pedro Kenedi Centro Federal de Educação Tecnológica - CEFET/RJ

Prof. Marcio da Silveira Carvalho

Vice Dean of Graduate Studies Centro Técnico Científico - PUC-Rio

Rio de Janeiro, June 5th, 2017. 
All rights reserved.

\section{Marco Vinicio Guamán Alarcón}

Majored in Mechanical Engineering at Escuela Politécnica Nacional (Quito-Ecuador, 2009). He obtained his master's degree in 2012 at PUC-Rio. He had experience in the area of structural integrity and fatigue, especially in the study of non-propagating short cracks.

Bibliographic data

Guamán Alarcón, Marco Vinicio

Short fatigue cracks departing from elongated notched specimens and their effect on fatigue limit / Marco Vinicio Guamán Alarcón; advisor: Jaime Tupiassú Pinho de Castro. - 2017.

109 f. : il. color. ; $30 \mathrm{~cm}$

Tese (doutorado)-Pontifícia Universidade Católica do Rio de Janeiro, Departamento de Engenharia Mecânica, 2017.

Inclui bibliografia

1. Engenharia Mecânica - Teses. 2. Trincas curtas não-propagantes. 3. Limite de fadiga. 4. Modelo do Gradiente de Tensão (GT). 5. Teoria da Distância Crítica (TDC). 6. Detecção de trincas curtas. I. Castro, Jaime Tupiassú Pinho de. II. Pontifícia Universidade Católica do Rio de Janeiro. Departamento de Engenharia Mecânica. III. Título.

CDD: 621 
To: GOD and my homeland; my parents: Anita y José; my brothers and sisters: Darwin, José, Mary, Tomás y Fernanda; my beloved wife, Patty. 


\section{Acknowledgements}

Firstly, I would like to thank my advisor Prof. Jaime Tupiassú Pinho de Castro for his guidance during the development of this work and acknowledge PUC-Rio and Brazil for the financial support trough the scholarships provided to me by CAPES and CNPq that made this work possible.

I would also like to thank everyone who contributed to the realization of the experimental program of this work, especially to: Rodrigo Landim and Mourad Chekchaki (Corrosion Lab, INT), Marcos Henrique and Prof. Sidnei Paciornik (LMD-DEQM), Adrian Giassone (ITUC), Euclides Neto (LEM-DEC), Asafe Cavalcanti (LMTT-DEQM), Giancarlo Gomes, Renato Vieira and Vitor Eboli (Fatigue Lab, DEM).

I would like to thank all the members of the Examination Committee for their invaluable suggestions and recommendations to improve this work, especially to Prof. Antonio Carlos Miranda for providing the FE analysis by Quebra2D software.

Furthermore, I want to thank my friends of Fatigue lab: Prof. José Luiz, Felipe, Giancarlo, Jesús, Jorge, José Eduardo, Julián, Prof. Ronaldo, Renato and Vitor and also my Ecuadorian friends: Prof. Guillermo Solórzano, Byron, Daniel, Diego, Jacobo, Lenin, Lucho and Verónica for their constant support.

Last but not least, I would like to thank my parents, my brothers and sisters so much for all of their unconditional love and help. And most importantly, I would like to thank my beloved wife Patty. Her constant encouragement, patience and unwavering love were my inspiration while developing this work. 


\section{Abstract}

Guamán Alarcón, Marco Vinicio; Castro, Jaime Tupiassú Pinho de (Advisor). Short fatigue cracks departing from elongated notched specimens and their effect on fatigue limit. Rio de Janeiro, 2017. 109p. Tese de Doutorado - Departamento de Engenharia Mecânica, Pontifícia Universidade Católica do Rio de Janeiro.

The mechanical design of structural components for high cycle fatigue applications needs reliable fatigue limits. However, mainly because of notches and the unavoidable presence of small defects, such a task still presents some challenges. Notches cause a stress concentration effect that can initiate short cracks at their tips, but such short cracks may propagate or become nonpropagating, depending not only on the load level, but on the stress gradient ahead of the notch tip as well. Notch-like defects, such as scratches, pores, and inclusions, behave in the same way. There are empirical and theoretical models to predict the fatigue limit of notched components. The latter includes the so-called Stress Gradient (SG) model, based on linear elastic fracture mechanics concepts and using the El Haddad-Topper-Smith (ETS) characteristic size $a_{\mathrm{R}}$, as a promissory approach. However, there is a lack of experimental data verifying their fatigue limit predictions. In this context, $\mathrm{C}(\mathrm{T})$-like notched specimens of SAE 1020 steel with several notch root radii were tested under constant load amplitude control at $40 \mathrm{~Hz}$ and a stress ratio $R=0.1$, to evaluate their fatigue limit through accelerated tests involving step loading procedures with blocks of $3 \cdot 10^{6}$ cycles. The experimental fatigue limit was compared with values predicted by SG model, following three approaches: $\mathrm{SG}_{\mathrm{C}-\mathrm{P}}, \mathrm{SG}_{\mathrm{s}-\mathrm{e}}$, and $\mathrm{SG}_{\text {Quebra, }}$ according to the determination of the geometric factor of the stress concentration factor; and with an alternative prediction by the Point Method based on the theory of criticaldistance (TCD). SG $\mathrm{S}_{\mathrm{C}-\mathrm{P}}, \mathrm{SG}_{\text {Quebra }}$ and TCD model predictions are almost coincident for blunt notches and they present a good agreement with experimental results, but they are non-conservatives in the case of sharp notches; while $\mathrm{SG}_{\mathrm{C}-\mathrm{P}}$ predictions are conservative for both blunt and sharp notches. Since both models are based on linear elastic concepts, it was demonstrated that an elastic analysis presents limitations to model the behavior of short cracks emanating from sharp notches, due to the local stress at the critical point can exceed the yield strength of the 
material. Furthermore, according to SG model, the fatigue limit is related to the presence of non-propagating short cracks (NPSC). Such surface NPSCs on the face of the specimens were monitored by non-destructive techniques including optical microscopy, digital image correlation (DIC) and micro-computed tomography; whereas subsurface NPSCs were detected through destructive metallographic technique. The sizes of the detected NPSCs were much smaller than those values predicted by SG model, which in turn makes the detection of these cracks a more complex problem.

\section{Keywords}

Non-propagating short cracks; fatigue limit; Stress Gradient (SG) model; Theory of Critical Distance (TCD); detection of short cracks. 


\section{Resumo}

Guamán Alarcón, Marco Vinicio; Castro, Jaime Tupiassú Pinho de (Orientador). Trincas curtas de fadiga emanando da ponta de entalhes alongados e seu efeito no limite de fadiga. Rio de Janeiro, 2017. 109p. Tese de Doutorado - Departamento de Engenharia Mecânica, Pontifícia Universidade Católica do Rio de Janeiro.

O projeto mecânico de componentes estruturais para vidas longas à fadiga requer limites de fadiga confiáveis. Porém, a previsão do limite de fadiga ainda apresenta alguns desafios, especialmente por causa dos inevitáveis entalhes e pela presença de pequenos defeitos intrínsecos do material que podem ser considerados como microtrincas. Os entalhes atuam como concentradores de tensão e microtrincas podem ser geradas na ponta destes. Tais microtrincas (geradas ou intrínsecas) podem propagar até provocar a falha do componente ou parar de propagar depois de crescer uma pequena distância e se tornarem não-propagantes, dependendo do nível de carga e do gradiente de tensão à frente do entalhe. Modelos empíricos e teóricos têm sido propostos para fazer previsão do limite de fadiga de componentes entalhados. Entre os teóricos, o chamado modelo do Gradiente de Tensão (GT), que utiliza conceitos da mecânica da fratura linear elástica, apresenta-se como um modelo promissor. No entanto, a validação experimental das previsões deste modelo ainda não tem sido completamente realizada. Neste contexto, corpos de prova tipo $\mathrm{C}(\mathrm{T})$ do aço 1020 e com vários valores do raio da ponta do entalhe foram testados sob controle de amplitude de carga constante, frequência de $40 \mathrm{~Hz}$ e razão de tensão $R=0.1$ para avaliar o limite de fadiga através de testes acelerados com cargas tipo "step up" durante blocos de $3 \cdot 10^{6}$ ciclos. O limite de fadiga determinado experimentalmente foi comparado com as previsões do modelo GT e do Método do Ponto, um dos métodos da chamada Teoria da Distância Crítica (TDC). No modelo GT foram considerados três métodos: $\mathrm{GT}_{\mathrm{C}-\mathrm{P}}, \mathrm{GT}_{\mathrm{s}-\mathrm{e}}$ e $\mathrm{GT}_{\text {Quebra }}$, segundo o método usado para achar o fator geométrico para determinar o fator de intensidade de tensão. As previsões dos modelos $\mathrm{GT}_{\mathrm{C}-\mathrm{P}}, \mathrm{GT}_{\text {Quebra }}$ e TDC são similares no caso de entalhes com raios de ponta grandes, e bem próximas do limite de fadiga medido experimentalmente, enquanto que eles são não-conservativos no caso de entalhes afiados (raios de ponta pequenos). As previsões do modelo $\mathrm{GT}_{\mathrm{s} \text {-e }}$ foram 
conservativas para entalhes afiados e não afiados. Devido a que os dois modelos são baseados em conceitos lineares elásticos, foi demonstrado que uma análise elástica apresenta limitações para modelar o comportamento à fadiga em entalhes afiados, pois nesses casos a tensão local no ponto crítico pode exceder o limite de escoamento do material. Alem disso, o modelo GT também permite estimar o tamanho da maior trinca curta não-propagante (TCNP) associada ao limite de fadiga. Tais TCNP foram monitoradas nas faces do $\mathrm{C}(\mathrm{T})$ através de técnicas nãodestrutivas tais como microscopia óptica, correlação digital de imagens e tomografia; enquanto que as TCNP internas foram detectadas usando a técnica destrutiva da metalografia. Os tamanhos das TCNP detectadas foram muito menores do que as estimadas pelo modelo GT, dificultando ainda mais o problema de detecção daquelas trincas.

\section{Palavras-chave}

Trincas curtas não-propagantes; limite de fadiga; modelo do Gradiente de Tensão (GT); Teoria da Distância Crítica (TDC); detecção de trincas curtas. 


\section{Table of contents}

$\begin{array}{lll}1 & \text { Introduction } & 20\end{array}$

1.1. Objectives 22

1.1.1. General objective 22

1.1.2. Specific objectives 22

1.2. Summary 23

$2 \quad$ Preliminary concepts and literature review 24

2.1. Stress concentration at notches 24

2.2. Stress concentration around crack tips 28

2.3. Similitude concept in fracture mechanics 30

2.4. Relationship between notch and crack stress distributions 31

2.5. Short crack propagation threshold and the ETS model 32

2.6. The Stress Gradient model 35

2.6.1. Short cracks departing from semielliptical elongated notches in plates 35

2.6.2. Short cracks departing from elongated notches in $\mathrm{C}(\mathrm{T})$ specimens $\quad 37$

2.7. The Theory of Critical Distances (TCD) 39

2.7.1. The Point Method (PM) 39

2.7.2. The Line Method (LM) 40

2.7.3. The Area (AM) and Volume (VM) Methods 40

2.8. Experimental techniques for detection of short fatigue cracks 41

2.8.1. Optical techniques 41

2.8.2. Digital image correlation, DIC [29] 42

2.8.3. X-ray micro-computed tomography 43

2.9. Short fatigue cracks: literature review 47

2.9.1. Short fatigue cracks at sharp notches 48

2.9.2. Fatigue limit predictions in notched specimens 51

3 Estimation of the short crack characteristic size $a_{0.1} \quad 53$

3.1. Selection of the material for the experimental verification 53

3.2. Standard tension testing and average grain size 54

3.3. Long crack propagation threshold $\Delta K_{0.1} \quad 56$

3.3.1. Compression-compression precracking + constant amplitude loading 57 
3.3.2. ASTM E647: $K$-decreasing $+K$-increasing 58

3.4. Smooth specimen fatigue limit $\Delta S_{0.1} \quad 59$

3.4.1. Dixon's up-and-down method 60

3.4.2. IR thermography method 63

3.5. Short crack characteristic size $a_{0.1} \quad 69$

4 Experimental verification 71

4.1. Geometry and dimensions of the specimen 71

4.2. Fatigue limit prediction of the $\mathrm{C}(\mathrm{T})$-like specimen 74

4.2.1. SG model $\quad 74$

4.2.2. TCD model $\quad 77$

4.3. Experimental procedure for $K_{\mathrm{f}}$ assessment 79

4.4. $\mathrm{C}(\mathrm{T})$-like specimen preparation 81

4.5. Techniques and equipment for short crack detection 82

4.5.1. Optical microscopy 82

4.5.2. Digital Image Correlation, DIC 82

4.5.3. X-ray micro-computed tomography 83

5 Results and discussions $\quad 85$

5.1. Fatigue limit assessment of the $\mathrm{C}(\mathrm{T})$-like specimen 85

5.2. Attempts for short cracks detection 88

5.2.1. Optical microscopy 88

5.2.2. Digital Image Correlation, DIC 89

5.2.3. Destructive metallographic analysis 90

5.2.4. X-ray micro-computed tomography 91

5.3. Discussion 95

5.3.1. $K_{\mathrm{f}}$ predictions $\quad 95$

5.3.2. $a_{\max }$ predictions and short cracks detection 96

6 Conclusions and future works 98

6.1. Conclusions 98

6.2. Future works 99

$\begin{array}{lll}7 & \text { References } & 101\end{array}$ 


\section{List of figures}

Figure 2.1- Stress concentration problem: Inglis' plate.

Figure 2.2- Comparison between experimentally obtained $K_{\mathrm{f}}$ and $K_{\mathrm{t}}$ [9].

Figure 2.3- Non-propagating short cracks founded at notch tips when $S_{\mathrm{L}} / K_{\mathrm{t}}<\sigma_{\mathrm{na}}<S_{\mathrm{L}} / K_{\mathrm{f}}$ at $R=-1$ [11].

Figure 2.4- The three modes of loading and notation [14]. 28

Figure 2.5- Coordinate system for Creager-Paris approach [14].

Figure 2.6- Kitagawa-Takahashi plot describing the fatigue propagation of short and long cracks under pulsating loads $(R=0)$ in a HT80 steel with $\Delta K_{0}=11.2 \mathrm{MPa} \sqrt{\mathrm{m}}$ and $\Delta S_{0}=575 \mathrm{MPa}[19]$.

Figure 2.7- Short-crack to long-crack FCG thresholds ratio as a function of $a / a_{0}[14]$.

Figure 2.8- Experimental results of stress gradients ahead a semielliptical notch with $c \leq b$, reported by Nishitani and Tada, fitted using Quebra $2 D$ software $\left(\Delta \sigma=\Delta \sigma_{\mathrm{n}}\right)$ [5].

Figure 2.9- a) PM and b) LM methods applied on the elastic stress field ahead of a notch tip [24].

Figure 2.10- Experimental configuration for the in-situ detection of short fatigue crack by optical microscopy [28].

Figure 2.11- Matching between the subsets of the reference and deformed images.

Figure 2.12- Scheme of X-ray microCT principle, showing acquisition and reconstruction processes [30].

Figure 2.13- a) Configuration of a conventional microCT system, where a microfocus X-ray source is shown and b) Illustration of the geometric blurring $r_{S}$ induced by the size of the source spot S [36].

Figure 2.14- Differences between blunt and sharp notches as a function of $K_{\mathrm{t}}$, based on Frost diagram (adapted from Meneghetti et al. [39]).

Figure 2.15- Differences between short and long crack propagation (adapted from [50]). 
Figure 2.16- Schematic representation of the growth rate $\mathrm{d} a / \mathrm{d} N$ as a function of the crack length $a$ (adapted from [50]).

Figure 3.1- Dimension of the TS for tension tests according to ASTM E8M-13a standard.

Figure 3.2- Stress-strain curves of the tension tests of two specimens.

Figure 3.3- Typical micrograph of the austenitic grain structure of SAE 1020 steel.

Figure 3.4- Dimensions in $\mathrm{mm}$ of the $\mathrm{C}(\mathrm{T})$-like specimen used for $\Delta K_{0.1}$ assessment.

Figure 3.5- Loading applied to a $\mathrm{C}(\mathrm{T})$ specimen for $\Delta K_{0.1}$ assessment.

Figure 3.6- $\mathrm{d} a / \mathrm{d} N \times \Delta K$ curves of the trial and error procedure for $\Delta K_{0.1}$ assessment.

Figure 3.7- Loading applied to a $\mathrm{C}(\mathrm{T})$ specimen for $\Delta K_{0.1}$ assessment following ASTM E647.

Figure 3.8- $\mathrm{d} a / \mathrm{d} N \times \Delta K$ curves of the trial and error procedure for $\Delta K_{0.1}$ assessment following ASTM E647.

Figure 3.9- Dimensions in $\mathrm{mm}$ of the test specimen used for $\Delta S_{0.1}$ assessment.

Figure 3.10- Fatigue limit of the tested SAE 1020 steel measured by the Dixon's up-and-down method for $R=0.1$ and $N>$ $2 \cdot 10^{6}$.

Figure 3.11- Phases of the thermal behaviour of $\Delta T \times N$ curve for a hot point in the specimen surface during typical fatigue tests [65].

Figure 3.12- a) Camera FLIR A655sc and b) reference and specimen areas and thermal profile used to measure the specimen surface temperature in the fatigue tests.

Figure 3.13- Cycles needed to achieve a steady-state temperature (phase 2) with a FLIR A655sc camera.

Figure 3.14- Fatigue limit evaluation of three test specimens (TS) of SAE 1020 steel tested by thermography, $R=0.1$.

Figure 3.15- a) $100 \mathrm{kN}$ INSTRON machine and the IR thermographic camera, b) test specimen enclosed by the insulated wood chamber. 
Figure 3.16- $\sigma_{a} \times \sigma_{\mathrm{m}}$ empirical curves and experimental results from Dixon's up-and-down and IR thermography methods for SAE 1020 steel.

Figure 4.1- Dimensions in $\mathrm{mm}$ of the $\mathrm{C}(\mathrm{T})$-like specimen used to verify the SG predictions, whose stress concentration factor was calculated by finite elements.

Figure 4.2- a) $K_{\mathrm{t}}(\mathrm{FEM}) / K_{\mathrm{t}}(\mathrm{C}-\mathrm{P})$ distribution along the notch front. b) and c) are the typical ratio $f_{1}=\sigma_{y}(x) / \sigma_{\mathrm{n}}$ that describes the stress concentration gradient ahead the notch tip.

Figure 4.3- Ratio $f_{1}=\sigma_{y}(x) / \sigma_{\mathrm{n}}$ that describes the stress concentration effect ahead the notch tip of a $\mathrm{C}(\mathrm{T})$-like specimen for several $\rho$ values.

Figure 4.4- Estimated $\left(f_{1}\right)$ and calculated $(f)$ geometry factor functions of the SIF of short cracks that depart from the notch tip in a $\mathrm{C}(\mathrm{T})$-like specimen $(W=60 \mathrm{~mm}, b=15 \mathrm{~mm})$. Notch root radius a) $\rho=0.15 \mathrm{~mm}$, and b) $\rho=1.25 \mathrm{~mm}$.

Figure 4.5- Curves of the dimensionless $f_{1, \mathrm{C}-\mathrm{P}}$ and $g$ functions used to calculate $K_{\mathrm{f}}$ for a $\mathrm{C}(\mathrm{T})$ with $b=15 \mathrm{~mm}$ and $\rho=0.15 \mathrm{~mm}$.

Figure 4.6- The SIF range of short cracks emanating at the notch tip and the short crack propagation threshold $\Delta K_{\text {th }}$ as a function of the crack length $a$ for $S G_{c-p}$ model.

Figure 4.7- Dimensionless ratio $f_{1, \mathrm{C}-\mathrm{P}}=\sigma_{y}(x) / \sigma_{\mathrm{n}}$ ahead the notch tip for prediction of $K_{\mathrm{f}}$ by TCD using the Point Method.

Figure 4.8- a) $K_{\mathrm{t}}$ estimated by the C-P's approach and $K_{\mathrm{f}}$ predicted by the SG and TCD-PM models, and b) $a_{\max }$ predicted by the SG model, as a function of the notch radius $\rho$.

Figure 4.9- $\mathrm{C}(\mathrm{T})$-like notched specimen tested in a servo-hydraulic machine. A traveling microscope is included for in-situ monitoring of the notch root region.

Figure 4.10- Sanding direction and grits used the notch tip area of the specimens.

Figure 4.11- Optical microscope for crack detection.

Figure 4.12- a) Notch root area of the painted face of the $\mathrm{C}(\mathrm{T})$-like specimen analyzed by DIC, and b) DIC system for crack detection.

Figure 4.13- a) External and b) internal configurations of ZEISS Xradia 510 Versa microtomograph. X-ray source (left), specimen (middle) and detector (right).

Figure 5.1- Frost diagram for five $\mathrm{C}(\mathrm{T})$-like specimens with different notch root radii $\rho$. The upper limit for non-propagating 
cracks is defined by the curve of each model and the lower limit is defined by $\Delta S_{0.1} / K_{\mathrm{t}}$ ratio.

Figure 5.2- Frost diagram for $17 \mathrm{C}(\mathrm{T})$-like specimens with notch root radius $\rho=0.15 \mathrm{~mm}$. (NPSC: non-propagating short cracks).

Figure 5.3- Optical micrographs for the three surface NPSCs detected.

Figure 5.4- Stress-displacement plots for CT-0.15-4 specimen 89

Figure 5.5- Stress-displacement plots for CT-0.15-11 specimen. 90

Figure 5.6- Optical images of subsurface (internal) NPSC. Plane located at a) $2 \mathrm{~mm}$ and b) $3.5 \mathrm{~mm}$ from the face of the $\mathrm{C}(\mathrm{T})$.

Figure 5.7- Images obtained by X-ray microCT examination. a) 3D notch tip region and b) plane located at $4 \mathrm{~mm}$ from the face of the Al6061T3 C(T)-like specimen.

Figure 5.8- X-ray transmission rate as a function of the largest dimension of low carbon steel and aluminum $\mathrm{C}(\mathrm{T})$ specimen, when the voltage of the source is $150 \mathrm{kV}$. 


\section{List of tables}

Table 3.1- Estimations of the characteristic short crack size $a_{0}$ for several structural low carbon steels.

Table 3.2- Chemical composition of the tested SAE 1020 steel.

Table 3.3- Basic mechanical properties of the tested SAE 1020 steel.

Table 3.4- Determination of the constants $A, B$ and $C$ for DixonMood's statistical analysis.

Table 3.5- Stress amplitude $(\Delta \sigma / 2)$ and the corresponding $\Delta T$ for each load step applied on three specimens of tested SAE 1020 steel.

Table 4.1- Predictions of the fatigue SCF $K_{\mathrm{f}}$ for a C(T)-like specimen with $W=60 \mathrm{~mm}, b=15 \mathrm{~mm}$ and several notch tip radius $\rho$.

Table 4.2- Predictions of the largest tolerable crack $a_{\max }$ for a C(T)like specimen with $W=60 \mathrm{~mm}, b=15 \mathrm{~mm}$ and several notch tip radius $\rho$.

Table 4.3- Characteristic of ZEISS Xradia 510 Versa system. 84

Table 4.4- Chemical composition of Al6061T3 aluminum alloy.

Table 4.5- Mechanical properties from the literature, including $K_{\mathrm{f}}$ and $a_{\max }$ predicted by SG model applied to an Al6061T3 $\mathrm{C}(\mathrm{T})$-like specimen.

Table 5.1- $\mathrm{C}(\mathrm{T})$-like specimens codification based on their notch root radius $\rho$.

Table 5.2- X-ray transmission rate for SAE 1020 and Al6061T3 $\mathrm{C}(\mathrm{T})$-like specimen. 


\section{List of abbreviations and symbols}

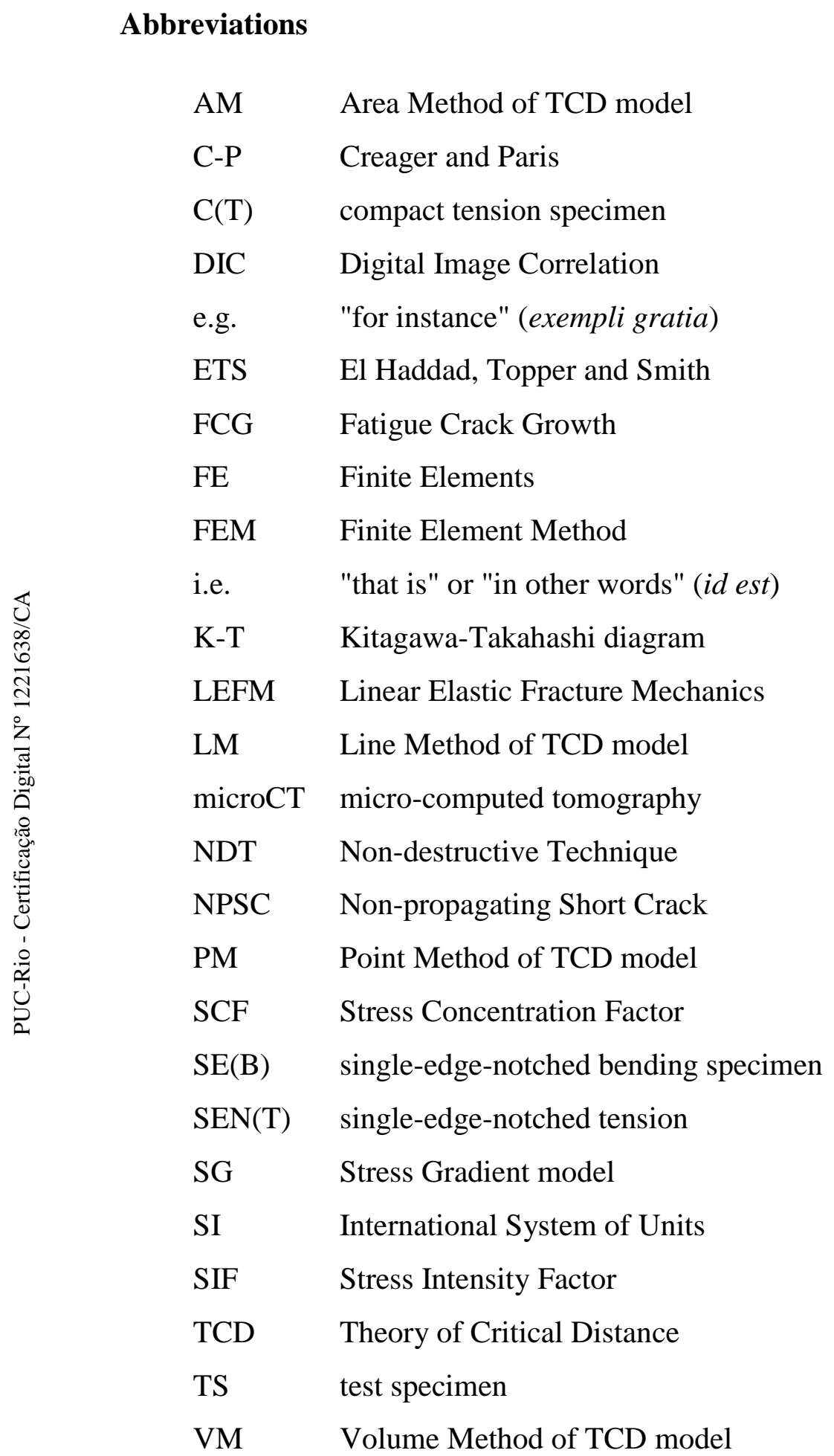




\section{Symbols}

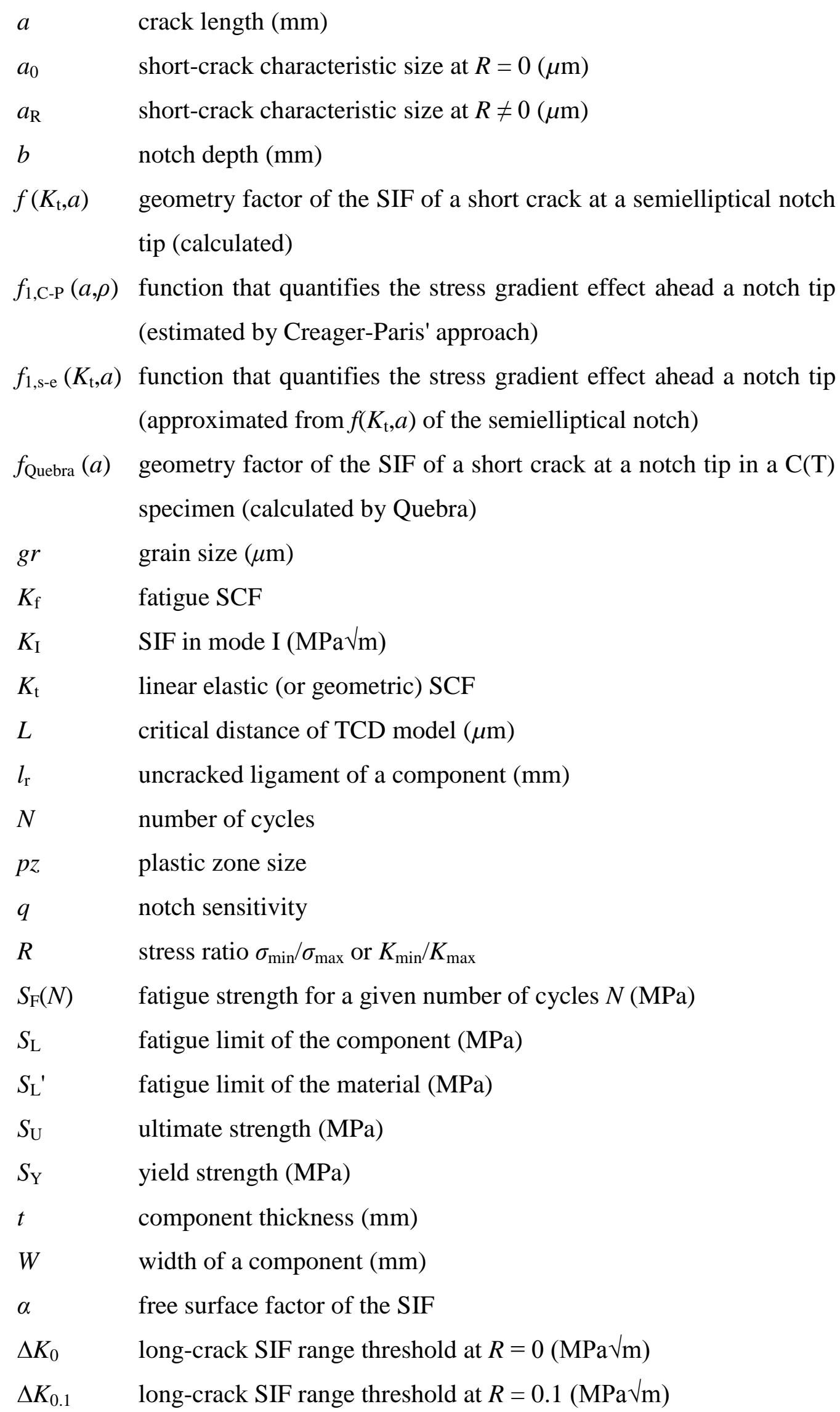


$\Delta K_{\mathrm{R}} \quad$ long-crack SIF range threshold at $R \neq 0(\mathrm{MPa} \sqrt{\mathrm{m}})$

$\Delta K_{\mathrm{I}} \quad$ SIF range in mode I $(\mathrm{MPa} \sqrt{ } \mathrm{m})$

$\Delta K_{\mathrm{R}} \quad$ long-crack SIF range threshold for a stress ratio $R(\mathrm{MPa} \sqrt{\mathrm{m}})$

$\Delta K_{\text {th }} \quad$ short-crack SIF range threshold (MPa $\left.\sqrt{\mathrm{m}}\right)$

$\Delta P \quad$ applied load range $(\mathrm{kN})$

$\Delta S_{0} \quad$ smooth specimen fatigue limit at $R=0(\mathrm{MPa})$

$\Delta S_{0.1} \quad$ smooth specimen fatigue limit at $R=0.1(\mathrm{MPa})$

$\Delta S_{\mathrm{R}} \quad$ smooth specimen fatigue limit at $R \neq 0(\mathrm{MPa})$

$\Delta \sigma \quad$ stress range at the critical point (MPa)

$\Delta \sigma_{\mathrm{n}} \quad$ nominal stress range (MPa)

$\gamma \quad$ Bazant's data-fitting parameter

$\mu \quad$ SI prefix micro- $\left(10^{-6}\right)$

$\rho \quad$ notch-tip radius $(\mathrm{mm})$, or density of the material $\left(\mathrm{g} / \mathrm{cm}^{3}\right)$

$\sigma_{a} \quad$ alternate stress component (MPa)

mean stress component ( $\mathrm{MPa})$

maximum (peak) stress (MPa)

minimum stress $(\mathrm{MPa})$

nominal stress $(\mathrm{MPa})$

non-dimensional geometry function of the SIF 


\section{Introduction}

Fatigue failures of engineering structures and components generally initiate at geometrical discontinuities generically called notches, where short fatigue cracks are nucleated due to their localized stress concentration factor (SCF) $K_{\mathrm{t}}$ effects. Notch-like defects, such as scratches, pores, and inclusions, behave in the same way. Since notches cannot be avoided, the understanding of the behaviour of short fatigue cracks emanating from them plays an important role for designing engineering components for long fatigue lives. Actually, uncracked structural components often spend most of their fatigue lives nucleating and propagating relatively short cracks [1].

The so-called short cracks can be subdivided in microstructurally short or mechanically short cracks. Microstructurally short cracks are associated to sizes in the order of microstructural features such as the grain size $g r$, thus they are influenced by grain boundaries, crystal anisotropy, second phase particles and other similar characteristics of the material microstructure. Hence, these cracks cannot be well modeled by classic macroscopic fracture mechanics concepts. Mechanically short cracks, on the other hand, are longer than $g r$ and can be modeled by linear elastic or elastoplastic fracture mechanics concepts, depending on the stress field that surrounds them. The linear elastic fracture mechanics (LEFM) is a continuum mechanics theory that idealizes the material as linear, isotropic and homogeneous continuum. Therefore, short cracks that nucleate at notch roots only can be modeled with LEFM concepts when their sizes are greater than the grain size $g r$, otherwise the assumed idealizations of the material would not be valid. These short cracks may become non-propagating, depending not only on the load level, but on the stress gradient ahead of the notch tip as well.

Fatigue limits of structural notched components can be associated to the propagation behavior of short cracks at their notch roots and can be estimated by several models analyzed from an energetic point of view [2,3] or based on LEFM 
concepts. The pioneer model based on LEFM concepts was proposed by El Haddad, Toper and Smith (ETS) [4], and it has been extended to consider notch sensitivity effects by Meggiolaro et al. [5] in the so-called Stress Gradient (SG) model. This model considers the stress gradient effect ahead a notch tip and allows estimating the largest non-propagating short crack (NPSC) and the fatigue limit of the notched test specimen. However, there is a lack of experimental data verifying their fatigue limit predictions and confirming the existence of NPSCs.

The in-situ detection and measurement of NPSCs still present several challenges mainly due to their small size, usually in order of tens of micrometers depending on the material properties and notch geometry. Among non-destructive techniques (NDTs) for this detection, X-ray micro-computed tomography is a promissory method since it in principle allows $3 \mathrm{D}$ visualization and quantification of the initiation and growth of fatigue cracks. Digital image correlation (DIC) and optical microscopy can be used as well as NDTs for in-situ monitoring of surface cracks, but for internal cracks a destructive metallographic analysis is necessary.

In this context, the aim of this work is to predict the fatigue limit of notched specimens by modeling the short cracks departing from their notch tips under constant amplitude loading control by using the aforementioned Stress Gradient (SG) model. These fatigue limit predictions were verified testing notched specimens of SAE 1020 steel designed to induce NPSCs at their notch tips. Different attempts to detect NPSCs were carried out to verify their existence and to measure their sizes.

Furthermore, the accuracy of the fatigue predictions obtained by any model, particularly the SG, depends on the mechanical properties of the material, mainly on their fatigue limit and (long) fatigue crack propagation threshold. Hence, they should be properly measured to obtain less-scattered predictions. The fatigue limit of the material can be assessed by testing smooth standardized specimens. However, its experimental assessment by conventional methods based on fatigue tests at different fixed strain or stress amplitudes is at least inconvenient, due to the large number of required specimens and to the long time needed for such testing. The much faster infrared (IR) thermographic method, which uses surface temperature increments as a fatigue damage indicator, may be a useful alternative 
tool to study the fatigue behaviour of materials, in particular to measure their fatigue limits. Thus, a comparison between the fatigue limits of the material obtained by IR thermography and conventional Dixon's up-and-down methods is also presented in this work.

\section{1.}

\section{Objectives}

\subsection{1.}

\section{General objective}

Experimental verification of the fatigue limit predictions made by the Stress Gradient model using notched specimens of a low carbon steel.

\subsection{2.}

\section{Specific objectives}

Selection of the material and geometry of the test specimen designed to induce non-propagating short cracks at their notch tips.

Estimation of the short crack characteristic size from the experimental measurement of i) the long fatigue crack propagation threshold and ii) the fatigue limit of the material by using IR thermography and Dixon's up-and-down methods.

Prediction of the fatigue limit and of the largest non-propagating short crack for the designed test specimens by the Stress Gradient and by the Theory of Critical Distance (TCD) models.

Experimental verification of the predictions by the Stress Gradient and TCD models using an accelerated test involving step loading procedures and the monitoring of surface short cracks.

Detection of non-propagating short cracks through different characterization techniques, such as optical microscopy and metallographic analysis, DIC and Xray micro-computed tomography for a complementary verification of the Stress Gradient model. 


\section{2.}

\section{Summary}

This thesis consists of six chapters, namely: introduction, preliminaries and literature review, mechanical characterization of the material, experimental program, results and discussion, and conclusions. References and appendixes are also included.

Chapter 2 presents the mechanical fundamentals to support the Stress Gradient (SG) model and a preliminary background for a better understanding of the content of this work. Moreover, a review of the recent literature in the area of short fatigue cracks is included.

Chapter 3 describes the selection of the material for the experimental verification and the experimental procedures involved in obtaining the so-called short crack characteristic size.

Chapter 4 presents the predictions of the fatigue limits (by SG and TCD models) and of the largest non-propagating short cracks for the designed test specimen by applying the SG model. Moreover, the procedure for the experimental verification and several attempts to detect such short cracks are also included.

Chapter 5 summarizes the predicted and experimental results.

Finally, chapter 6 presents the principal conclusions derived from this work and the areas for further research. 


\section{2 \\ Preliminary concepts and literature review}

Structural components always have small flaws or imperfections, which can behave like small cracks, even before they are subjected to service loads. These small cracks can be introduced accidentally in the component during the machining or heat treatment processes. According to Pippan et al. [6], their size may be in the order of or smaller than $10 \mu \mathrm{m}$ in high-strength materials, and can be $1 \mathrm{~mm}$ in cast alloys or welded structures. Besides small flaws, stress raisers such as holes, shoulders, and threaded connections cannot be avoided in engineering components. These stress raisers, commonly called notches, generate a stress gradient ahead of the notch tip, where short fatigue cracks are generally nucleated due to the stress concentration. These short cracks can propagate accelerating, decelerating or even arrest and becoming a non-propagating short crack (NPSC), depending on the applied stress level. In fact, the fatigue limit and fatigue failures can be associated with the presence of NPSCs at notch tips and their study is important to properly address long-life designs.

Hence, in this chapter the preliminary concepts related to fatigue cracks at notches and the theory to support the Stress Gradient (SG) model are presented. Moreover, a review of the recent literature in the area of short fatigue cracks is included.

\section{1.}

\section{Stress concentration at notches}

Notches in engineering components cause an inhomogeneous stress distribution around the notch root. Accordingly, classic formulae from traditional stress analysis cannot be applied to describe the stress state at those locals. The so-called linear elastic or geometrical stress concentration factor (SCF), $K_{\mathrm{t}}$, is typically used to quantify the notch stress concentration effect. This factor is defined as the ratio between the local maximum stress $\sigma_{\max }$ at notch root and the 
applied nominal stress $\sigma_{\mathrm{n}}$ that would act there if the notch had no effect on the stress field that surround it, as indicated in Eq. (2.1).

$$
K_{\mathrm{t}}=\frac{\sigma_{\max }}{\sigma_{\mathrm{n}}}
$$

There are several analytical solutions for the stress fields around notch roots, as a function of the notch geometry and applied nominal stress $\sigma_{\mathrm{n}}$. The maximum stress $\sigma_{\max }$ ahead a notch tip, in the direction of the applied nominal stress $\sigma_{\mathrm{n}}$, can be determined from these analytical solutions. Particularly, the SCF of an elliptic hole in an infinite plate under uniaxial tension, with principal axes $2 b$ and $2 c$, as shown in Figure 2.1, was analytically solved by Inglis [7] in 1913, as indicated in Eq. (2.2).

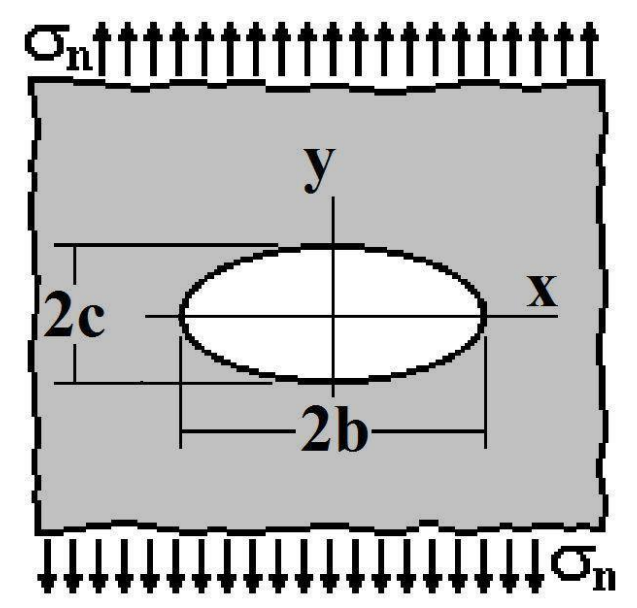

Figure 2.1- Stress concentration problem: Inglis' plate.

$$
K_{\mathrm{t}}=\frac{\sigma_{\max }}{\sigma_{\mathrm{n}}}=\frac{\sigma_{x= \pm b, y=0}}{\sigma_{\mathrm{n}}}=1+2\left(\frac{b}{c}\right)=1+2 \sqrt{\frac{b}{\rho}}
$$

where $\rho=c^{2} / b$ is the smaller radius of the elliptical hole, at $x= \pm b$.

The so-called Inglis' plate problem, but in this case including a crack of size $a$ at the hole border in $x$-direction, where $0.2 \leq a / b \leq 1$, was also solved by Tada $e t$ $a l$. [8] and this solution is shown in Eq. (2.3).

$$
K_{\mathrm{t}}=\left[1+2\left(\frac{b}{c}\right)\right]\left[1+\frac{0.1215}{(1+c / b)^{2.5}}\right]=\left(1+2 \sqrt{\frac{b}{\rho}}\right)\left[1+\frac{0.1215}{(1+\sqrt{\rho / b})^{2.5}}\right]
$$


Based on traditional long-life design methods, for example stress-life SN and strain-life $\varepsilon \mathrm{N}$ approaches, the nominal fatigue strength of notched specimens should be reduced by a factor equal to $K_{\mathrm{t}}$ as compared to the one from plain specimens. However, experimental results [9] indicate that the presence of a notch in a specimen subjected to a cyclic nominal stress reduces the fatigue strength of a plain specimen by a factor equal to $K_{\mathrm{f}}$ instead of $K_{\mathrm{t}}$. The factor $K_{\mathrm{f}}$ is the fatigue SCF and it can be defined as the ratio between the fatigue limit of a plain specimen $S_{\mathrm{L}}^{\prime}$ and that of the notched specimen $S_{\mathrm{L}}$, as shown in Eq. (2.4).

$$
K_{\mathrm{f}}=\frac{\text { fatigue limit of a plain specimen }}{\text { fatigue limit of a notched specimen }}=\frac{S_{\mathrm{L}}{ }^{\prime}}{S_{\mathrm{L}}}
$$

In general, $K_{\mathrm{f}}$ is less than or equal to $K_{\mathrm{t}}$, so the use of $K_{\mathrm{t}}$ instead of $K_{\mathrm{f}}$ in notch fatigue design can be too conservative because it neglects the notch sensitivity effect. The difference between $K_{\mathrm{t}}$ and $K_{\mathrm{f}}$ increases as the notch root radius $\rho$ decreases and the ultimate strength $S_{\mathrm{U}}$ of the material increases. The socalled notch sensitivity $q$, expressed by Eq. (2.5), is used to quantify the difference between $K_{\mathrm{t}}$ and $K_{\mathrm{f}}$ and its values are in the range $0 \leq q \leq 1$. The lower limit $q=0$, and therefore, $K_{\mathrm{f}}=1$, indicates that the material is insensitive to the presence of the notch. Conversely, when $q=1$, and therefore, $K_{\mathrm{f}}=K_{\mathrm{t}}$, the material is highly sensitive to the presence of the notch and its behaviour is governed by the maximum stress at notch root.

$$
q=\frac{K_{\mathrm{f}}-1}{K_{\mathrm{t}}-1}
$$

Experimental data demonstrating the difference between $K_{\mathrm{t}}$ and $K_{\mathrm{f}}$ are shown in Figure 2.2 for an AISI 1015 steel. These data points, as cited by Dowling [9], were obtained by testing cylindrical specimens with diameter $d=$ $12.7 \mathrm{~mm}$ and a constant notch depth of $1.27 \mathrm{~mm}$. The range of the notch radii was $0.025 \mathrm{~mm}<\rho<2 \mathrm{~mm}$.

Several interpretations have been proposed to explain the fact that $K_{\mathrm{f}} \leq K_{\mathrm{t}}$, such as highly stressed volume at the notch tip, notch machining effect, biaxial stresses, reverse plasticity, etc. Nevertheless, classical LEFM analyses of crack propagation conditions have demonstrated that the $K_{\mathrm{f}} \leq K_{\mathrm{t}}$ effect can be associated 
to the presence of short cracks [10]. Indeed, according to Frost [11], nonpropagating short fatigue cracks nucleate at notch tips when $\Delta S_{\mathrm{R}} / K_{\mathrm{t}}<\Delta \sigma_{\mathrm{n}}<$ $\Delta S_{\mathrm{R}} / K_{\mathrm{f}}$, as shown in Figure 2.3, where $S_{\mathrm{L}}=\Delta S_{\mathrm{R}} / 2$ is the fatigue limit of a standard unnotched test specimen (TS) under a given stress ratio $R=\sigma_{\min } / \sigma_{\max }$, and $\sigma_{\text {na }}=$ $\Delta \sigma_{\mathrm{n}} / 2$ is the nominal alternating stress applied to the notched TS. Therefore, it is reasonable to expect that $q$ can be predicted based on the propagation behavior of short cracks emanating from notch tips [5].

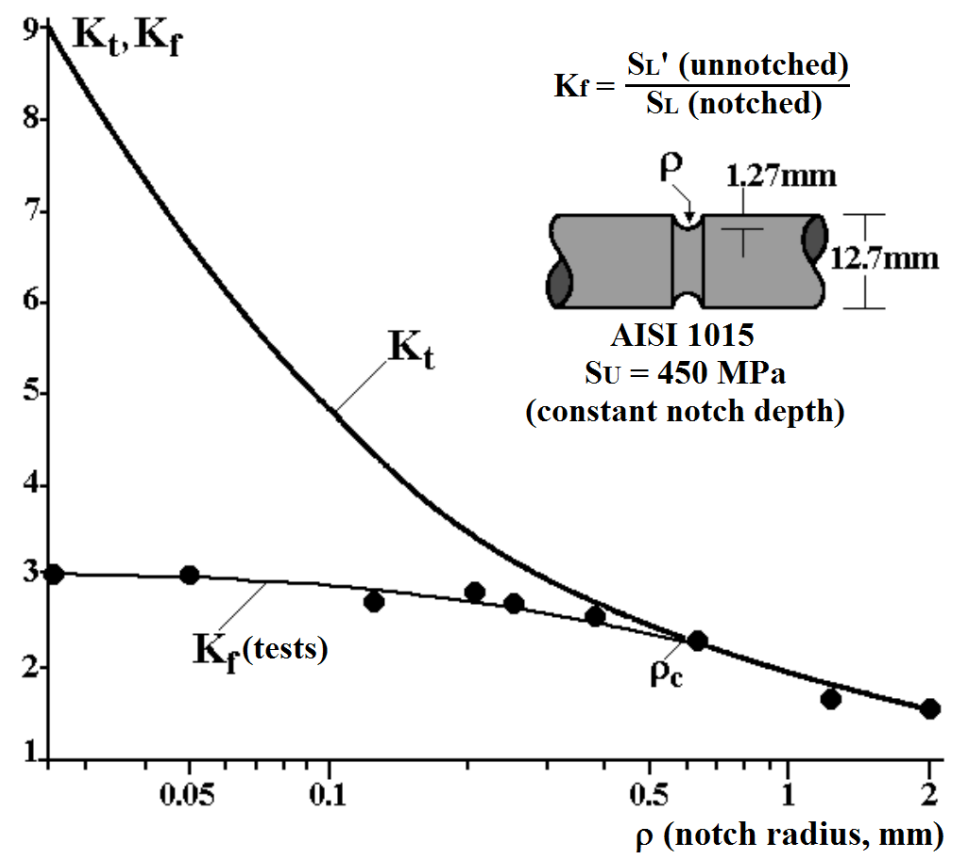

Figure 2.2- Comparison between experimentally obtained $K_{\mathrm{f}}$ and $K_{\mathrm{t}}[9]$.

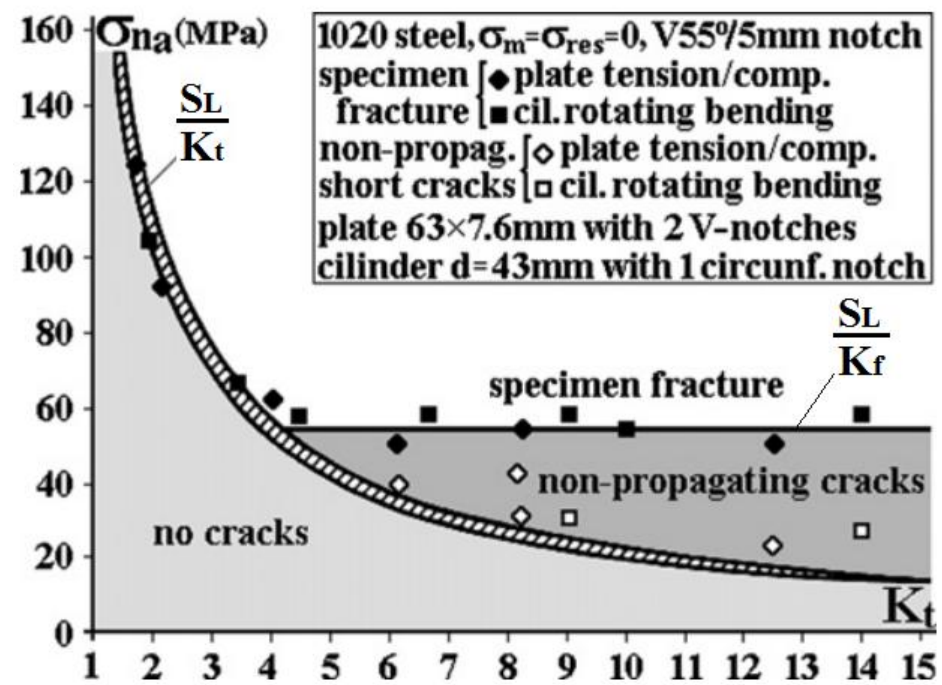

Figure 2.3- Non-propagating short cracks founded at notch tips when $S_{\mathrm{L}} / K_{\mathrm{t}}<\sigma_{\mathrm{na}}<S_{\mathrm{L}} / K_{\mathrm{f}}$ at $R=-1[11]$. 


\section{2.}

\section{Stress concentration around crack tips}

Cracks can be modeled as a sharp notch with a root radius $\rho \rightarrow 0$. Analytical solutions of an elliptical notch (Inglis' plate) are functions of $\sqrt{ }(b / \rho)$, as previously indicated in Eq. (2.2). Hence, notches with an idealized root radius $\rho=0$ would imply a mathematically singular stress at their tips $\sigma_{\max } \rightarrow \infty$, and also in $K_{\mathrm{t}} \rightarrow \infty$. Thus, the maximum stress can no longer be effective as a governing parameter of the stress concentration effect around crack tips. Williams [12] and Irwin [13] introduced the so-called stress intensity factor (SIF) to quantify the magnitude of LE stress fields around crack tips, giving a great advance in the LEFM theory. The stress field around crack tips in components loaded in mode I (see Figure 2.4), is controlled by the SIF $K_{\mathrm{I}}$ and it is expressed in Eq. (2.6).
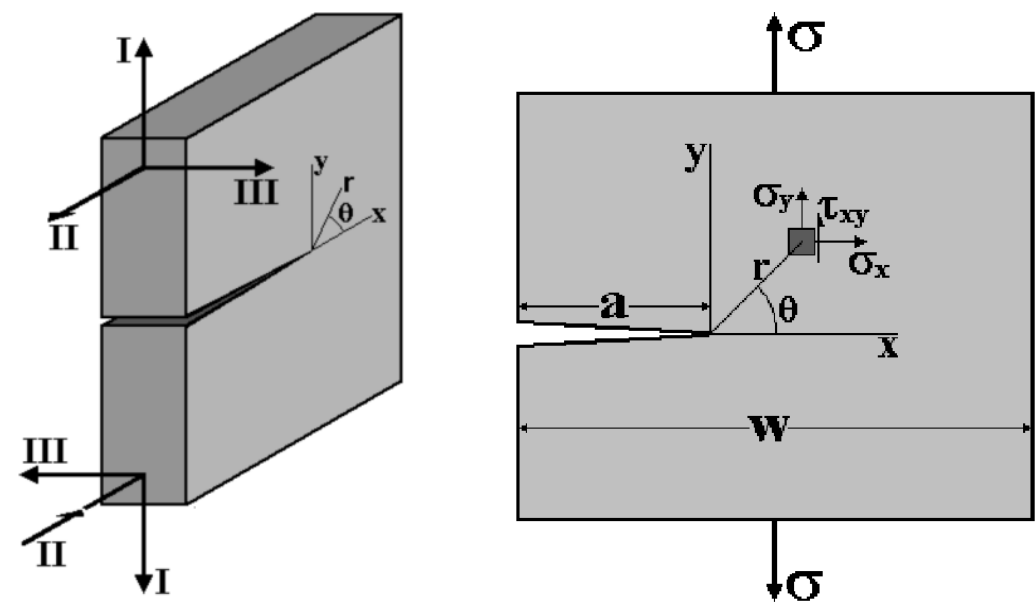

Figure 2.4- The three modes of loading and notation [14].

$$
\left\{\begin{array}{c}
\sigma_{x} \\
\sigma_{y} \\
\tau_{x y}
\end{array}\right\}=\frac{K_{\mathrm{I}}}{\sqrt{2 \pi r}} \cos \left(\frac{\theta}{2}\right)\left\{\begin{array}{c}
1-\sin (\theta / 2) \sin (3 \theta / 2) \\
1+\sin (\theta / 2) \sin (3 \theta / 2) \\
\sin (\theta / 2) \sin (3 \theta / 2)
\end{array}\right\}
$$

The mode I of loading is perpendicular to the crack plane and the Cartesian $(x y)$ or polar $(r \theta)$ coordinates system is centered at the crack tip. According to Williams [12] and Irwin [13], in addition to mode I, cracks can also be loaded in mode II (in-plane shear load) or mode III (out-of-plane shear load), as presented in Figure 2.4. However, mode $\mathrm{I}$ is by far the most important for practical applications and it will be considered in this work. According to Eq. (2.6), the stress field around crack tips is proportional to $1 / \sqrt{ } r$, where $r$ is the radial coordinate of the polar coordinate system at the crack tip, so that there is a 
singularity at the crack tip, where $r \rightarrow 0$ and $\sigma \rightarrow \infty$. Nevertheless, real cracks must have a non-linear region close to their tips, even when they are subjected to low nominal stresses. This region is known as the plastic zone and when its size $p z$ is small compared to the component and crack dimensions, the stress field around the crack tip remains predominantly LE and it can be described by the SIF parameter. This is known as the small-scale yielding (SSY) condition. Since $p z$ is small in many practical cases, particularly in the propagation of fatigue cracks, the SIF can be used to describe crack effects properly. There are several expressions to estimate $p z$ as a function of the SIF, depending on the mode of the loading. For a crack loaded in mode $I$, it takes the general form in Eq. (2.7), where $\lambda$ is a constant and $S_{\mathrm{Y}}$ is the yield strength.

$$
p z=\lambda\left(\frac{K_{\mathrm{I}}}{S_{\mathrm{Y}}}\right)^{2}
$$

A rough estimate of $p z$ can be obtained by making $\sigma_{\mathrm{y}}(r=p z, \theta=0)=S_{\mathrm{Y}}$ in Eq. (2.6), resulting in $\lambda=(1 / 2 \pi)$. This basic approximation was improved by Irwin, who included equilibrium requirements for the LE stress ahead a crack tip, obtaining for plane stress (pl- $\sigma$ ) conditions $\lambda=(1 / \pi)$ and for plane strain $(\mathrm{pl}-\varepsilon) \lambda=$ $(1 / 3 \pi)$. On the other hand, Dugdale [15] proposed the strip-yield model which estimates $\lambda=(\pi / 8)$, for $\mathrm{pl}-\sigma$ conditions.

The expression in Eq. (2.7) is simple, but useful to estimate monotonic plastic zones $p z$. Considering a growing fatigue crack subjected to a constant SIF range $\Delta K_{\mathrm{I}}$, the reversed plastic zone $p z_{\mathrm{r}}$ formed at the crack tip can be estimated by making $\Delta \sigma_{\mathrm{y}}\left(r=p z_{\mathrm{r}}, \theta=0\right)=2 S_{\mathrm{Yc}}$, and it results in Eq. (2.8) as a first approximation.

$$
p z_{\mathrm{r}}=\frac{1}{8 \pi}\left(\frac{\Delta K_{\mathrm{I}}}{S_{\mathrm{Yc}}}\right)^{2}
$$

It is important to point out that $p z$ and $p z_{\mathrm{r}}$ are estimated by using the SIF $K_{\mathrm{I}}$ and the SIF range $\Delta K_{\mathrm{I}}$, respectively. Besides, $p z$ and $p z_{\mathrm{r}}$ must fulfill the SSY conditions to validate the use of the SIF parameter. Hence, LEFM solutions are self-validating. 
The generic expression of the SIF range for a fatigue crack in a component loaded in mode I $\Delta K_{\mathrm{I}}$ is shown in Eq. (2.9).

$$
\Delta K_{\mathrm{I}}=\Delta \sigma_{\mathrm{n}} \sqrt{\pi a} \cdot \varphi(a / w)
$$

where $\Delta \sigma_{\mathrm{n}}$ is the nominal applied stress range, $a$ is the crack size, and $\varphi(a / w)$ is a non-dimensional factor that includes the influence of the component and crack geometry, and the loading mode.

\section{3.}

\section{Similitude concept in fracture mechanics}

The application of fracture mechanics concepts to fatigue crack propagation is based on the hypothesis that the stress field around the crack tip can be described by the SIF parameter. Moreover, it is assumed that the principle of similitude [16] is valid. In this way, considering two different cracks in different components of the same material under SSY conditions: when they are subjected to the same SIF, the stress and strain fields, and the monotonic plastic zone $p z$ around the crack tip should be be identical. On the other hand, when they are subjected to the same SIF range $\Delta K=K_{\max }-K_{\min }$ under a given stress ratio $R=$ $K_{\min } / K_{\max }$, their crack propagation rates $\mathrm{d} a / \mathrm{d} N$ should also be identical.

Therefore, the similitude concept allows evaluating the mechanical behavior of an in-service structural component by means of strength values that can be measured in the laboratory using standardized test specimens. Particularly in fatigue applications, after a crack emanates from a critical point, this problem must be treated using LEFM approaches, i.e. the crack propagation is controlled by the SIF range. Since SIF is a LE parameter and LE solutions are unique, SIFs has to be calculated just once for any geometry [14]. There are available SIFs solutions for several load/geometry combinations in the literature, such as those reported by Tada [8].

Finally, it is worth noting that exactly similitude conditions are very complicated to be obtained in the laboratory. For instance, in accordance to Miller [17], a compact tension $\mathrm{C}(\mathrm{T})$ specimen has an error up to $7 \%$ in its LE field analysis. This error is caused by the loss of similitude which occurs when the SSY conditions are exceeded due to high stress levels. Furthermore, the similitude 
concept seems not to work for short cracks. This can be explained considering that short cracks behave different than long ones, since their propagation thresholds are different.

\section{4.}

\section{Relationship between notch and crack stress distributions}

In 1967, Creager and Paris (C-P) [18] proposed a method to estimate the SCF $K_{\mathrm{t}}$ of slim notches from available similar SIFs solutions. They demonstrated that the elastic stress field around deep and slim notches with root radius $\rho$ would be estimated from the SIFs solutions of the corresponding cracks, by moving the origin of the coordinate system a distance $\rho / 2$ into the notch, as shown in Figure 2.5. The stress field around a notch tip in a component loaded in mode $I$ is described by Eq. (2.10).

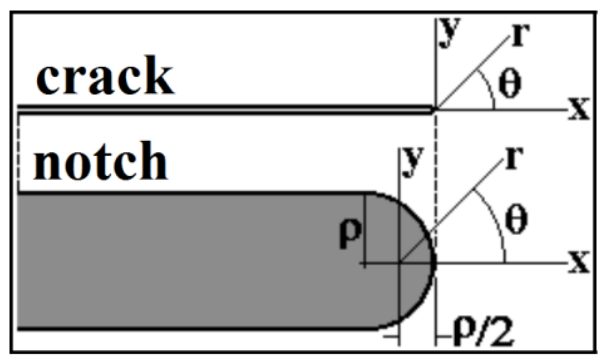

Figure 2.5- Coordinate system for Creager-Paris approach [14].

$$
\left\{\begin{array}{c}
\sigma_{x} \\
\sigma_{y} \\
\tau_{x y}
\end{array}\right\}=\frac{K_{I}}{\sqrt{2 \pi r}} \frac{\rho}{2 r}\left\{\begin{array}{c}
-\cos (3 \theta / 2) \\
\cos (3 \theta / 2) \\
-\sin (3 \theta / 2)
\end{array}\right\}+\frac{K_{I}}{\sqrt{2 \pi r}} \cos \left(\frac{\theta}{2}\right)\left\{\begin{array}{c}
1-\sin (\theta / 2) \sin (3 \theta / 2) \\
1+\sin (\theta / 2) \sin (3 \theta / 2) \\
\sin (\theta / 2) \sin (3 \theta / 2)
\end{array}\right\}
$$

Hence, SIFs can also be used to describe the stress field around the tip of slim notches, which are similar to "blunt cracks". Particularly, the SCF in $y$ direction of those notches can be estimated from Eq. (2.10), by imposing the polar coordinates $r=\rho / 2$ and $\theta=0$, which results in Eq. (2.11).

$$
K_{\mathrm{t}} \cdot \sigma_{\mathrm{n}}=\sigma_{\mathrm{y}}\left(r=\frac{\rho}{2}, \theta=0\right) \quad \therefore K_{\mathrm{t}}=\frac{2 K_{\mathrm{I}}}{\sigma_{\mathrm{n}} \cdot \sqrt{\pi \rho}}
$$

It is worth mentioning that Eq. (2.11) is a particular case of the general stress gradient in the $y$-direction ahead of the notch tip, for any $r \geq \rho / 2$. 


\section{5 .}

\section{Short crack propagation threshold and the ETS model}

The effect of short fatigue cracks on the fatigue crack growth (FCG) threshold of several metallic materials can be properly described by the KitagawaTakahashi (K-T) diagram [19], which relates the FCG threshold to the crack size $a$, as shown in Figure 2.6. This diagram illustrates the fatigue behavior of short cracks by relating the largest stress range $\Delta \sigma$ that any fatigue crack can tolerate without propagating to $\Delta K_{0}$ and $\Delta S_{0}$, the long crack propagation threshold and the smooth specimen fatigue limit (in the case of short cracks) for a stress ratio $R=$ $\sigma_{\min } / \sigma_{\max }=0$, where $\sigma_{\min }$ and $\sigma_{\max }$ are the minimum and maximum values of the stress in each cycle.

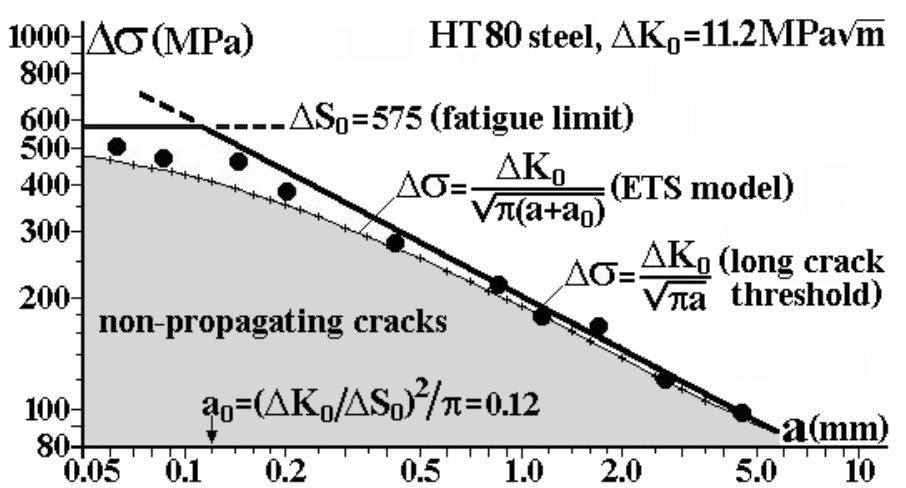

Figure 2.6- Kitagawa-Takahashi plot describing the fatigue propagation of short and long cracks under pulsating loads $(R=0)$ in a HT80 steel with $\Delta K_{0}=11.2 \mathrm{MPa} \sqrt{\mathrm{m}}$ and $\Delta S_{0}=575$ $\operatorname{MPa}[19]$.

El Haddad et al. [4] proposed the so-called ETS model to associate the fatigue crack propagation behavior of short and long cracks by adding the socalled short crack characteristic size, $a_{0}$, to the crack size $a$ of Irwin's plate, $\Delta K=$ $\Delta \sigma \sqrt{ }(\pi a)$. Thus, the correct asymptotic behaviors reproducing both the fatigue limit and the FCG threshold in a K-T diagram, i.e., $\Delta \sigma\left(a \leq a_{0}\right)=\Delta S_{0}$ for short cracks and $\Delta K_{0}\left(a>a_{0}\right)=\Delta K_{0}$ for long ones, is obtained using the modified SIF range $\Delta K_{\mathrm{I}}$ to describe the fatigue propagation of both short or long cracks, as shown in Eq. (2.12).

$$
\Delta K_{\mathrm{I}}=\Delta \sigma \sqrt{\pi\left(a+a_{0}\right)}, \text { where } a_{0}=\frac{1}{\pi}\left(\frac{\Delta K_{0}}{\Delta S_{0}}\right)^{2}
$$


Note that the stress range $\Delta \sigma$ in Eq. (2.12) reproduces the bi-linear behavior of the experimental $\Delta \sigma \times a$ curve in K-T plot trend when the SIF range $\Delta K_{\mathrm{I}}$ equals to the long cracks threshold $\Delta K_{0}$, i.e., $\Delta \sigma=\Delta K_{0} / \sqrt{ }\left[\pi\left(a+a_{0}\right)\right]$.

Eq. (2.12) can be generalized to analyze a crack in any geometry, in addition to the infinite plate with a central crack $2 a$ (Irwin's plate). To accomplish that, Yu et al. [20] introduced the geometry factor $\varphi(a / w)$ in Eq. (2.12), redefining the short crack characteristic size as presented in Eq. (2.13).

$$
\Delta K_{\mathrm{I}}=\varphi(a / w) \cdot \Delta \sigma \sqrt{\pi\left(a+a_{0}\right)}, \text { where } a_{0}=\frac{1}{\pi}\left(\frac{\Delta K_{0}}{\Delta S_{0} \cdot \varphi(a / w)}\right)^{2}
$$

Notice that $\Delta \sigma$ is the stress range at the notch root and in the case of notched components $\varphi(a / w)$ usually does not include the stress concentration effect of the notch. However, the catalogued SIFs use the nominal stress range $\Delta \sigma_{\mathrm{n}}$ instead of local one $\Delta \sigma$. In order to express Eq. (2.13) as a function of $\Delta \sigma_{\mathrm{n}}$, and use it to analyze cracks emanating from a notch, Meggiolaro et al. [5] divided the geometry factor into two parts: $\varphi(a / w)=f(a) \cdot \alpha$, where $f(a)$ describes the stress gradient effect ahead of the notch tip with radius $\rho$, which tends to $K_{\mathrm{t}}$ as the crack length $a \rightarrow 0$, and $\alpha$ encompasses all the remaining terms, such as the free surface correction. Hence, the new expression for $a_{0}$ results in Eq. (2.14).

$$
\Delta K=\alpha \cdot f(a) \cdot \Delta \sigma_{\mathrm{n}} \sqrt{\pi\left(a+a_{0}\right)} ; \quad \text { where } a_{0}=\frac{1}{\pi}\left(\frac{\Delta K_{0}}{\alpha \cdot \Delta S_{0}}\right)^{2}
$$

However, from an operational point of view, in the study of the behavior of short fatigue cracks it is more convenient to express the FCG threshold as a function of the crack size, $\Delta K_{\mathrm{th}}(a)$, taking into account the original definition of the SIF $\Delta K=\alpha \cdot f(a) \cdot \Delta \sigma_{\mathrm{n}} \sqrt{ }(\pi a)$. Thus, Eq. (2.15) is obtained.

$$
\frac{\Delta K_{\mathrm{th}}(a)}{\Delta K_{0}}=\frac{\alpha \cdot f(a) \cdot \Delta \sigma_{\mathrm{n}} \sqrt{\pi a}}{\alpha \cdot f(a) \cdot \Delta \sigma_{\mathrm{n}} \sqrt{\pi\left(a+a_{0}\right)}}=\frac{1}{\sqrt{1+\left(a_{0} / a\right)}}
$$

The ETS model expressed by Eq. (2.12) fits properly the experimental results of the K-T diagram, linking the behavior of short $\left(a<<a_{0}\right)$ and long cracks $\left(a \gg a_{0}\right.$ ) by means of a single equation. Nevertheless, Bazant [21] proposed a 
more general equation (see Eq. (2.16)) by incorporating a fitting parameter $\gamma$ in Eq. (2.15).

$$
\Delta K_{\mathrm{th}}(a)=\Delta K_{0} \cdot\left[1+\left(a_{0} / a\right)^{\gamma / 2}\right]^{-1 / \gamma}
$$

This equation reproduces the ETS model when $\gamma=2$. The bi-linear limit of K-T diagram, $\Delta \sigma(a \leq 0)=\Delta S_{0}$ for short cracks and $\Delta \sigma(a>0)=\Delta K_{0} / \sqrt{ }(\pi a)$ for long ones, is obtained when $\gamma \rightarrow \infty$. Most of the experimentally measured short crack FCG thresholds available in the literature are properly fitted by $1.5<\gamma<8$ [14], see Figure 2.7.

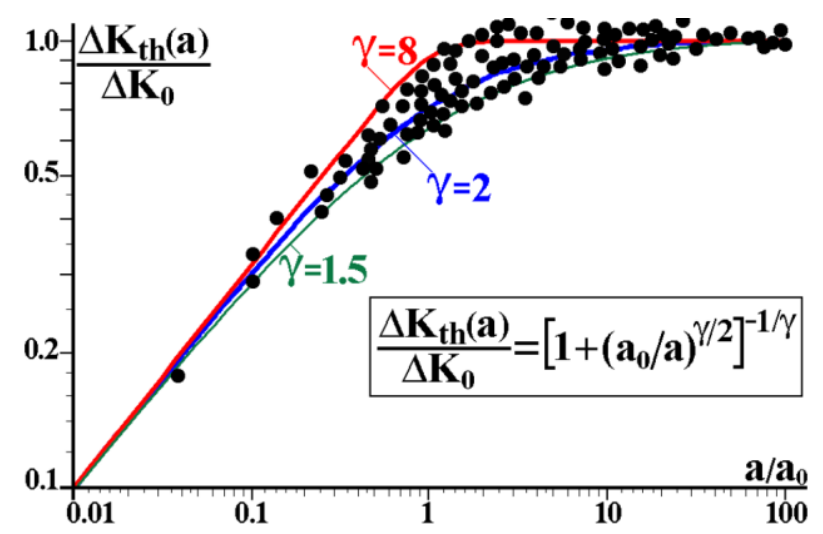

Figure 2.7- Short-crack to long-crack FCG thresholds ratio as a function of $a / a_{0}$ [14].

It is important to point out that ETS model and experimental results of K-T diagram have been reported for pulsating loads $(R=0)$. However, fatigue damage depends on two driving forces, $\Delta K$ and $K_{\max }$, since cracks are very effective concentrators when subjected to tensile loads, while they are almost harmless under compressive loads. Therefore, the expression in Eq. (2.16) can be generalized to include the effect of $K_{\max }$ on the behavior of short cracks. This effect can be indirectly quantified by the stress ratio $R$. Hence, Eq. (2.16) and the definition of $a_{0}$, including $R$ effect, results in Eq. (2.17).

$$
\Delta K_{\mathrm{th}, \mathrm{R}}(a)=\Delta K_{\mathrm{R}} \cdot\left[1+\left(a_{\mathrm{R}} / a\right)^{\gamma / 2}\right]^{-1 / \gamma} ; \text { where } a_{\mathrm{R}}=\frac{1}{\pi}\left(\frac{\Delta K_{\mathrm{R}}}{\alpha \cdot \Delta S_{\mathrm{R}}}\right)^{2}
$$

According to the K-T diagram, the short crack FCG threshold, $\Delta K_{\mathrm{th}, \mathrm{R}}(a)$, is more sensitive to the Bazant's parameter, $\gamma$, when $a=a_{0}$, the transition point between short and long cracks behaviors. Taking into account the two boundary values of the data in Figure 2.7, $\gamma=1.5$ and $\gamma=8, \Delta K_{\text {th, }}(a)$ tends to $63 \%$ and $92 \%$ 
of the long crack FCG threshold, $\Delta K_{0}$, respectively. Since lower $\gamma$ values lead to propagation curves below of the bi-linear limit of the K-T diagram (see Figure 2.6), the propagation of fatigue short cracks will occur at lower thresholds.

2.6.

\section{The Stress Gradient model}

Based on ETS model, in this section is presented the so-called Stress Gradient (SG) model. Short cracks behave differently from long ones, as it was previously shown in K-T plot trend depicted in Figure 2.6. SG model justifies the peculiar growth of short cracks that depart from elongated notch tips by fatigue (or environmentally assisted cracking, EAC [22]). It considers that albeit such cracks can be easily generated at sharp notches, which introduce high stress concentration effects at their tips due to the high stress gradient acting around them, the short cracks can also stop to grow by fatigue after having propagated through a small distance, thereby becoming non-propagating cracks that can be tolerated in service if $\Delta S_{\mathrm{R}} / K_{\mathrm{t}} \leq \Delta \sigma_{\mathrm{n}} \leq \Delta S_{\mathrm{R}} / K_{\mathrm{f}}$ [11], where $\Delta \sigma_{\mathrm{n}}$ is the nominal stress range, and $K_{\mathrm{t}}$ and $K_{\mathrm{f}}$ are the LE and the fatigue SCFs, respectively.

In the following two sections the SG model is applied to a single notched finite plate subjected to uniaxial tension and to a compact tension $\mathrm{C}(\mathrm{T})$ specimen, where combined tension and bending stresses are generated.

\subsection{1. Short cracks departing from semielliptical elongated notches in plates}

From the original definition of the SIF range given in Eq. (2.9) and repeated herein for convenience, $\Delta K=\varphi(a / w) \cdot \Delta \sigma_{\mathrm{n}} \sqrt{ }(\pi a)$, for a finite plate with a single semielliptical notch with semi-axes $b$ and $c$ (where $b$ is in the same direction of the crack plane), loaded with a nominal stress range $\Delta \sigma_{\mathrm{n}}$ perpendicular to the crack, the SIF range of a crack $a$ emanating from the notch root can be described by Eq. (2.18) [5].

$$
\Delta K(a)=\alpha \cdot f(a / b, c / b) \cdot \Delta \sigma_{\mathrm{n}} \sqrt{\pi a}
$$

where $\alpha=1.1215$ is the free surface correction, and the geometry factor $f(a / b, c / b)$ quantifies the stress gradient ahead the root of a semielliptical notch. This factor 
was calculated by Miranda et al. [23] using the Quebra2D software and fitted within $3 \%$ by Eq. (2.19), as a function of $K_{\mathrm{t}}$ and $s, f\left(K_{\mathrm{t}}, s\right)$, where $K_{\mathrm{t}}$ was determined by Eq. (2.3) and $s=a /(a+b)$.

$$
f\left(\frac{a}{b}, \frac{c}{b}\right) \equiv f\left(K_{\mathrm{t}}, s\right)=K_{\mathrm{t}} \cdot \sqrt{\frac{1-e^{\left(-K_{\mathrm{t}}^{2} \cdot s\right)}}{K_{\mathrm{t}}^{2} \cdot s}} \quad \text { for } \quad c \leq b
$$

The experimental results of the geometry factor $f(a / b, c / b)$ reported by Nishitani and Tada and quoted by Bazant [21] are presented in Figure 2.8, as well as the curves fitted $f\left(K_{\mathrm{t}}, s\right)$ by the finite element (FE) method using Quebra2D software.

Since the FCG threshold $\Delta K_{\mathrm{th}, \mathrm{R}}(a)$ represents the loading SIF criterion under which a short crack will not propagate, a short crack emanating from a semielliptical notch will propagate if the applied SIF is greater than $\Delta K_{\mathrm{th}, \mathrm{R}}(a)$, as indicated in Eq. (2.20).

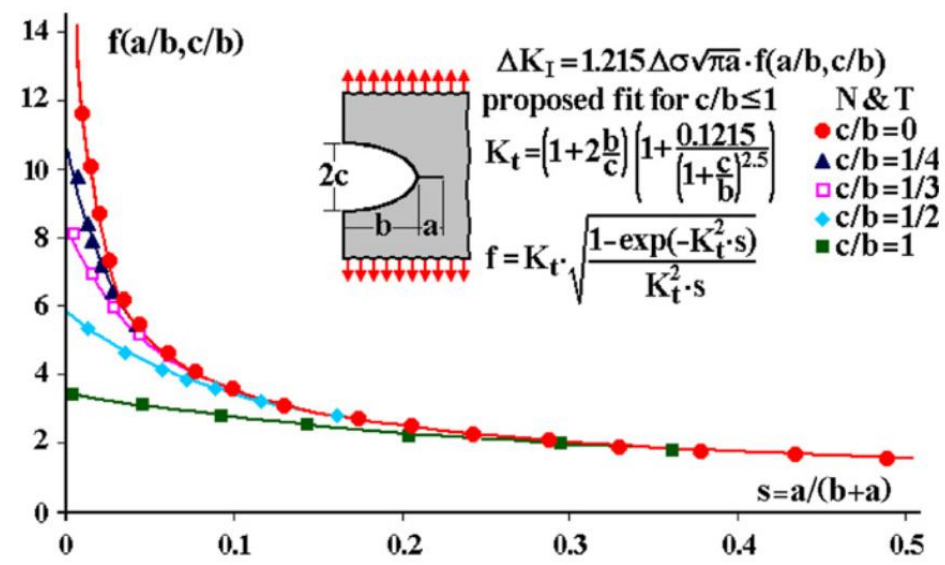

Figure 2.8- Experimental results of stress gradients ahead a semielliptical notch with $c \leq$ $b$, reported by Nishitani and Tada, fitted using Quebra2D software $\left(\Delta \sigma=\Delta \sigma_{\mathrm{n}}\right)$ [5].

$$
\Delta K(a)=\alpha \cdot f\left(K_{\mathrm{t}}, s\right) \cdot \Delta \sigma_{\mathrm{n}} \sqrt{\pi a}>\Delta K_{\mathrm{th}, \mathrm{R}}(a)=\Delta K_{\mathrm{R}} \cdot\left[1+\left(a_{\mathrm{R}} / a\right)^{\gamma / 2}\right]^{-1 / \gamma}
$$

The propagation criterion in Eq. (2.20) can be rewritten in terms of the geometry factor $f$, related to the notch stress gradient, and a dimensionless function $g\left(a, \Delta K_{\mathrm{R}} / \Delta S_{\mathrm{R}}, \Delta S_{\mathrm{R}} / \Delta \sigma_{\mathrm{n}}, \gamma\right)$, as shown in Eq. (2.21).

$$
f\left(K_{\mathrm{t}}, a\right)>\left(\frac{\Delta K_{\mathrm{R}}}{\Delta S_{\mathrm{R}}}\right)\left(\frac{\Delta S_{\mathrm{R}}}{\Delta \sigma_{\mathrm{n}}}\right)\left[(\alpha \sqrt{\pi a})^{\gamma}+\left(\frac{\Delta K_{\mathrm{R}}}{\Delta S_{\mathrm{R}}}\right)^{\gamma}\right]^{-1 / \gamma} \equiv g\left(a, \frac{\Delta K_{\mathrm{R}}}{\Delta S_{\mathrm{R}}}, \frac{\Delta S_{\mathrm{R}}}{\Delta \sigma_{\mathrm{n}}}, \gamma\right)
$$


Since the semi-axes $b$ and $c$ are known constant values, the crack size $a$ is the only variable and thus, $f\left(K_{\mathrm{t}}, s\right) \rightarrow f\left(K_{\mathrm{t}}, a\right)$.

Following Meggiolaro's reasoning [5], there is merely one value of crack size $a_{\max }$ that limits the propagation/non-propagation condition of fatigue short cracks, so that Eq. (2.21) is satisfied for a given material/notch pair. The smallest nominal stress range $\Delta \sigma_{\mathrm{n}}$ that causes crack initiation and propagation without arrest is associated to the fatigue limit of the pair. Hence, the ratio $\Delta S_{\mathrm{R}} / \Delta \sigma_{\mathrm{n}}$ associated to $a_{\max }$ is equal to the fatigue SCF $K_{\mathrm{f}}$ of the notch. Therefore, $K_{\mathrm{f}}$ and $a_{\max }$ can be estimated from the smooth specimen fatigue limit $\Delta S_{\mathrm{R}}$ and the long crack FCG threshold $\Delta K_{\mathrm{R}}$, and the geometry of a notched component, by solving the system of equations in Eq. (2.22).

$$
\left\{\begin{array}{l}
f\left(K_{\mathrm{t}}, a_{\text {max }}\right)=g\left(a_{\text {max }}, K_{\mathrm{f}}, \frac{\Delta K_{\mathrm{R}}}{\Delta S_{\mathrm{R}}}, \gamma\right) \\
\frac{\partial}{\partial a}\left[f\left(K_{\mathrm{t}}, a_{\text {max }}\right)\right]=\frac{\partial}{\partial a}\left[g\left(a_{\text {max }}, K_{\mathrm{f}}, \frac{\Delta K_{\mathrm{R}}}{\Delta S_{\mathrm{R}}}, \gamma\right)\right]
\end{array}\right.
$$

The partial derivative $\partial f / \partial a$ in Eq. (2.22) is related to the SIF's gradient of small cracks that initiates from notch tips, with respect to their size $a$. In fact, that is the reason why this model was called "stress gradient".

\subsection{2.}

\section{Short cracks departing from elongated notches in $\mathrm{C}(\mathrm{T})$ specimens}

Since an analytical expression of the geometry factor $f$ for the case of a $\mathrm{C}(\mathrm{T})$-like specimen is not available, the SIF of a small crack that departs from its notch tip can be estimated by Eq. (2.23)

$$
\Delta K(a) \cong \alpha \cdot f_{1}\left(K_{\mathrm{t}}, a\right) \cdot \Delta \sigma_{\mathrm{n}} \sqrt{\pi a}
$$

where the function $f_{1}$ describes the stress concentration gradient ahead the notch tip. Two approximations were considered in this work to estimate $f_{1}$ for a $\mathrm{C}(\mathrm{T})$-like specimen: the Creager-Paris' (C-P) approach, and a geometrical approximation, considering the notch of the $\mathrm{C}(\mathrm{T})$ as a semielliptical one. 
In the first approximation, the general C-P expression given in Eq. (2.10) can be used to estimate $f_{1, \mathrm{C}-\mathrm{P}}$ of a $\mathrm{C}(\mathrm{T})$-like specimen, making $r=x+\rho / 2$ (due to the definition of the C-P coordinates) and $\theta=0^{\circ}$ as detailed in Eq. (2.24).

$$
\begin{aligned}
& \Delta \sigma_{\mathrm{y}}\left(r=x+\frac{\rho}{2}, \theta=0\right)=\Delta \sigma_{\mathrm{y}}(x, \rho) \equiv f_{1, \mathrm{C}-\mathrm{P}}(x, \rho) \cdot \Delta \sigma_{\mathrm{n}} \\
& \Delta \sigma_{\mathrm{y}}(x, \rho)=\frac{\Delta K_{\mathrm{I}}}{\sqrt{\pi(2 x+\rho)}}\left(1+\frac{\rho}{2 x+\rho}\right) \\
& \therefore f_{1, \mathrm{C}-\mathrm{P}}(x, \rho) \equiv \frac{\Delta \sigma_{\mathrm{y}}(x, \rho)}{\Delta \sigma_{\mathrm{n}}}=\frac{\Delta K_{\mathrm{I}}}{\Delta \sigma_{\mathrm{n}} \sqrt{\pi(2 x+\rho)}}\left(1+\frac{\rho}{2 x+\rho}\right)
\end{aligned}
$$

According to Castro and Meggiolaro [14], the SIF of a crack near the border of the notch can be estimated from the stress distribution along the $x$-coordinate, considering $x \equiv a$ in Eq. (2.24). It is worth mentioning that the identity $x \equiv a$ is only valid for small cracks, e.g. in the case of circular notches, when $a$ is much smaller than the hole radius. Since this work is intended to model short cracks, the use of that identity is justified. Thus, $f_{1, \mathrm{C}-\mathrm{P}}(a, \rho)$, estimated from the stress distribution ahead of a notch tip (without crack) can be used to estimate the SIF.

In the second way to estimate $f_{1}$ of a $\mathrm{C}(\mathrm{T})$-like specimen, the geometry of its notch can be approximated to a semi-ellipse, the case presented in the previous section. Since that $f_{1}\left(K_{\mathrm{t}}, \mathrm{a}\right)$ depends on the SCF (see Eq. (2.19)), the $K_{\mathrm{t}}$ of the C(T) can be estimated by C-P approach, by means of Eq. (2.11). Thus, the estimated $f_{1, \text { s-e }}$ considers the $f_{1}\left(K_{\mathrm{t}}\right.$, a) of a small crack departing from a semielliptical notch tip, but maintaining the actual $K_{\mathrm{t}}$ of the $\mathrm{C}(\mathrm{T})$ specimen.

After obtaining the approximated expression for $f_{1}$ and following the same procedure used for a notched plate under uniaxial tension aforementioned in section 2.6.1, the crack propagation criterion for a $\mathrm{C}(\mathrm{T})$-like specimen (tensile + bending stresses) can be expressed in terms of $f_{1}$ and a dimensionless function $g$ that depends on $\Delta \sigma_{\mathrm{n}}, a, \rho, \Delta S_{\mathrm{R}}$ and $\Delta K_{\mathrm{R}}$, as shown in Eq. (2.25).

$$
f_{1}(a, \rho)>\left(\frac{\Delta K_{\mathrm{R}}}{\Delta S_{\mathrm{R}}}\right)\left(\frac{\Delta S_{\mathrm{R}}}{\Delta \sigma_{\mathrm{n}}}\right)\left[(\alpha \sqrt{\pi a})^{\gamma}+\left(\frac{\Delta K_{\mathrm{R}}}{\Delta S_{\mathrm{R}}}\right)^{\gamma}\right]^{-1 / \gamma} \equiv g\left(a, \frac{\Delta K_{\mathrm{R}}}{\Delta S_{\mathrm{R}}}, \frac{\Delta S_{\mathrm{R}}}{\Delta \sigma_{\mathrm{n}}}, \gamma\right)(
$$


The ratio $\Delta S_{\mathrm{R}} / \Delta \sigma_{\mathrm{n}}$ in Eq. (2.25) associated to the largest non-propagating short crack $a_{\max }$ is equal to $K_{\mathrm{f}}$. Therefore, $K_{\mathrm{f}}$ and $a_{\max }$ can be obtained by solving the system of equations in Eq. (2.26).

$$
\left\{\begin{array}{l}
f_{1}\left(a_{\text {max }}, \rho\right)=g\left(a_{\text {max }}, K_{\mathrm{f}}, \frac{\Delta K_{\mathrm{R}}}{\Delta S_{\mathrm{R}}}, \gamma\right) \\
\frac{\partial}{\partial a}\left[f_{1}\left(a_{\text {max }}, \rho\right)\right]=\frac{\partial}{\partial a}\left[g\left(a_{\text {max }}, K_{\mathrm{f}}, \frac{\Delta K_{\mathrm{R}}}{\Delta S_{\mathrm{R}}}, \gamma\right)\right]
\end{array}\right.
$$

On the other hand, the SIF range $\Delta K=\alpha \cdot f(a) \cdot \Delta \sigma_{\mathrm{n}} \sqrt{ }(\pi a)$ of short cracks emanating from the notch root of a $\mathrm{C}(\mathrm{T})$ can be calculated using a proper $\mathrm{FE}$ software. In this work, the Quebra2D software was used to obtain the SIF $\Delta K$ of a small crack tip by a series of FE analysis for several values of the crack size $a$, assuming a plane stress condition. A total crack length $a=2 \mathrm{~mm}$ ahead the notch root was evaluated, with crack size increments $\Delta a=0.02 \mathrm{~mm}$ for each analysis. Then, the geometry factor $f(a)$ can be obtained, but only in graph form. Finally, $K_{\mathrm{f}}$ and $a_{\max }$ can be obtained graphically using the crack propagation criterion showed in Eq. (2.25).

\section{7.}

\section{The Theory of Critical Distances (TCD)}

In TCD model Taylor assumes a characteristic material length parameter, the so-called critical distance $L$, which can be estimated from $\Delta K_{\mathrm{R}}$ and $\Delta S_{\mathrm{R}}$ (Eq. (2.27)). The TCD group includes the Point Method (PM), the Line Method (LM), the Area Method (AM), and the Volume Method (VM), which is the most general one. To make predictions, the TCD model requires that the elastic stress range (in the loading direction) to be known as a function of its distance $x$ ahead of the notch tip, $\Delta \sigma(x)$.

$$
L=\frac{1}{\pi}\left(\frac{\Delta K_{R}}{\Delta S_{R}}\right)^{2}
$$

\subsection{1.}

\section{The Point Method (PM)}

The PM is the simplest form of the TCD. In this approach, the criterion for crack propagation (fatigue limit) is that the local stress at a distance $x=L / 2$ ahead 
of the notch tip equals to the smooth specimen fatigue limit $\Delta S_{\mathrm{R}}$. It can be expressed mathematically by Eq. (2.28).

$$
\Delta \sigma(L / 2)=\Delta S_{R}
$$

The PM applied on a notch is illustrated in Figure 2.9a. At the fatigue limit the stress range at $x=L / 2$ is the smooth specimen fatigue limit $\Delta S_{\mathrm{R}}$.

\subsection{2.}

\section{The Line Method (LM)}

The LM method uses an average stress over a distance $x=2 L$ from the notch tip rather than a stress at particular point, as described in the PM method. For the fatigue limit determination it is required that such average stress equals to the smooth specimen fatigue limit of $\Delta S_{\mathrm{R}}$, as expressed by Eq. (2.29).

$$
\frac{1}{2 L} \int_{0}^{2 L} \Delta \sigma(x) d x=\Delta S_{R}
$$

The LM method applied on a notch is shown in Figure 2.9b. At the fatigue limit the average stress amplitude over $x=[0,2 L]$ is the smooth specimen fatigue limit $\Delta S_{\mathrm{R}}$.

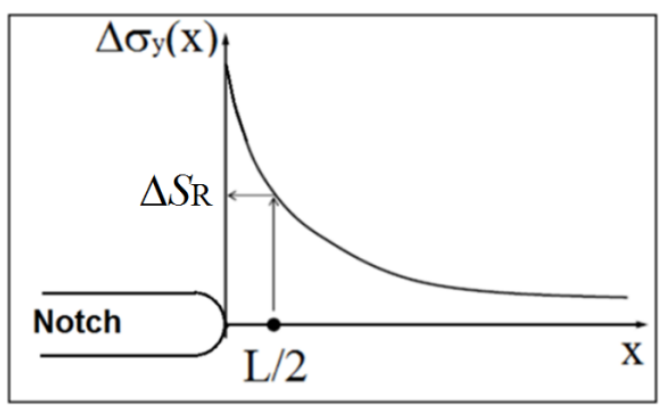

(a)

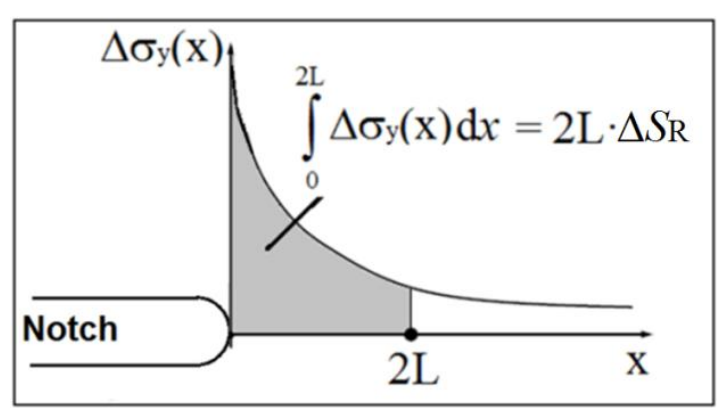

(b)

Figure 2.9- a) PM and b) LM methods applied on the elastic stress field ahead of a notch tip [24].

\subsection{3.}

\section{The Area (AM) and Volume (VM) Methods}

The AM involves an average stress over some area in the vicinity of the notch tip, whereas the VM makes use of a volume average. Considering a semicircular area, or a hemispherical volume in the VM, centered on the notch root, Bellet et al. [25] demonstrated that the radius of the semicircular area is 
1.32. $\mathrm{L}$ and that of the hemispherical volume is $1.54 \cdot \mathrm{L}$. However, the PM and the LM methods are more used because they are easier to apply, and because the AM and VM do not seem to improve the accuracy of the predictions when compared with the experimental data [24].

To close this section, albeit the predictions of the TCD model have been experimentally verified, e.g. by Susmel [26], the critical distance for each method (PM, LM, AM and VM) has not yet clearly defined throughout mechanical fundamentals. These distances are empirically related to $a_{0}$, the ETS's short crack characteristic size.

\section{8.}

\section{Experimental techniques for detection of short fatigue cracks}

Since short fatigue cracks cause only tiny changes in specimen compliance and a high magnification is needed to find them, their detection and measurement is a complex issue. Among the techniques for detection of short cracks, there are non-destructive and destructive methods. The former includes optical microscopy, digital image correlation (DIC) and X-ray micro-computed tomography, whereas metallographic analysis is an example of a potentially destructive method. These techniques were used in this work for the detection of short fatigue cracks at the end of each test and their fundamentals are explained below.

\subsection{1. Optical techniques}

Visible-light microscopy is probably the most positive mean to detect and measure the length of fatigue cracks, especially the long ones, due to the simplicity of the technique and to the wide availability of the equipments. However, this method requires highly polished surfaces and commonly involves not only the analysis of the specimen surface, but also it can implicate sectioning of the specimen, which in turn is extremely laborious and destructive.

Regarding to the detection of non-propagating short cracks, Frost and Dugdale [27] used an optical hand-microscope with a magnification of 10X for insitu monitoring of surface fatigue cracks in the notch root area of mild steel plain specimens tested under several stress ratio $R$ conditions. Besides, they employed an optical microscope with magnification up to $500 \mathrm{X}$ to perform a metallographic 
examination of the region around the notch in those specimens remained unbroken.

Currently, high quality optical microscopes with resolution up to $\sim 1 \mu \mathrm{m}$ are used to in-situ detection of the initiation and growth of short cracks. For instance, Amiri and Modarres [28] studied the behavior of short cracks emanating from a semi-circular single edge notch by optical microscopy, with the configuration presented in Figure 2.10. In this case, Al 7075-T6 specimens were subjected to uniaxial constant amplitude fatigue loads and crack sizes in the range of $50 \mu \mathrm{m}$ were detected at the surface of specimens by this technique.

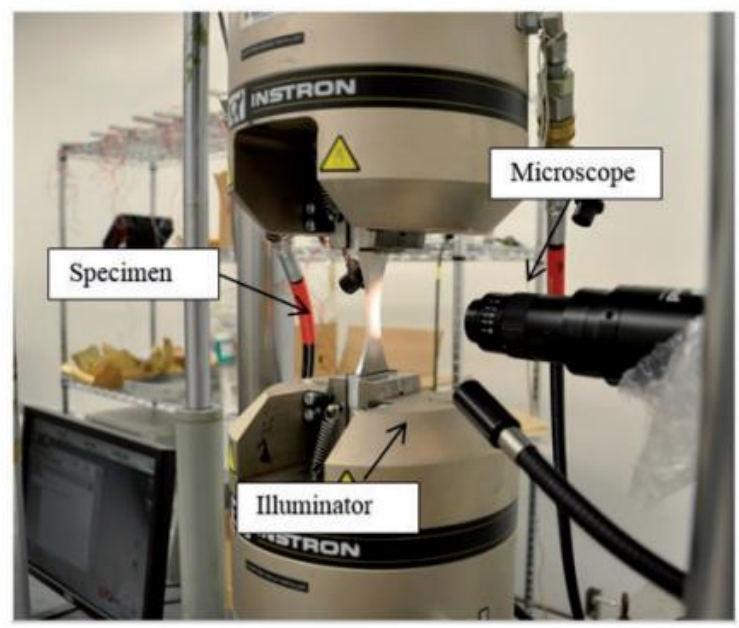

Figure 2.10- Experimental configuration for the in-situ detection of short fatigue crack by optical microscopy [28].

The major disadvantage of optical methods is that the crack must be observable on the side of the specimen that is being monitored. Nevertheless, real cracks can initiate in any local of the notch root through the specimen thickness and propagate to the back and front faces.

\subsection{2.}

\section{Digital image correlation, DIC [29]}

Digital Image Correlation (DIC) is an optical full-field method used to measure displacement fields at properly prepared surfaces during a test. In this method, digital images taken before (reference image) and after (deformed image) deformation are compared and analyzed by an image correlation routine. These images can be taken by a single camera for bi-dimensional (2D) measurements or by two or more cameras for tri-dimensional (3D) measurements. The image 
correlation routine divides the reference image into small regions called subsets which contains several pixels. Then, the DIC algorithm uses a correlation function to identify matching regions of subsets in both the reference and the deformed images.

This process can be efficiently performed if the surface of the object presents a high-contrast granular morphology. Hence, the surface to be analyzed by DIC is previously painted with a thin layer of white paint, and then by applying over it a random pattern of black dots (speckle pattern). Once the location of all subsets in the deformed image is found, their displacements can be determined, as shown in Figure 2.11, where $u$ and $v$ are the displacements along the $x$ and $y$ directions. The density of the displacement measurements is controlled by the step size: for a step size of 1 , displacements are computed at every pixel of the digital image. Besides, the strain field can be calculated from the measured displacement data.

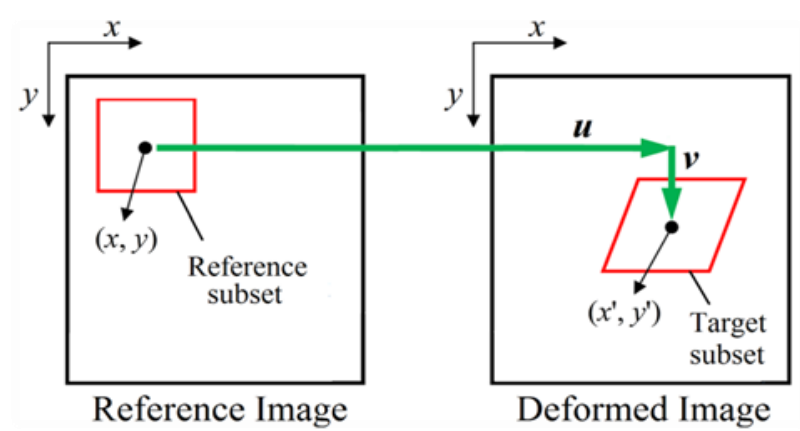

Figure 2.11- Matching between the subsets of the reference and deformed images.

However, DIC presents some drawbacks: for example, stress gradients near boundary critical points in stress concentration areas are difficult to measure accurately due to both the subset and the step sizes, and also the previous surface preparation.

\subsection{3.}

\section{X-ray micro-computed tomography}

The X-ray micro-computed tomography (microCT) is a NDT for 3D characterization of the material structure at a micron level spatial resolution at a scale of 0.3 to $100 \mu \mathrm{m}$ [30]. The principle of this technique is depicted in Figure 2.12. An X-ray beam passes through a specimen, which is rotated around a vertical axis at various viewing angles. The transmitted X-ray beam is converted 
to visible light by a scintillator and a photodetector allows the acquisition of $2 \mathrm{D}$ projection images. Based on mathematical principles of tomography, this sequence of images is reconstructed to produce a $3 \mathrm{D}$ digital image, which is composed by voxels (volume element or 3D pixel) [30].

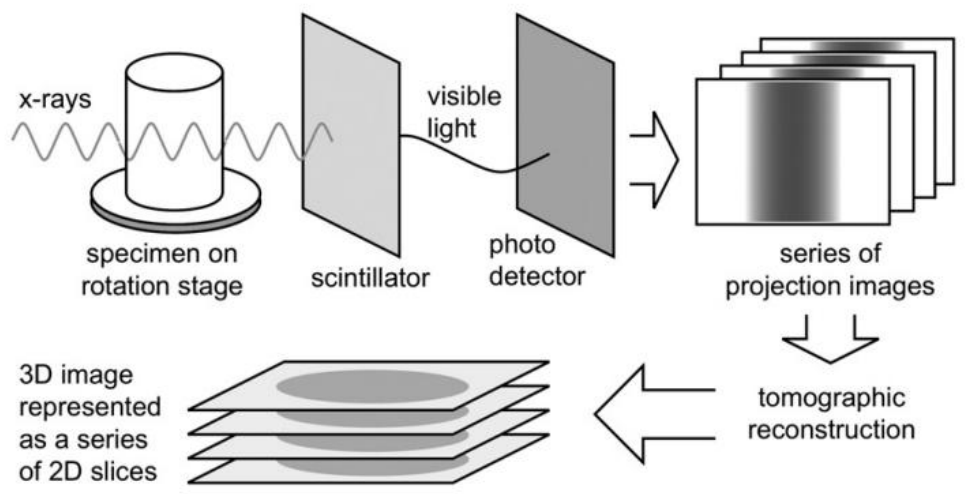

Figure 2.12- Scheme of X-ray microCT principle, showing acquisition and reconstruction processes [30].

As the incident X-ray beam passes through the specimen, its intensity decreases as a result of X-ray absorption by the material [31]. Thus, the transmitted beam emerging from the sample is attenuated, as demonstrated by the Lambert-Beer's law (see Eq. (2.30)).

$$
I=I_{0} e^{-\mu_{t} t}
$$

where $I$ and $I_{0}$ are the intensities of the transmitted (attenuated) and the incident $\mathrm{X}$-ray beams, respectively, $t$ is the thickness of the specimen and $\mu_{l}$ is the X-ray linear attenuation coefficient of the material, which is proportional to the material's density $\rho$ and to its atomic number $Z$ at a specific X-ray energy level. Commonly, $\mu_{l}$ is expressed as a function of the mass attenuation coefficient of the material $\mu_{m}, \mu_{m}=\mu_{l} / \rho$, which is a parameter widely available in literature. Thus, the Lambert-Beer's law can be re-written as shown in Eq. (2.31).

$$
I=I_{0} e^{-\mu_{\mathrm{m}} \rho t}
$$

The X-ray contrast of two different materials in microCT arises from the difference of their linear attenuation coefficients $\mu_{l}$ (absorption contrast). Therefore, the variation of $\mu_{l}$ in the volume of the specimen can be reconstructed by combining a number of $2 \mathrm{D}$ projection images to obtain a $3 \mathrm{D}$ array of voxels 
[32]. The absorption contrast can be used in the X-ray microCT for the detection of fatigue cracks. When a crack exits in a specimen, the X-ray attenuation in the crack is smaller than that of the surrounding matrix due to the negligible density. Such a difference can theoretically allow the detection of a crack, but it might not be effective in those cases where the crack opening is extremely small [33].

Since the degree of X-ray attenuation depends on the density and atomic number of the material, it can be inferred from Eq. (2.31) that metals (high density materials) are often a challenge for X-ray microCT, due to their relative high Xray absorption. This limits the penetrating ability of the X-ray. In fact, the transmitted beam is highly attenuated (less photons reach the detector) and the acquired images are prone to noise and poor contrast. To overcome this problem, the analysis of dense metals requires either very high-energy X-rays or very small specimens [30]. It is important to point out that Lambert-Beer's law is ideally valid for monochromatic X-ray sources (single energy X-ray) [31].

There are two types of microCT systems depending on the X-ray source: conventional and synchrotron-based systems. In the first case, a microfocus X-ray tube source is employed, which generates a polychromatic X-ray cone beam, namely, the beam is composed by X-rays with different energies. This system is commonly available at laboratory scale and depending on the size of the specimen and on its geometrical configuration, it can provide spatial resolutions up to $\sim 0.7$ $\mu \mathrm{m}$. The disadvantage of the conventional equipments is that the low intensity of $\mathrm{X}$-rays generated from the X-ray tube source does not allow the X-ray energy filtering [34]. Since polychromatic beams are formed by a range of energy X-ray spectrum, preferential attenuation of low energy X-rays can lead to artifacts in the reconstructed images and the relationship between attenuation coefficient and material's density is not linear. Therefore, the beam transmission does not follow exactly the Lambert-Beer's law.

On the other hand, higher spatial resolution $(<0.7 \mu \mathrm{m})$, higher contrast reconstruction and excellent signal-to-noise ratio can be achieved using synchrotron X-ray sources. The advantage of this system is that it generates a parallel monochromatic X-ray beam, composed by single X-ray energy, which possesses much higher intensity than that provided by microfocus tube. However, 
synchrotron studies can be inaccessible to many researchers, because of the scarcity of synchrotron facilities [35].

The spatial resolution in synchrotron-based systems depends basically on the detector's resolution [34]. Nevertheless, in conventional micro-CT this parameter is adjustable and depends not only on the detector spatial resolution, but also on the specimen size and the geometrical magnification, which is dictated by the position of the specimen between the source and the detector (see Figure 2.13a) $[34,36]$.

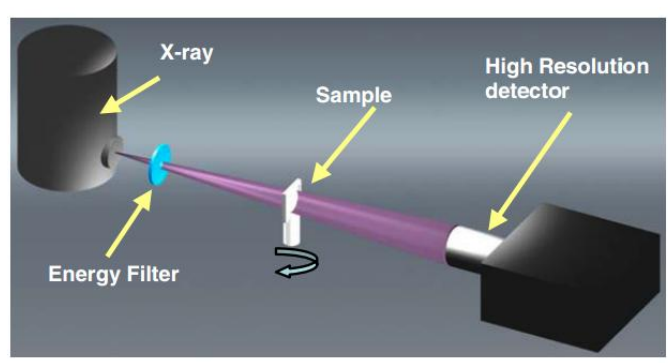

(a)

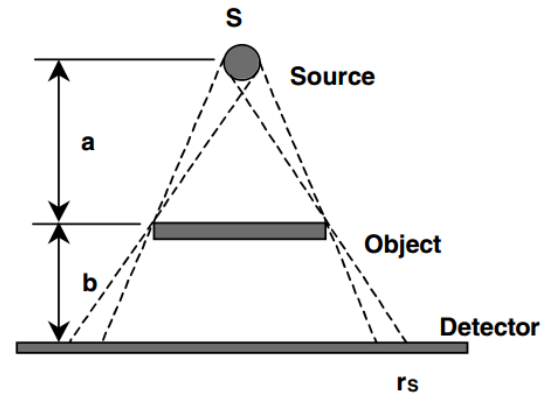

(b)

Figure 2.13- a) Configuration of a conventional microCT system, where a microfocus Xray source is shown and b) Illustration of the geometric blurring $r_{S}$ induced by the size of the source spot $S[36]$.

The resolution $R_{\text {total }}$ can be estimated using Eq. (2.32) [36].

$$
R_{\text {total }}=\left(\sqrt{r_{D}^{2}+r_{S}^{2}}\right) / M
$$

where, $r_{\mathrm{D}}$ is the resolution of the detector system, $r_{\mathrm{S}}$ is the blurring due to the geometric unsharpness induced by the size of the source spot $S$ (see Figure 2.13b) and it is given by Eq. (2.33), where $a$ and $b$ are source-to-specimen and specimento-detector distances, respectively. The magnification $M$ is calculated using Eq. (2.34) [36].

$$
\begin{aligned}
& r_{S}=S(b / a) \\
& M=(a+b) / a
\end{aligned}
$$

Note that the magnification $M$ increases as the distance between the source and the specimen $a$ decreases. In order to achieve high system resolution $R_{\text {total }}$, the 
specimen ought to be located very close to the source so that its projection is greatly magnified onto the detector, as well as, the spot size of the source $S$ must be very small to achieve minimal geometric bluntness. Moreover, the desired magnification can be accomplished using a set of objective lenses (optical magnification), but in this cases the sample representativeness decreases [36]. Another important parameter to increase the spatial resolution is the acquisition time. Long acquisition time is usually required to achieve high spatial resolution in conventional-based systems because the amount of detected photons is usually limited [34].

It is worth noting that the proximity of the specimen to the source rigorously restricts the size of the specimen that can be analyzed by conventional X-ray micro-CT. For extended specimens, the distance between source and specimen must be increased to allow the specimen to be rotated, which decreases the system resolution [36]. Hence, this is a drawback for the detection of cracks in large specimens.

\section{9.}

\section{Short fatigue cracks: literature review}

The short fatigue cracks nucleated at notch tips under constant amplitude loading can grow for a small distance at a decreasing rate $\mathrm{d} a / \mathrm{d} N$, and then their growth rate can increase after reaches a minimum or even arrest, depending on the nominal stress level and the notch severity [10,37,38]. Indeed, notches can be classified in increasing order of their severity as "blunt notches" and "sharp notches". The former are related to large notch tip radii $\rho$, while the latter are understood as notches having relatively small radii. For blunt notches under low applied load levels, the peak stresses may not exceed the yield strength of the material and the local strain will remain elastic. If a crack nucleates under these conditions, the crack growth rate will be higher than that of a long crack until reaching the behaviour of a long crack. Conversely, for a sharp notch or higher loading levels, local stresses can reach and exceed the yield strength and produce a zone of local plasticity. As a result, the nucleated crack can propagate decelerating up to arrest, becoming a non-propagating one, or until achieve a minimum growth rate before re-accelerating until reaching the behavior of a long crack. The differences between blunt and sharp notches in terms of the notch 
radius represented by $K_{\mathrm{t}}$, are depicted schematically in Figure 2.14, following the Frost diagram (see Figure 2.3). The nominal stress $\Delta \sigma_{\mathrm{n}}$ applied on a notched specimen with a constant depth $b$ is expressed in terms of $\Delta K_{\mathrm{R}}$ and $\Delta S_{\mathrm{R}}$, the long crack propagation threshold and the smooth specimen fatigue limit for a stress ratio $R$.

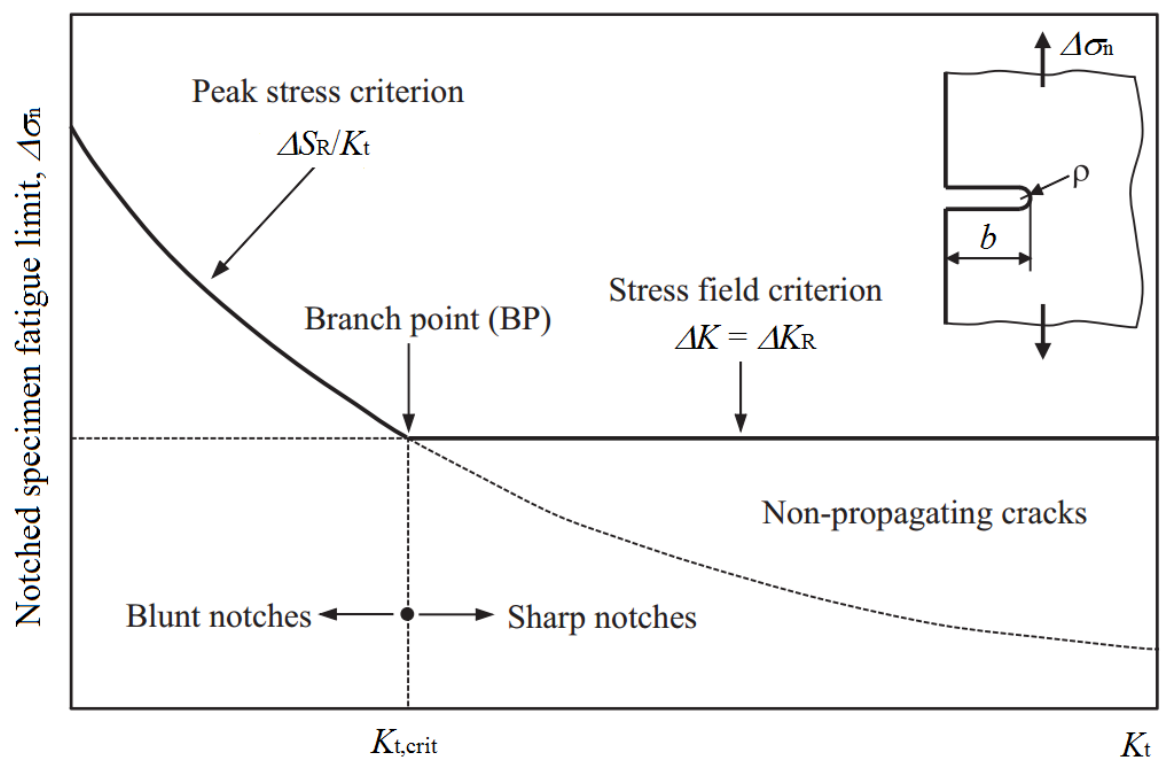

Figure 2.14- Differences between blunt and sharp notches as a function of $K_{\mathrm{t}}$, based on Frost diagram (adapted from Meneghetti et al. [39]).

\subsection{1.}

\section{Short fatigue cracks at sharp notches}

The initiation and propagation of short cracks at notch tips has been widely studied over the years both theoretically and experimentally in specimens of several materials to understand why their growth is different from that of long cracks. This understanding has a practical significance since fatigue life and fatigue limit predictions depend on it.

For instance, Dowling [40] tested notched specimens of a medium carbon steel to validate fatigue life predictions by dividing it into crack initiation and propagation phases, while Cameron and Smith [41] predicted and determined experimentally the stress levels for initiation and propagation of a fatigue crack at a notch by testing mild steel notched specimens. Shin and Smith [42] tested stainless steel double-edge notched specimens and concluded that short cracks from notches grow faster than long cracks, when they are subjected to the same SIF range $\Delta K$. Likewise, Tanaka and Nakai [43] demonstrated that a crack 
nucleated at a sharp notch tip propagates decelerating, followed by an accelerating growth rate or a non-propagating crack, depending on the applied load level.

As aforementioned, sharp notches are generally related to zones of local plasticity at notch tip due to their high $K_{\mathrm{t}}$ and for this reason several researches included notch plasticity effects on the study of short cracks behaviour. Based on the work previously reported by Smith and Miller [44], Hammouda et al. [45] proposed that crack initiation and propagation are controlled by total plastic shear deformation. In fact, short cracks propagate inside the notch plastic zone, where the total shear deformation is derived from the sum of the crack tip plasticity and notch induced plasticity, behaviour that differs from long crack propagation, which is controlled solely by shear deformation derived from the crack tip plasticity. The notch contribution for short crack growth decreases with the crack length, whilst the crack tip contribution increases. As a result, the crack growth rate can decelerate and the short crack initiated at notch tip may become a nonpropagating one if the crack tip plasticity is too small to maintain the growth beyond the notch plastic zone.

Moreover, Dong et al. [46] proposed a two-stage crack growth model to modify the SIF for short cracks at notches by using finite element (FE) solutions. The stress state at notch plastic zone was redistributed by separating it in two parts: i) notch-induced stress and ii) nominal stress. Hence, the conventional Paris law for fatigue crack propagation was modified to take into account these two stages of SIF. This model was applied for extensive data from the literature and it was demonstrated that the crack growth of short cracks at notches can be unified with long crack data.

Ding et al. [47] investigated quantitatively and qualitatively the crack growth behaviour near a notch tip by using the FE method with the implementation of an elastic-plastic analysis. The stress-strain results obtained from FE simulations were used to determine the fatigue damage in the so-called notch influencing zone. They attributed the behavior of short cracks at notches to the combination of i) the effect of notch plasticity and ii) the contact of the cracked surfaces during a portion of the loading cycle when $R<0$. The former are related with fatigue damage accumulation during crack initiation, whilst the latter 
causes a reduction of cyclic plasticity which is proportional to the crack length. For $R>0$ cases, it was assumed no contact between the cracked surfaces. It is worth noting that this crack surface contact is different from the typically used crack closure concept. Finally, the predictions were compared with experimental observations by testing disk-shaped compact $\mathrm{DC}(\mathrm{T})$ specimens of a low carbon steel.

Sadananda and Vasudevan [48] justified the behavior of short cracks at notches by considering the existence of i) two long crack propagation threshold $\Delta K_{\text {th }}$ and $K_{\text {max,th }}$ parameters and ii) internal stresses related to the presence of the notch. This approach explains the deceleration of short cracks, and the existence of non-propagating cracks, as a function of the second SIF threshold: as the crack grows ahead of the notch tip, the contribution from internal stresses decreases and the maximum SIF $K_{\max }$ caused from the total stress may fall below $K_{\max \text {,th. }}$ Thereby, they stated that short cracks at notches grow with a rate equal to that of long cracks as long as both the applied and the notch-induced internal stress field gradients are considered.

Benedetti et al. [49] investigated the initiation and early propagation of fatigue cracks at notches in $\beta$-titanium alloy specimens. Stress redistribution and crack closure effects, both of them caused by notch plasticity, were found to influence the behaviour of short fatigue cracks. These effects were assessed by FE modeling, assuming that crack closure is related only to compressive residual stresses at notch tips, and neglecting sources of closure such as crack tip plasticity or crack surface roughness.

In summary, based on the works presented in this section, the growth of short fatigue cracks at sharp notches under constant amplitude stress control can be described as follows: a crack i) initiates at notch tip, ii) propagates ahead the notch with a decelerating growth rate, iii-a) arrests and becomes a nonpropagating crack (see curve 1 in Figure 2.15) or iii-b) reaches a minimum growth rate and then accelerates behaving as a long crack (see curve 2 in Figure 2.15). Several models and approaches were considered and the same conclusion was obtained. 


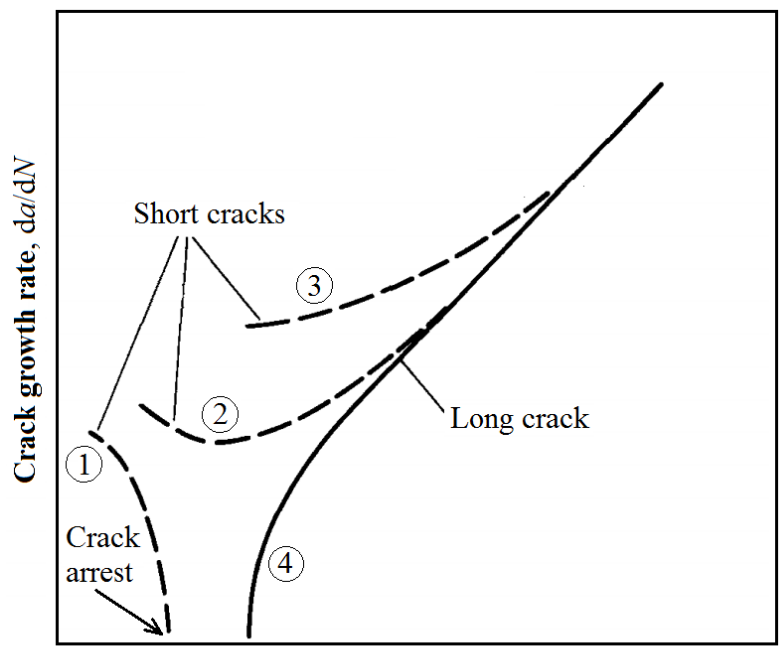

SIF range, $\Delta K$

Figure 2.15- Differences between short and long crack propagation (adapted from [50]).

\subsection{2.}

\section{Fatigue limit predictions in notched specimens}

Fatigue limit of notched structural components can be estimated by many semi-empirical and theoretical methods that can be classified as total-life, criticaldistance, and fracture-mechanics approaches. The $\mathrm{SN}$ and $\varepsilon \mathrm{N}$ procedures use the total-life approach which does not recognize cracks. The classical critical-distance procedures are those based on the stress at a certain point ahead of the notch tip, initially proposed by Peterson [51], Neuber [52], and Heywood [53]. Recent research, based on the average of the stress over a certain distance or in a certain representative volume of the material, has been developed by Taylor [24,54] with the so-called Theory of the Critical Distance (TCD), as explained above in Section 2.7.

On the other hand, another philosophy to predict fatigue limits has been proposed based on linear elastic fracture mechanics (LEFM) concepts. Its main advantage is to recognize cracks and their effects on the fatigue limit, modeling the actual fatigue limit more realistically because there are no defect-free materials in practice. In fact, considering the three phases of a short fatigue crack at a notch, explained in the previous section, there are two characteristic stress levels: the initiation limit and the propagation limit. The former is the minimum applied stress that nucleates a crack at notch tip, related to $K_{\mathrm{t}}$ (see curve 1 in Figure 2.16). The latter is the minimum applied stress that a short crack needs to reach the behaviour of a long one after passing through a minimum growth rate 
and, by definition, this is the fatigue limit of the notched specimen (see curve 3 in Figure 2.16). If the applied stress is between these two stress limits, the result always will be a non-propagating crack, as represented by curve 2 in Figure 2.16. The pioneer model based on this methodology was proposed by El Haddad, Toper and Smith (ETS) [4], and it has been recently extended to consider notch effects $[5,22,55]$ in the so-called Stress Gradient (SG) model, briefly described in Section 2.6 .

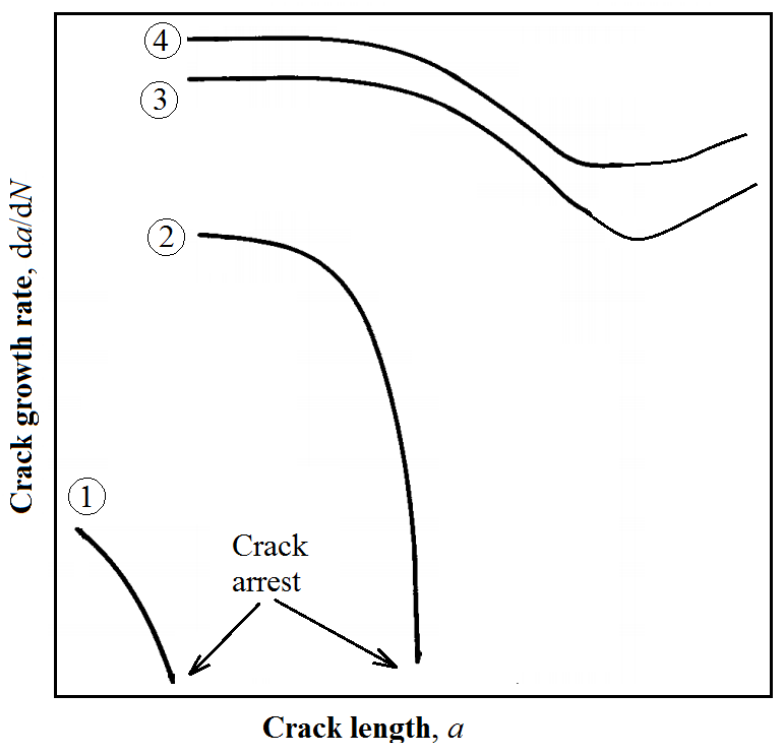

Figure 2.16- Schematic representation of the growth rate $\mathrm{d} a / \mathrm{d} N$ as a function of the crack length $a$ (adapted from [50]). 


\section{3 \\ Estimation of the short crack characteristic size $a_{0.1}$}

The short crack characteristic size for a given stress ratio $R, a_{\mathrm{R}}$, is a very important parameter for the Stress Gradient (SG) model. As already studied in Chapter 2, $a_{\mathrm{R}}$ depends on two fatigue properties: the long crack propagation threshold $\Delta K_{\mathrm{R}}$ and the smooth specimen fatigue limit $\Delta S_{\mathrm{R}}$ for a given stress ratio $R$ (see Eq. (2.17)). Therefore, the accuracy of the predications made by the SG model depends on the accuracy of $\Delta K_{\mathrm{R}}$ and $\Delta S_{\mathrm{R}}$ assessments. These fatigue properties, as well as the monotonic mechanical properties of a structural low carbon steel used to verify the SG model predictions, were experimentally measured, as explained in this chapter. Fatigue tests were conducted using a 100 kN INSTRON computer controlled servo-hydraulic machine, while tensile test was performed in a $50 \mathrm{kN}$ INSTRON electromechanical machine.

Compact tension $\mathrm{C}(\mathrm{T})$-like specimens were used in this work to verify experimentally the predictions made by the SG model, as indicated in the next chapter. This test specimen (TS) type is recommended for tension-tension or compression-compression tests, but it is not recommended for tensioncompression tests due to the possible impact load between the pin in the loading fixture and the hole of the TS. Nevertheless, it is important to point out that there are works in which tension-compression tests were carried out (for example, see [47]). In the present work, tension-tension tests were performed, with a stress ratio $R=0.1$, except in the case of precracking procedure for the evaluation of $\Delta K_{R}$, where compression-compression tests were used.

\section{1.}

\section{Selection of the material for the experimental verification}

The material for test specimens was selected based on the value of the short crack characteristic size $a_{\mathrm{R}}$, which limits the behavior between short and long cracks in fatigue, as described in Chapter 2. Hence, the larger the size of $a_{\mathrm{R}}$, the simpler it is to detect and measure by proper techniques non-propagating short 
cracks at notch tips. Several low carbon steels were considered and their $a_{\mathrm{R}}$ values were estimated from the long crack propagation threshold $\Delta K_{\mathrm{R}}$ and the fatigue limit $\Delta S_{\mathrm{R}}$, using the Eq. (2.17). Since data for pulsating loads condition $(R=0)$ are more easily founded in the literature, those $\Delta K_{0}$ and $\Delta S_{0}$ data were considered to obtain a first estimation of $a_{0}$. The fatigue limit $\Delta S_{0}$ was estimated from the fatigue limit for fully reversed load condition $(R=-1), \Delta S_{-1}=S_{U}$, then, the equivalent value $\Delta S_{0}$ was computed via Goodman approach: $\Delta S_{0}=2 S_{U} / 3$. These values, from the literature [14] and the estimated ones are summarized in Table 3.1. Cracks with sizes greater than $100 \mu \mathrm{m}$ are theoretically easy to be detected and measured by optical microscopy, and that is why these materials were considered.

Table 3.1- Estimations of the characteristic short crack size $a_{0}$ for several structural low carbon steels.

\begin{tabular}{ccccc}
\hline Material & $\begin{array}{c}S_{\mathrm{U}}{ }^{\mathrm{a}} \\
(\mathrm{MPa})\end{array}$ & $\begin{array}{c}\Delta S_{0}{ }^{*} \\
(\mathrm{MPa})\end{array}$ & $\begin{array}{c}\Delta K_{0}^{\mathrm{a}} \\
(\mathrm{MPa} \sqrt{\mathrm{m}})\end{array}$ & $\begin{array}{c}a_{0} * * \\
(\mu \mathrm{m})\end{array}$ \\
\hline $1006(85 \mathrm{HB})$ & 318 & 212 & 11 & 681 \\
\hline $1009(90 \mathrm{HB})$ & 345 & 230 & 11 & 579 \\
\hline $1018(106 \mathrm{HB})$ & 354 & 236 & 11 & 550 \\
\hline $1015(80 \mathrm{HB})$ & 414 & 276 & 11 & 402 \\
\hline $1020(108 \mathrm{HB})$ & 491 & 327.3 & 11.6 & 318 \\
\hline $0030(137 \mathrm{HB})$ & 496 & 330.7 & 8.8 & 179 \\
\hline $1030(128 \mathrm{HB})$ & 454 & 302.7 & 7 & 135 \\
\hline $1035(140 \mathrm{HB})$ & 476 & 317.3 & 7 & 123 \\
\hline $\mathrm{A} 36(160 \mathrm{HB})$ & 414 & 276 & 6 & 120 \\
\hline
\end{tabular}

${ }^{a}$ Values from [14]; * Estimated from $S_{\mathrm{U}}$ by Goodman, ** Computed using Eq. (2.17).

Another important factor is the commercial availability of the material in the local market. From this point of view, A36 and 1020 steels are the best options, thus, based on $a_{0}, 1020$ steel was selected. Since the entire experimental program was conducted under $R=0.1$, the corresponding $a_{0.1}$ was computed from the experimentally assessed $\Delta K_{0.1}$ and $\Delta S_{0.1}$, as detailed below.

\section{2.}

\section{Standard tension testing and average grain size}

The material used for the experimental program was characterized by a standard tension test, according to ASTM E8M-13a standard. The test specimens (TS) were machined from a flat bar of SAE 1020 low carbon steel, obtained from GERDAU S. A. supplier in Mogi das Cruzes - SP, Brazil. The chemical composition of this steel given by the supplier is presented in Table 3.2. 
Table 3.2- Chemical composition of the tested SAE 1020 steel.

\begin{tabular}{ccccccc}
\hline Element & $\mathrm{Mn}$ & $\mathrm{Si}$ & $\mathrm{C}$ & $\mathrm{Cr}$ & $\mathrm{Cu}$ & $\mathrm{Ni}$ \\
\hline $\mathrm{wt} \%$ & 0.36 & 0.24 & 0.2 & 0.19 & 0.1 & 0.04 \\
\hline
\end{tabular}

The TS dimensions are shown in Figure 3.1. These specimens were tested at a crosshead speed of $0.9 \mathrm{~mm} / \mathrm{min}$. The basic mechanical properties are shown in Table 3.3 while the stress-strain curves for two tested specimens are presented in Figure 3.2.

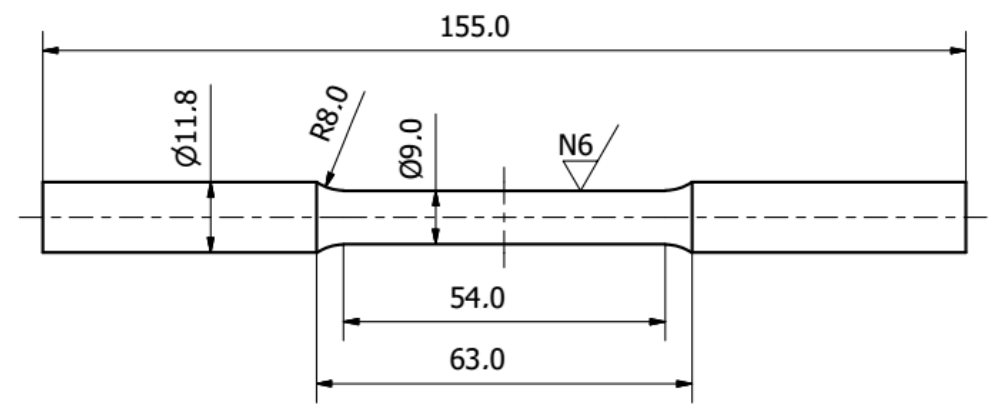

Figure 3.1- Dimension of the TS for tension tests according to ASTM E8M-13a standard.

Table 3.3- Basic mechanical properties of the tested SAE 1020 steel.

\begin{tabular}{ccc}
\hline$S_{\mathrm{Y}}(\mathrm{MPa})$ & $S_{\mathrm{U}}(\mathrm{MPa})$ & $E(\mathrm{GPa})$ \\
\hline 313 & 490 & 197 \\
\hline
\end{tabular}

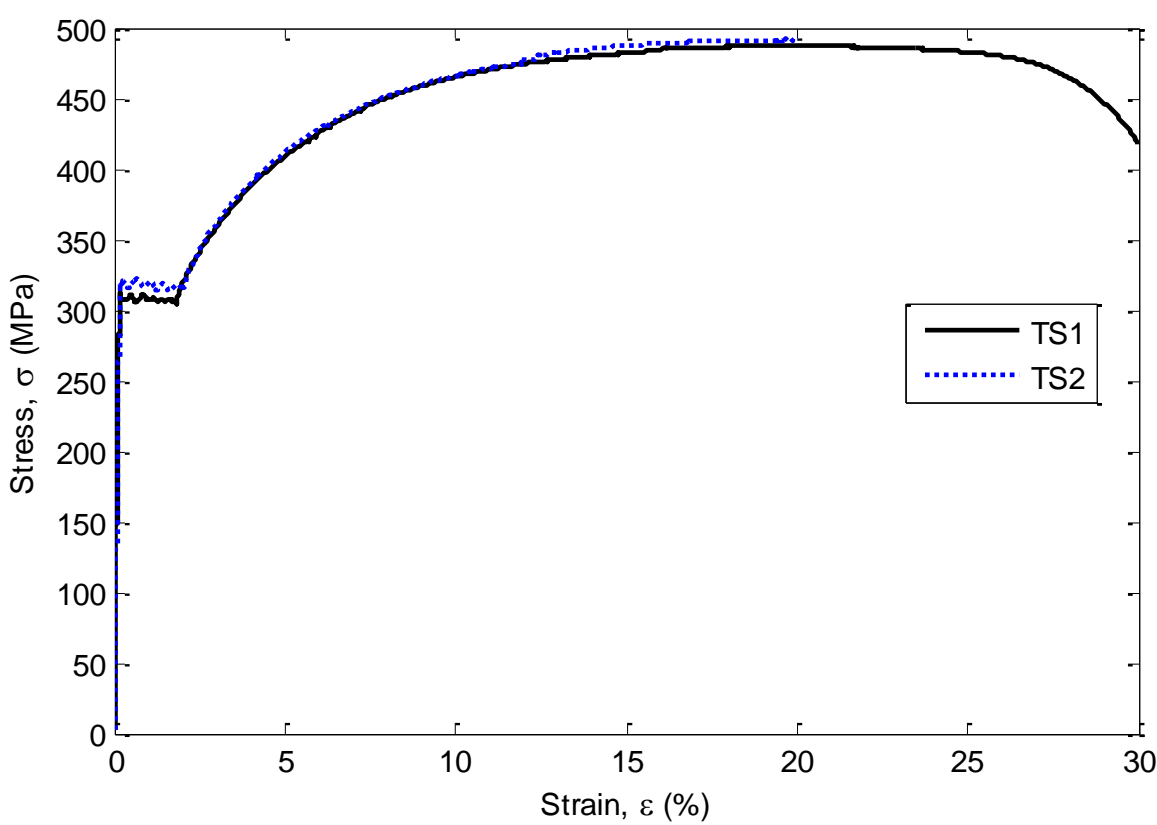

Figure 3.2- Stress-strain curves of the tension tests of two specimens.

The average grain size of SAE 1020 steel was determined according ASTME112 standard and a typical micrograph is shown in Figure 3.3. The measured average diameter was $\sim 32 \mu \mathrm{m}$, corresponding to a grain size No. G 7.0. 


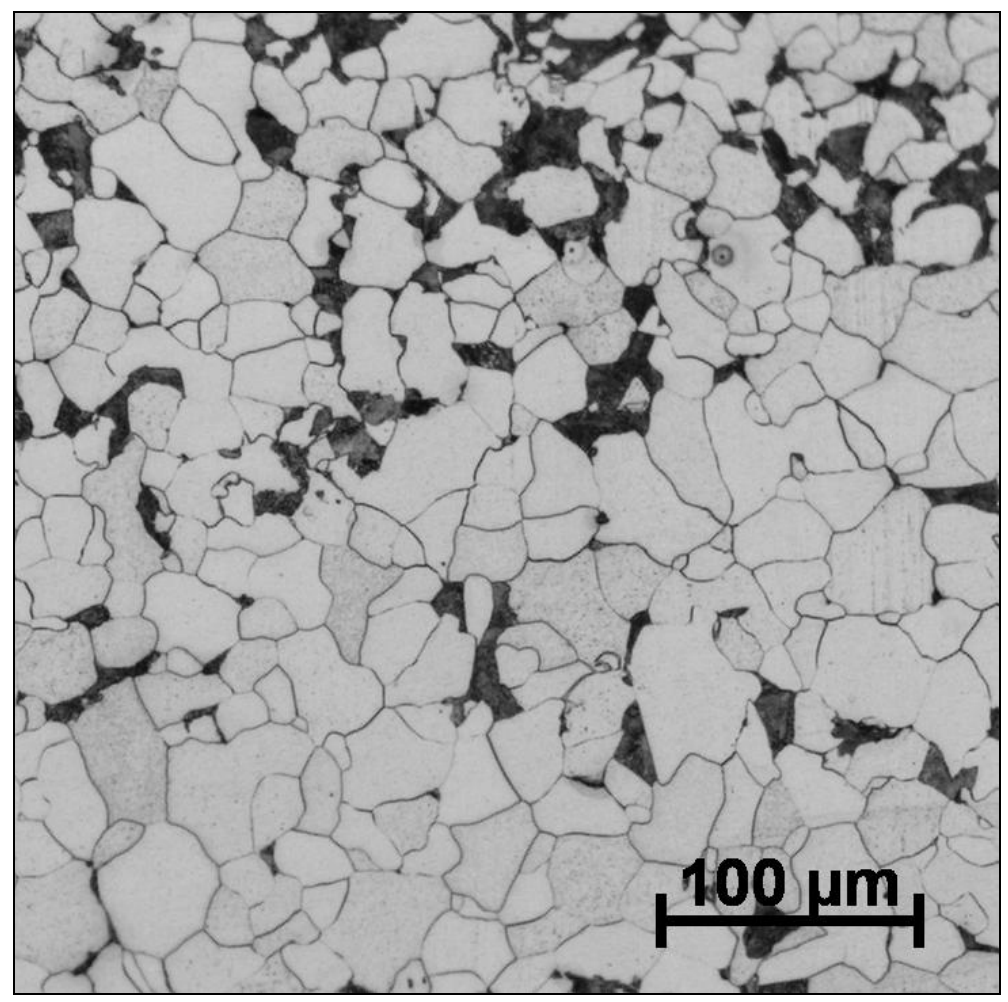

Figure 3.3- Typical micrograph of the austenitic grain structure of SAE 1020 steel.

\section{3.}

\section{Long crack propagation threshold $\Delta K_{0.1}$}

The fatigue crack growth (FCG) threshold for long cracks is operationally defined by the ASTM E647 as the asymptotic value of the SIF range $\Delta K$ that corresponds to a growth rate $\mathrm{d} a / \mathrm{d} N$ of $10^{-10} \mathrm{~m} /$ cycle. The tests were conducted on two $\mathrm{C}(\mathrm{T})$ specimens whose dimensions are shown in Figure 3.4.
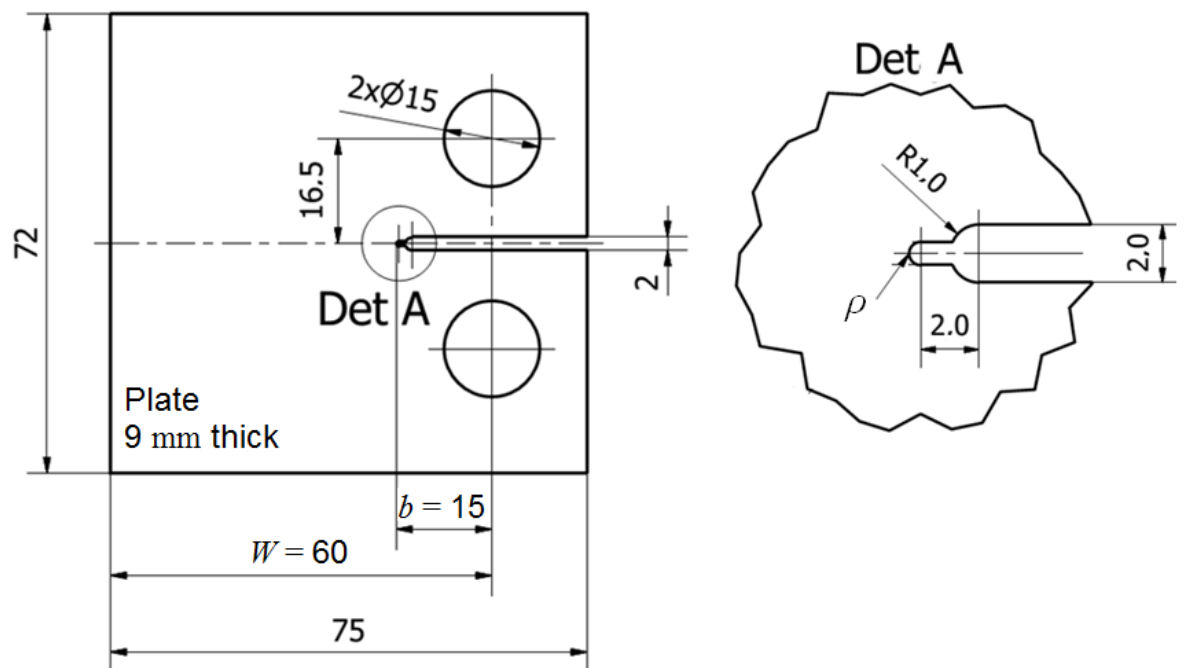

Figure 3.4- Dimensions in $\mathrm{mm}$ of the $\mathrm{C}(\mathrm{T})$-like specimen used for $\Delta K_{0.1}$ assessment. 
The evaluation of the FCG threshold $\Delta K_{0.1}$ through the two approaches detailed below was conducted by testing two $\mathrm{C}(\mathrm{T})$ specimens, under constant amplitude stress-control at frequency of $90 \mathrm{~Hz}$ and stress ratio $R=0.1$.

\subsection{1.}

\section{Compression-compression precracking + constant amplitude loading}

Following Newman's reasoning [56] the precracking procedure was carried out under compression-compression loads in order to evaluate $\Delta K_{0.1}$ without appreciable load-history effects. This precracking method induces a tensile residual stress field instead of the compressive one from the conventional tensiontension method.

A trial and error procedure was applied to determine the tensile loading, which corresponds to the long crack FCG threshold. The load history under $R=$ 0.1 , including the precracking load under $R=10\left(\sigma_{\min }=-8 \mathrm{kN}\right.$ and $\sigma_{\max }=-0.8$ $\mathrm{kN}$ ), are presented in Figure 3.5. Since a tensile residual stress field at the notch tip is induced by this precracking method, an initially fully open crack is developed under the subsequent constant amplitude load. This crack propagates decelerating because the tensile residual stress field decreases as the crack grows. If no significant propagation occurred after $\sim 2 \cdot 10^{6}$ cycles, the amplitude load was increased by $\sim 10 \%$, maintaining $R=0.1$. When the crack propagates accelerating, the amplitude load was maintained constant to obtain the lower region of the $\mathrm{d} a / \mathrm{d} N \times \Delta K$ curve (see Figure 3.6), where the FCG threshold $\Delta K_{0.1}$ can be obtained.

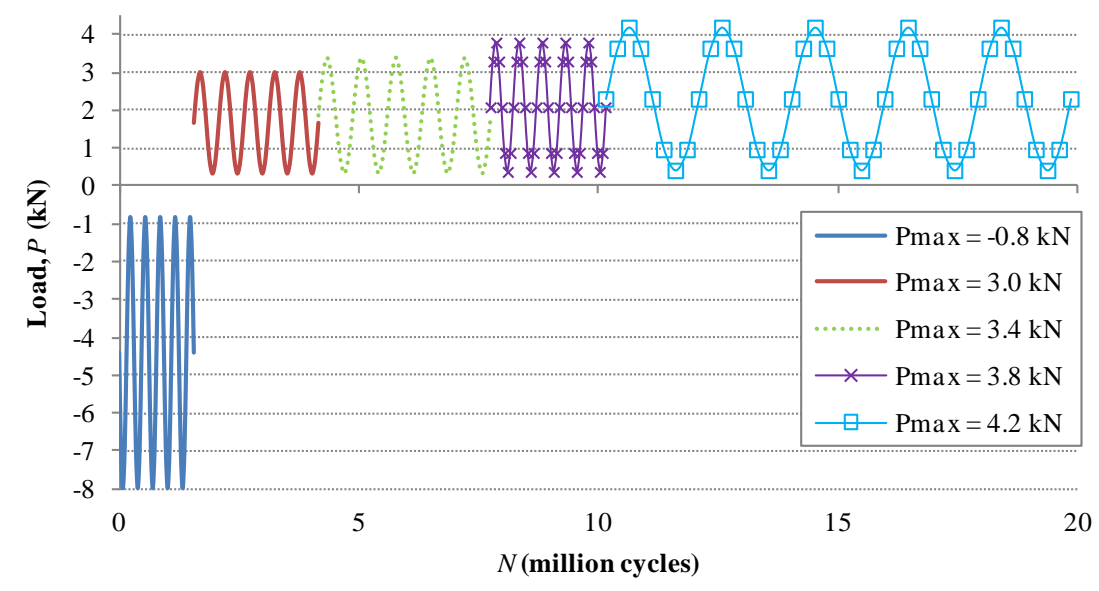

Figure 3.5- Loading applied to a $\mathrm{C}(\mathrm{T})$ specimen for $\Delta K_{0.1}$ assessment. 


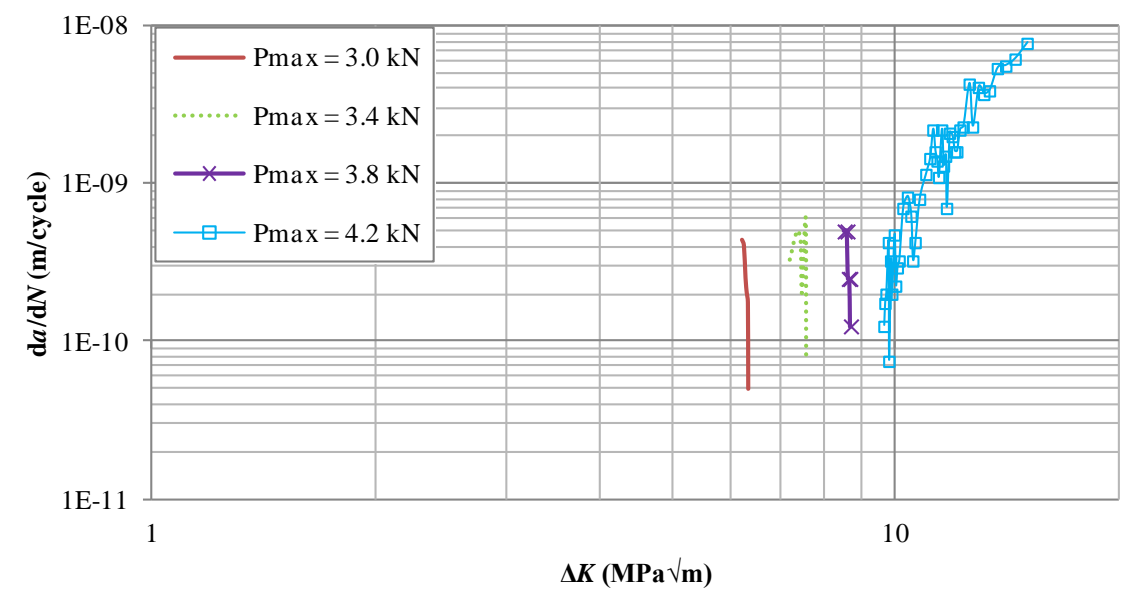

Figure 3.6- $\mathrm{d} a / \mathrm{d} N \times \Delta K$ curves of the trial and error procedure for $\Delta K_{0.1}$ assessment.

From Figure 3.6, the long crack FCG threshold $\Delta K_{0.1}$ is approximately 10 $\mathrm{MPa} \sqrt{\mathrm{m}}$, which corresponds to a growth rate $\mathrm{d} a / \mathrm{d} N=10^{-10} \mathrm{~m} /$ cycle. It is worth noting that this value was obtained for a total crack size $a>3 \mathrm{~mm}$ from the initial notch tip, so the last curve was measured without any transient effects resulted from the notch-induced plastic zone of the precracking procedure. Crack sizes were measured by two redundant techniques: optical (with a travelling microscope) and by compliance (with a strain-gage on the back-face of $\mathrm{C}(\mathrm{T})$ ).

\subsection{2.}

\section{ASTM E647: $K$-decreasing $+K$-increasing}

Once the first approach explained above was completed, a $K$-decreasing test procedure was applied, followed by a $K$-increasing test, according to ASTM E647 procedures. The valid growth rates were measured for crack sizes $a>13 \mathrm{~mm}$. The load history is shown in Figure 3.7 while the corresponding propagation curves are indicated in Figure 3.8.

Therefore, from Figure 3.8, the measured $\Delta K_{0.1}$ is approximately 10 $\mathrm{MPa} \sqrt{\mathrm{m}}$, for $\mathrm{d} a / \mathrm{d} N=10^{-10} \mathrm{~m} /$ cycle, for $K$-decreasing and $K$-increasing procedures, which is the same value obtained using the compression-compression precracking + constant amplitude load. 


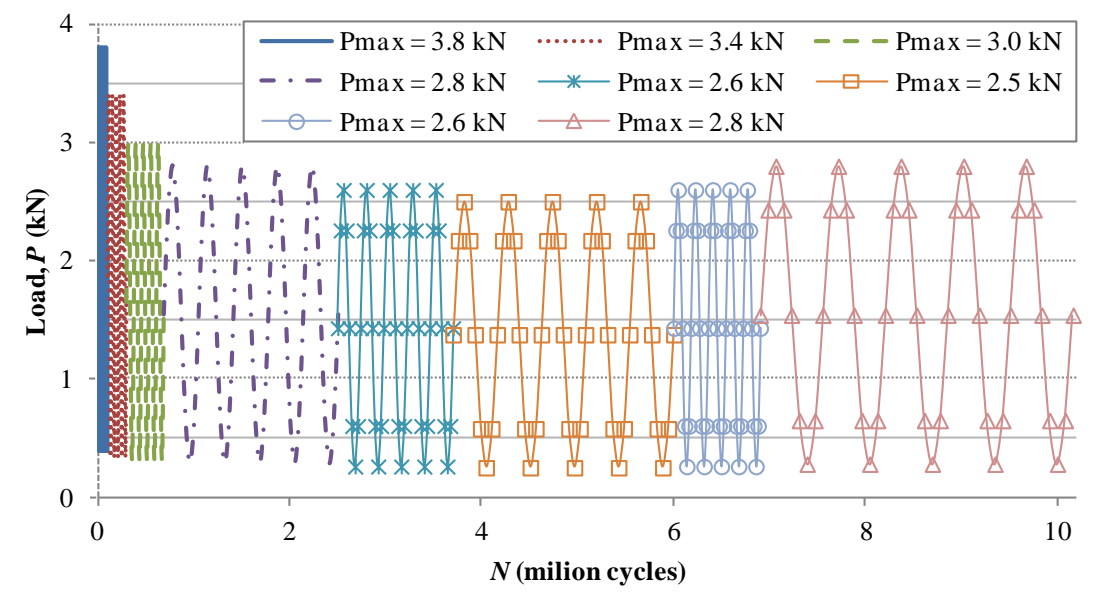

Figure 3.7- Loading applied to a $\mathrm{C}(\mathrm{T})$ specimen for $\Delta K_{0.1}$ assessment following ASTM E647.

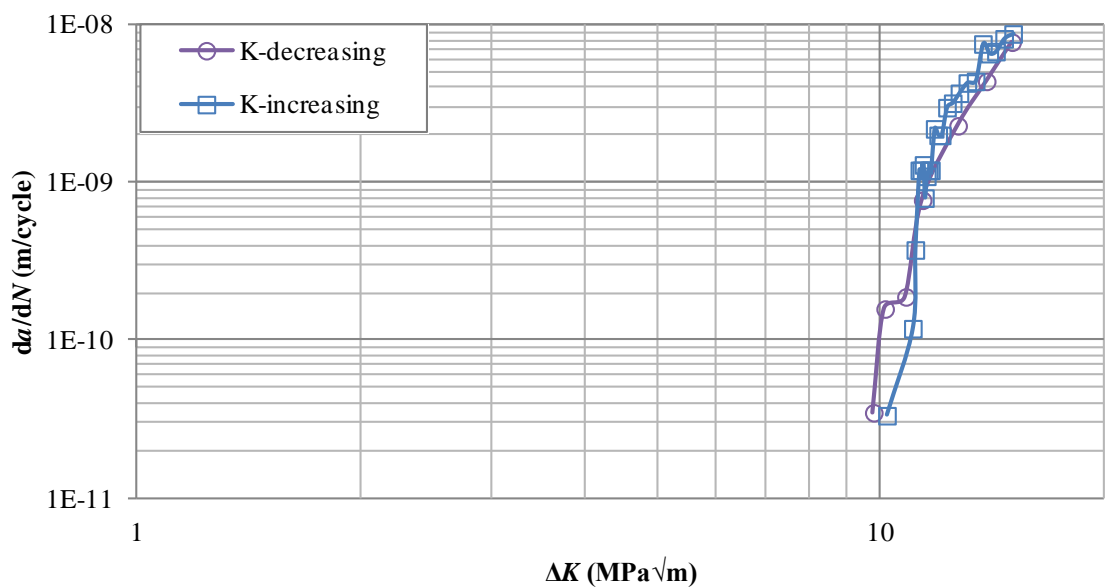

Figure 3.8- $\mathrm{d} a / \mathrm{d} N \times \Delta K$ curves of the trial and error procedure for $\Delta K_{0.1}$ assessment following ASTM E647.

\section{4.}

\section{Smooth specimen fatigue limit $\Delta S_{0.1}$}

The experimental assessment of the fatigue limit of a material presents some drawbacks, in particular due to the large number of required specimens and the long time needed for testing. This limit is usually measured by a series of constant stress amplitude uniaxial push-pull or push-push tests (which typically depend on the value of the stress ratio $R$ ), or by rotating bending tests [57]. Since conventional methods to measure the fatigue limit are very expensive and time consuming, two of the so-called accelerated methods were used in this work: Dixon's up-and-down and infrared (IR) thermography. 
Cylindrical specimens according to ASTM E606M-12 standard were machined from a $76.2 \mathrm{~mm} \times 12.7 \mathrm{~mm}$ flat bar of SAE 1020 steel to evaluate the fatigue limit $\Delta S_{0.1}$ using the two proposed methods under $R=0.1$ and their dimensions are shown in Figure 3.9.

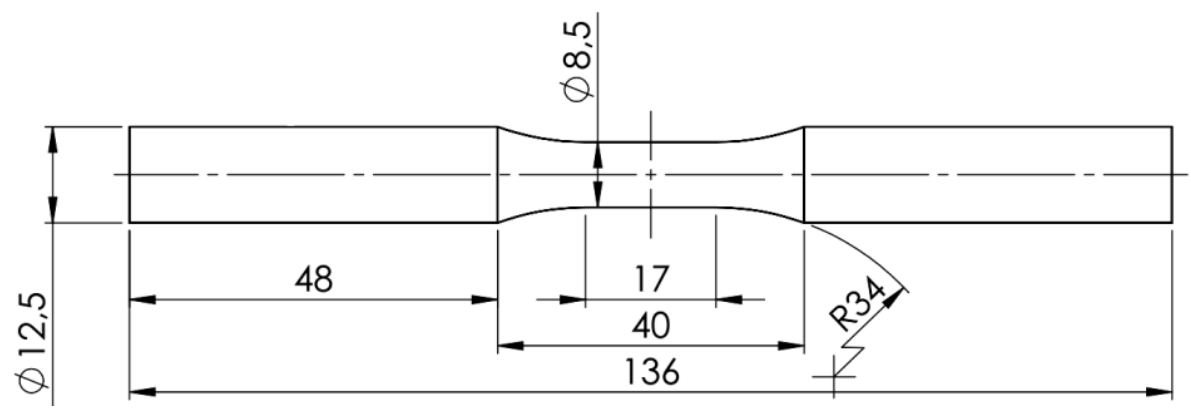

Figure 3.9- Dimensions in $\mathrm{mm}$ of the test specimen used for $\Delta S_{0.1}$ assessment.

\subsection{1.}

\section{Dixon's up-and-down method}

The so-called up-and-down method, first proposed by Dixon [58], is widely used today and is considered as a reference test for validating new techniques to assess the fatigue limit. The principal advantages of this method are: i) all the specimens are tested under loads close to the actual fatigue limit and ii) the statistical analysis of a specific number of tested specimens can use approximate formulae to calculate the mean and the standard deviation of the fatigue limit [59]. This method assumes that the fatigue limit follows a normal distribution. It consists of a series of consecutive SN tests, where the load in the next test depends on whether the previous specimen failed or survived for a fixed number of cycles (e.g. for steels $10^{6}<N<10^{7}$ ). If the specimen fails, the load applied on the next test is reduced by one fixed step $s$. If it survives, the next test load is raised by one step $s$, and so on.

The evaluation of the fatigue limit through this method was conducted testing 14 specimens (see Figure 3.9), under constant amplitude stress-control at frequency of $57 \mathrm{~Hz}$ and stress ratio $R=0.1$. Concentricity and angularity misalignments between the upper fixture, the test specimen, and the lower fixture were minimized by proper procedures. The fatigue limit was evaluated at the specified $N=2 \cdot 10^{6}$ cycles, because this value is high enough to characterize an "infinite" fatigue life in steel specimens. In fact, Juvinall [60] reported 
experimental data for several steels with the monotonic ultimate strength $S_{\mathrm{U}}<$ $1400 \mathrm{MPa}$ in a SN curve. These data demonstrated a good steady-state behavior of the stress amplitude value for $N$ ranging between $10^{6}$ and $10^{7}$ cycles, obtained by rotating bending tests using standard Moore type specimens.

The stress range for the first test was estimated from the $S_{\mathrm{U}}$. Indeed, for ideal rotating bending tests $(R=-1)$, where the mean stress $\sigma_{\mathrm{m}}$ is zero and the alternating stress $\sigma_{a}$ is equal to $\sigma_{\max }$, the smooth specimen fatigue limit can be estimated as $\Delta S_{(R=-1)}=S_{U}$. For real tests and for design purposes, this estimation shall be affected by several $k_{i} \leq 1$ factors. Since a first approximation of the fatigue limit is required, those $k_{i}$ factors were not considered. Once the fatigue limit for $R=-1$ was obtained, the equivalent value $\Delta S_{0.1}$ for $R=0.1$ condition was computed via Gerber (Eq. (3.1)) approach to include the mean stress effect, $\left(\Delta S_{0.1} / 2\right)=S_{\mathrm{F}}(N)=190 \mathrm{MPa}$. However, for this specific SAE 1020 steel, this estimation was too much conservative and a step-up test method based on an accelerated fatigue test procedure, proposed by Nicholas [61] (see Appendix A.1), was applied to obtain a better estimation of the real value that was used as the initial stress amplitude $\sigma_{\mathrm{a}, \text { ini }}=203 \mathrm{MPa}$ in Dixon's up-and-down method.

$$
\frac{\sigma_{a}}{S_{\mathrm{F}}(N)}+\left(\frac{\sigma_{m}}{S_{\mathrm{U}}}\right)^{2}=1
$$

Preliminary tests were carried out in order to determine a step size $s=2.7$ MPa between the stress level amplitudes applied in the up-and-down method. This value was verified later to fulfill the requirement for applying the Dixon-Mood's statistical analysis to compute the mean and the standard deviation of fatigue limit.

The pass-fail results of the tested specimens are shown in Figure 3.10. The Dixon-Mood's statistical analysis was used to compute the mean $\left(\Delta S_{0.1} / 2\right)$ and the standard deviation $\sigma$ of the fatigue limit from these data. For this analysis only the runout specimens (not failed) or only the failed ones are used, depending on which group has smaller number of specimens. The equations for this statistical analysis are summarized in Eq. (3.2) - (3.5) [58]. 


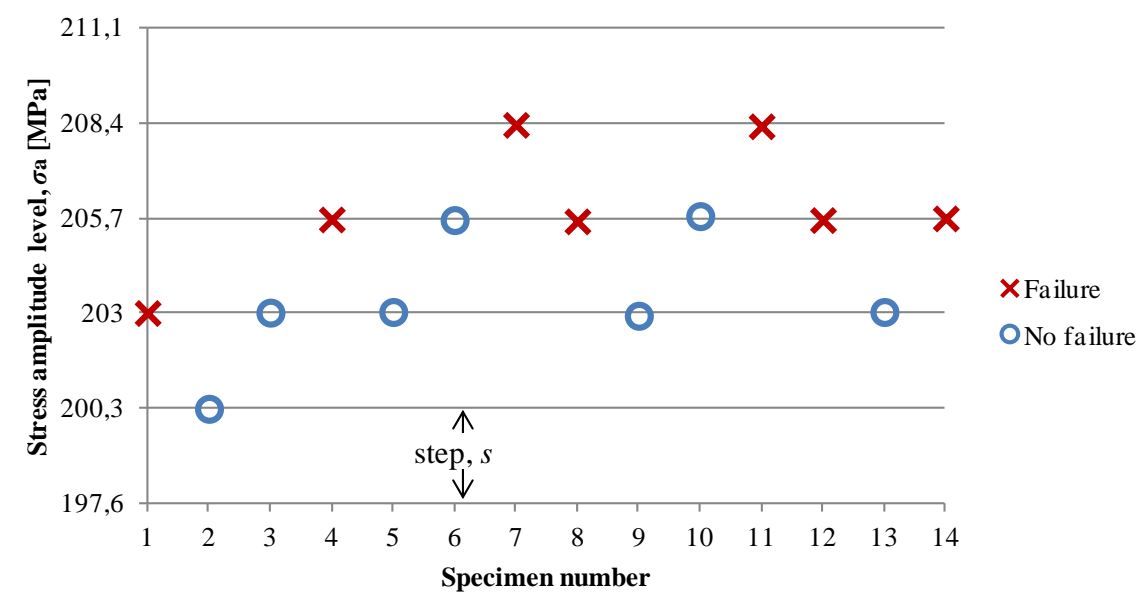

Figure 3.10- Fatigue limit of the tested SAE 1020 steel measured by the Dixon's up-anddown method for $R=0.1$ and $N>2 \cdot 10^{6}$.

$$
\begin{aligned}
& A=\sum_{i=0}^{i_{\max }} m_{i}, \quad B=\sum_{i=0}^{i_{\max }} i m_{i}, \quad C=\sum_{i=0}^{i_{\max }} i^{2} m_{i} \\
& \left(\Delta S_{0.1} / 2\right)=S_{0}+s\left(\frac{B}{A} \pm 0.5\right) \\
& \sigma=1.62 s\left(\frac{A C-B^{2}}{A^{2}}+0.029\right) \text { if } \quad \frac{A C-B^{2}}{A^{2}} \geq 0.3 \\
& \text { or } \quad \sigma=0.53 s \quad \text { if } \quad \frac{A C-B^{2}}{A^{2}}<0.3
\end{aligned}
$$

where $i$ is an integer denoting the stress levels for the event with smaller number of specimens, with $i=0$ and $i_{\max }$ corresponding to the lowest and highest stress level, respectively. The frequencies at each level are denoted by $m_{\mathrm{i}} . S_{0}$ is the stress value corresponding to the $i=0$ stress level; note that this is not necessarily the same as the initial starting stress, $\sigma_{a, \text { ini }}$. As already defined, $s$ is the step size. The plus sign in Eq. (3.3) is used when the analysis is based on the runouts, and the

\begin{tabular}{|c|c|c|c|c|}
\hline$\sigma_{a}(\mathrm{MPa})$ & $i$ & $m_{\mathrm{i}}$ & $i m_{\mathrm{i}}$ & $i^{2} m_{\mathrm{i}}$ \\
\hline 203.0 & 0 & 1 & 0 & 0 \\
\hline 205.7 & 1 & 4 & 4 & 4 \\
\hline 208.4 & 2 & 2 & 4 & 8 \\
\hline$\Sigma$ & & $A=7$ & $B=8$ & $C=12$ \\
\hline
\end{tabular}
minus sign when it is based on the failures. The determination of the constants $A$, $B$ and $C$ of Eq. (3.2) are summarized in Table 3.4.

Table 3.4- Determination of the constants $A, B$ and $C$ for Dixon-Mood's statistical analysis. 
Applying Eq. (3.2) - (3.5) to Figure 3.10 data, the mean of the fatigue limit is $\left(\Delta S_{0.1} / 2\right)=204.7 \mathrm{MPa}$ with a standard deviation $\sigma=1.9 \mathrm{MPa}$. Dixon-Mood's statistical analysis is valid when $0.5 \sigma<s<2 \sigma$, thus this condition is fulfilled.

\subsection{2.}

\section{IR thermography method}

Recently, a new promissory method for the assessment of the fatigue limit considers the fatigue damage as an energy dissipation process that is accompanied by some temperature variation $\Delta T$ [62]. Based on it, a procedure to measure the fatigue limit via IR thermography was proposed by Risitano et al. [63]. The test specimen is subjected to a number of blocks of constant stress amplitude loading cycles, which are gradually increased until they eventually cause failure. For stress amplitudes above the fatigue limit, the temperature increment $\Delta T$ increases during the first part of the test (phase 1), then remain constant for a while (phase 2), and finally are followed by a rapid increase prior to failure at a life of $N_{\mathrm{f}}$ cycles (phase 3), as depicted in Figure 3.11. The fatigue limit can be evaluated considering the heating rate $(\Delta T / \Delta N)$ or the steady-state temperature increment $\Delta T_{2}$. Linear regression lines are required to approximate the thermal data and to determine graphically the fatigue limit for both procedures. For stress amplitudes below the fatigue limit, $\Delta T$ increases only until the steady-state $\Delta T_{2}$ is reached without failure [64].

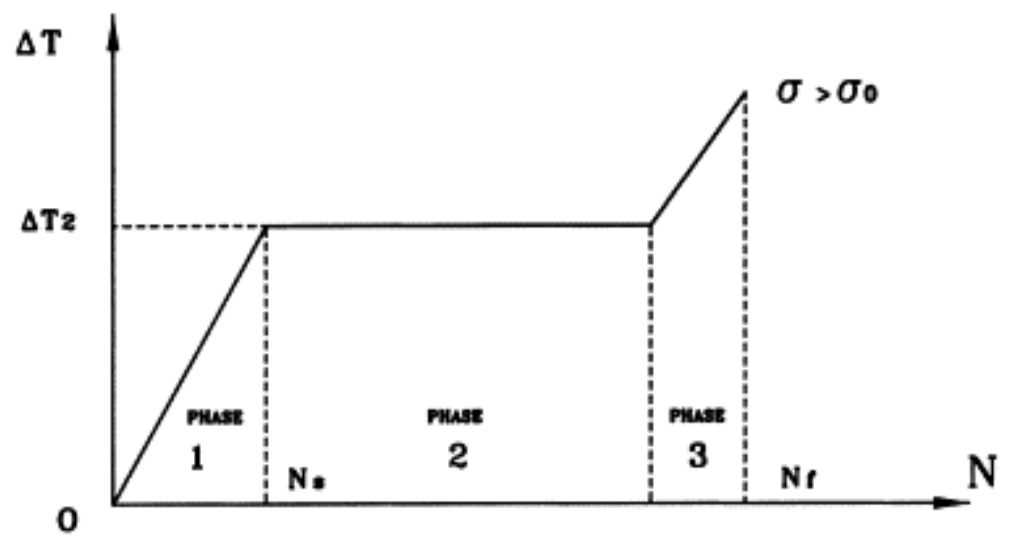

Figure 3.11- Phases of the thermal behaviour of $\Delta T \times N$ curve for a hot point in the specimen surface during typical fatigue tests [65].

This method significantly reduces the testing costs by decreasing the quantity of required specimens and by much shortening the testing time. Although 
realistic measurements of the fatigue limit are often obtained, this approach may still generate questionable results. Fatigue limits reported in literature using thermography analyses show variations up to $\sim 20 \%$ when compared with the upand-down method, depending on the material, equipment and testing conditions. For instance, Cura et al. [66] determined by thermography the fatigue limit of $\mathrm{Fe}$ 510 mild steel and reported a value $10 \%$ lower than that obtained by the up-anddown method (up to $2 \cdot 10^{6}$ cycles). Flat specimens under uniaxial fully reversed loads $(R=-1)$ and $100 \mathrm{~Hz}$ frequency were tested in an Amsler Vibrophore 10HFP 422 and thermal data were obtained with a thermocamera Thermovision ${ }^{\circledR} 900 \mathrm{LW}$. Most recently, De Finis et al. [67] evaluated the fatigue limit of ASTM A182 grade F6NM and 17-4 HP stainless steels by thermography and found values $17.3 \%$ and $5 \%$ lower than those obtained by the up-and-down method (up to $10^{7}$ cycles), respectively. Flat specimens under uniaxial fully reversed loads $(R=-1)$ and $17 \mathrm{~Hz}$ frequency were tested in a $100 \mathrm{kN}$ MTS 370 servohydraulic fatigue machine and the thermal data were acquired with a IR camera FLIR SC 640. On the other hand, Lipski [68] measured by thermography a value of fatigue limit 5\% higher than that obtained by the up-and-down method (up to $10^{7}$ cycles) for X5CrNi18-10 steel. Cylindrical specimens under reversed bending load $(R=-1)$ tests and $100 \mathrm{~Hz}$ rotational frequency were used. The thermal data were obtained with a thermocamera CEDIP Silver 420M (FLIR SC5200).

The preparation of thermographic specimens is described elsewhere [69]. Basically, nine specimens machined according to ASTM E606M-12 standard (see Figure 3.9) were painted with a thin layer of opaque black paint to increase their emissivity, making it close to the value of a black body along their whole surfaces. During each fatigue test, the surface temperature of the specimen was recorded in real time by a bolometer thermocamera FLIR A655sc, depicted in Figure 3.12a. It uses a focal plane array (FPA) of 640 x 480 pixels of 17 microns each, data acquiring frequency of $50 \mathrm{~Hz}$ on full frame configuration up to $200 \mathrm{~Hz}$ for a quarter frame and spectral range from 7.5 to $14 \mu \mathrm{m}$, with sensitivity below $30 \mathrm{~m}^{\circ} \mathrm{K}$. Then, the $\Delta T \times \Delta \sigma$ curve was obtained, where $\Delta T$ is the difference between the maximum specimen surface temperature values $\left(T_{\mathrm{i}}\right)$ for each stress range level $\Delta \sigma_{\mathrm{i}}$ and the reference temperature $\left(T_{\mathrm{r}}\right)$. The temperature data was acquired and analyzed using the ResearchIR software from FLIR and the thermal 
profile for the first specimen is shown in Figure 3.12b. Environmental temperature and the heating associated to the loading machine contribute to increase the surface temperature of specimen [67]. In this work, the latter factor was neglected because of the large dimensions of the testing machine and the grips, the relatively low frequency $(15 \mathrm{~Hz})$ of the test and the low number of cycles for each load step $\left(1.5 \cdot 10^{4}\right)$. The effect of environmental temperature was eliminated by the compensation $\Delta T_{\mathrm{i}}=\left(T-T_{\mathrm{r}}\right)_{\mathrm{i}}-\left(T-T_{\mathrm{r}}\right)_{\text {initial }}$.

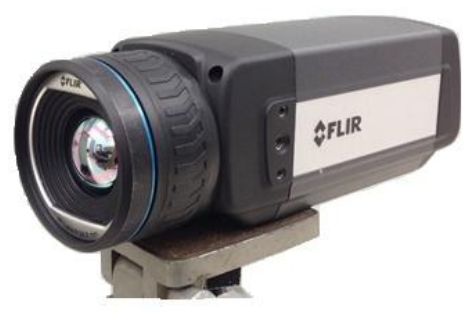

(a)

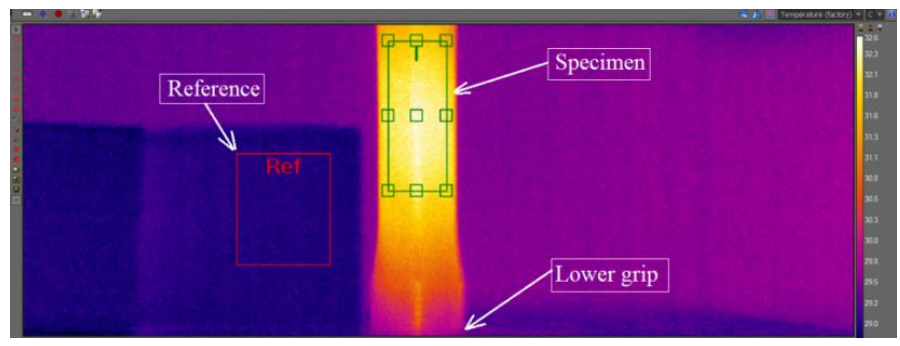

(b)

Figure 3.12- a) Camera FLIR A655sc and b) reference and specimen areas and thermal profile used to measure the specimen surface temperature in the fatigue tests.

Based on the experimental methodology proposed by De Finis [67], the specimens were tested under stepped loading procedure, sequentially applied to each specimen at a constant amplitude force-control, with $15 \mathrm{~Hz}$ frequency and $R$ $=0.1$. At each step, the load was maintained fixed during blocks of $N=1.5 \cdot 10^{4}$ cycles, a value that was enough to achieve a stable thermal behavior, as determined by preliminary tests (see Figure 3.13). Afterwards, the load was increased until the specimen failed.

In Figure 3.13 are plotted the $\Delta T \times(\Delta \sigma / 2)$ curves for three tested specimens of SAE 1020 steel, obtained for the loading history detailed in Table 3.5. At stresses below the fatigue limit, $\Delta T$ increases slowly with a constant rate $\mathrm{d}(\Delta T) / \mathrm{d}(\Delta \sigma / 2)$. However, when the stress amplitude overcomes the fatigue limit value, the rate $\mathrm{d}(\Delta T) / \mathrm{d}(\Delta \sigma / 2)$ suddenly increases and two linear trends in the plot are clearly defined. The fatigue limit can be determined by a graphical method, proposed by Luong [70], as the intercept of the two linear fit of the experimental data points. Therefore, the fatigue limit at $R=0.1$ evaluated with this method was approximately $177 \mathrm{MPa}$. 


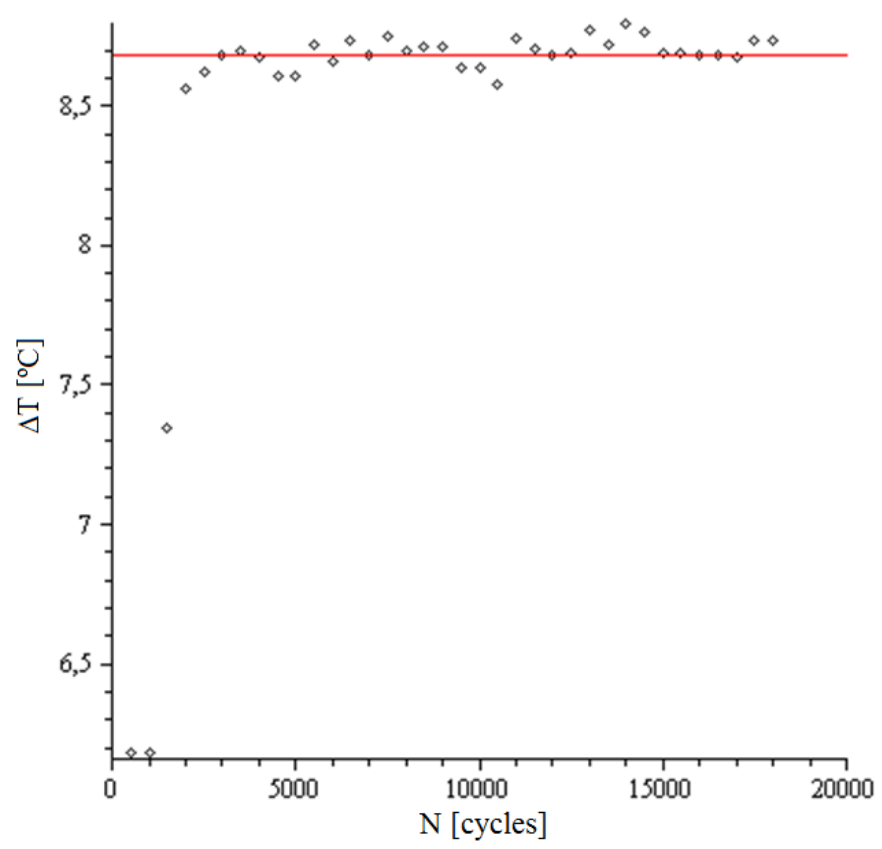

Figure 3.13- Cycles needed to achieve a steady-state temperature (phase 2) with a FLIR A655sc camera.

Table 3.5- Stress amplitude $(\Delta \sigma / 2)$ and the corresponding $\Delta T$ for each load step applied on three specimens of tested SAE 1020 steel.

\begin{tabular}{ccccccc}
\hline Specimen & \multicolumn{2}{c}{1} & \multicolumn{2}{c}{2} & \multicolumn{2}{c}{3} \\
\hline \multirow{2}{*}{ Step } & $\begin{array}{c}\Delta \sigma / 2 \\
(\mathrm{MPa})\end{array}$ & $\begin{array}{c}\Delta T \\
\left({ }^{\circ} \mathrm{C}\right)\end{array}$ & $\begin{array}{c}\Delta \sigma / 2 \\
(\mathrm{MPa})\end{array}$ & $\begin{array}{c}\Delta T \\
\left({ }^{\circ} \mathrm{C}\right)\end{array}$ & $\begin{array}{c}\Delta \sigma / 2 \\
(\mathrm{MPa})\end{array}$ & $\begin{array}{c}\Delta T \\
\left({ }^{\circ} \mathrm{C}\right)\end{array}$ \\
\hline 1 & 80.2 & 0.08 & 80.2 & 0.02 & 80.2 & 0.00 \\
\hline 2 & 108.9 & 0.17 & 108.9 & 0.11 & 108.9 & 0.03 \\
\hline 3 & 137.5 & 0.54 & 137.5 & 0.62 & 137.5 & 0.09 \\
\hline 4 & 166.2 & 1.89 & 166.2 & 1.77 & 154.7 & 0.28 \\
\hline 5 & 171.9 & 2.38 & 171.9 & 2.27 & 166.2 & 0.63 \\
\hline 6 & 177.6 & 2.85 & 177.6 & 2.82 & 171.9 & 1.77 \\
\hline 7 & 183.4 & 3.50 & 183.4 & 3.42 & 177,6 & 2.70 \\
\hline 8 & 189.1 & 4.15 & 189.1 & 4.22 & 183.4 & 3.60 \\
\hline 9 & 191.9 & 4.80 & 191.9 & 4.77 & 189.1 & 4.83 \\
\hline 10 & 194.8 & 5.65 & 194.8 & 5.62 & 191.9 & 5.84 \\
\hline 11 & 197.7 & 7.20 & 197.7 & 6.47 & -- & -- \\
\hline 12 & -- & -- & 200.5 & 7.97 & -- & -- \\
\hline
\end{tabular}

The intrinsic error associated with the measures acquired using this method is in the range experimentally determined by La Rosa and Risitano [64], less than $10 \%$. In the methodology proposed by these authors, it is pointed out that many characteristic errors of fatigue tests can be eliminated. Indeed, they stated that the fatigue limit could be measured with only one specimen, but in practice recommend to report the mean value of the fatigue limit of three specimens. Three specimens are enough due to the fact that thermography data show lower 
scattering $(<10 \%)$. Therefore, the errors associated with the use of many specimens (with different surface finishing, small differences in macro and microstructure, etc.) can be decreased.

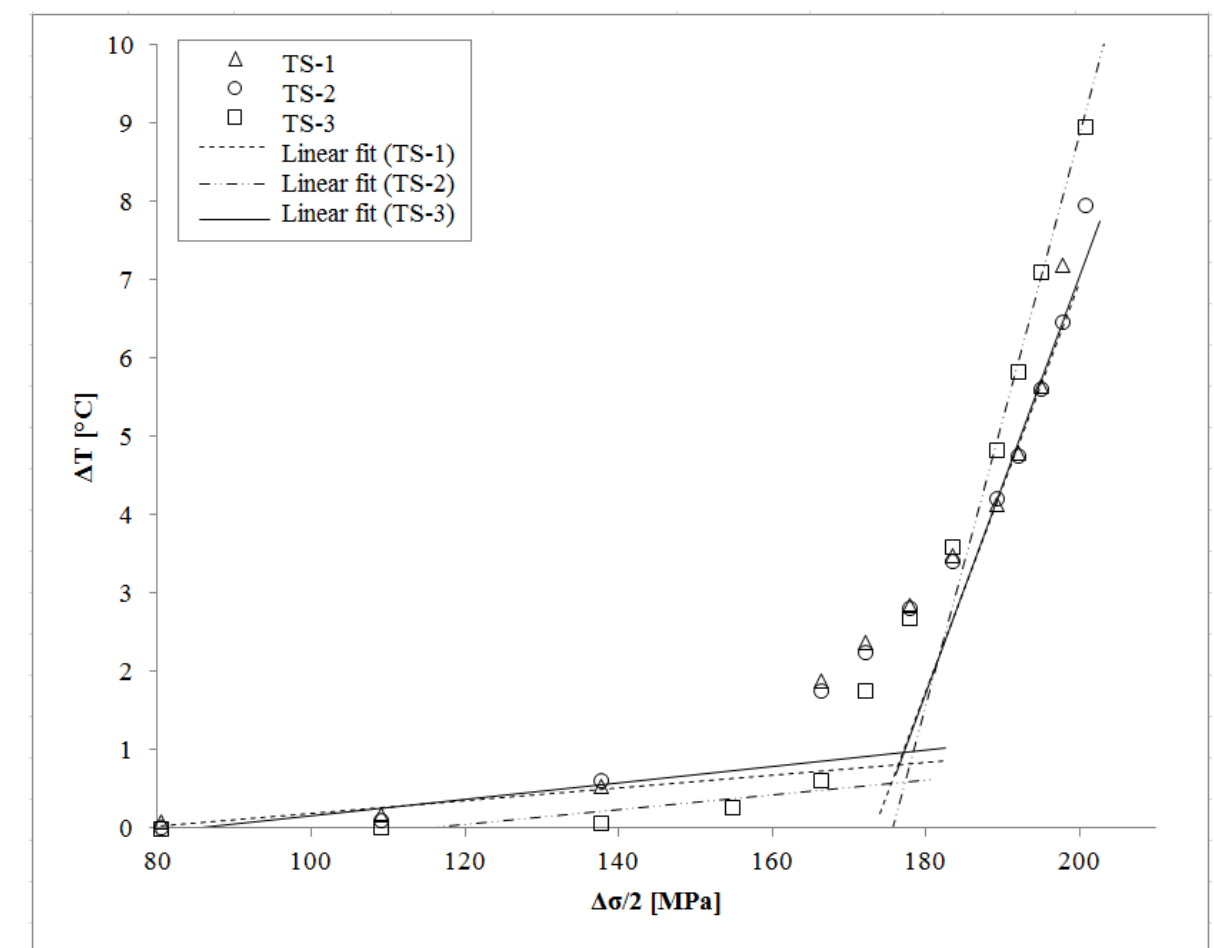

Figure 3.14- Fatigue limit evaluation of three test specimens (TS) of SAE 1020 steel tested by thermography, $R=0.1$.

In order to improve this procedure, an insulated wood chamber was fabricated to enclose the test specimen for avoiding the heat reflections because of eventual external heat sources, as indicated in Figure 3.15.

Following the same procedure described above, four new specimens were tested for $R=0.1$ condition resulting in an average value $\left(\Delta S_{0.1} / 2\right)=180 \mathrm{MPa}$, approximately, which demonstrated that the heat reflections for this particular material and configuration are negligible.

Furthermore, two specimens were tested under fully reversed stress condition $(R=-1)$, for evaluating the mean stress effect on the fatigue limit. The fatigue limits obtained were 231.2 $\mathrm{MPa}$ and $225 \mathrm{MPa}$. All of these experimentally measured data are summarized in a $\sigma_{a} \mathrm{x} \sigma_{\mathrm{m}}$ curve in Figure 3.16, where Goodman, Gerber and Soderberg approaches for the tested SAE 1020 steel are also plotted. 


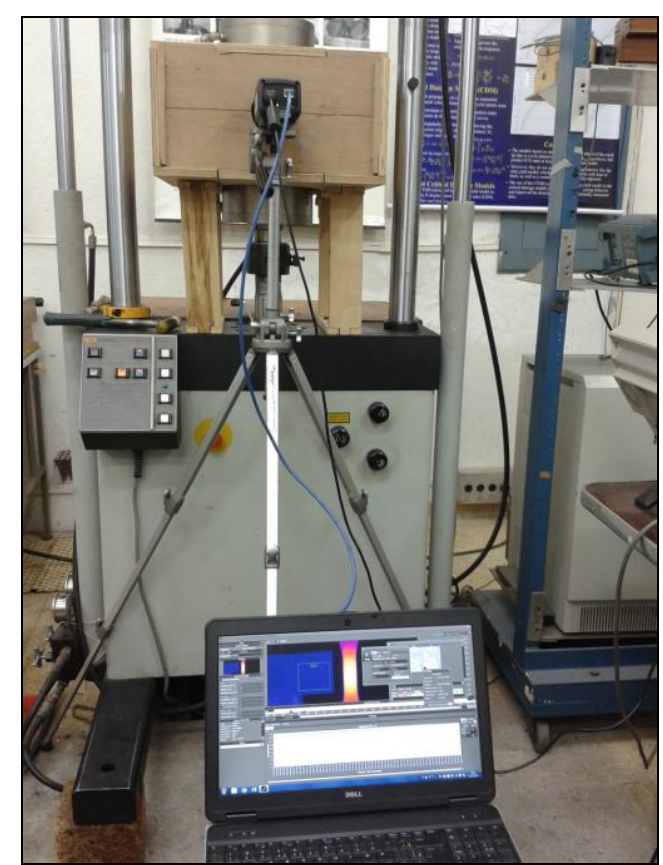

(a)

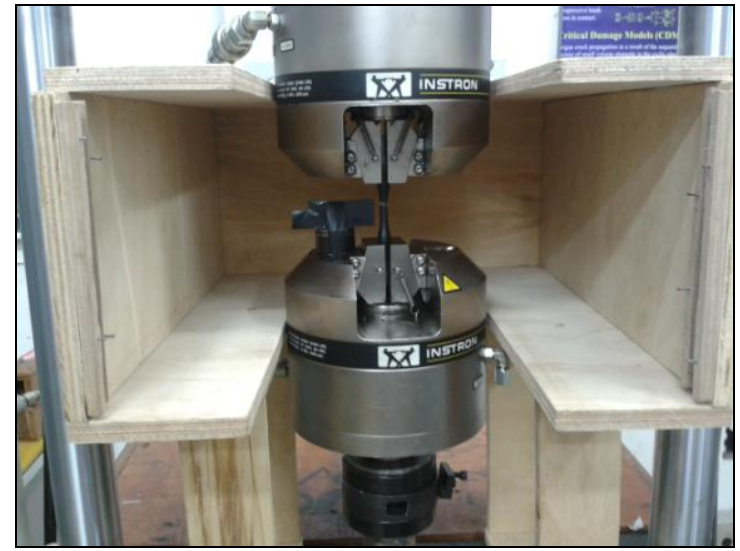

(b)

Figure 3.15- a) $100 \mathrm{kN}$ INSTRON machine and the IR thermographic camera, b) test specimen enclosed by the insulated wood chamber.

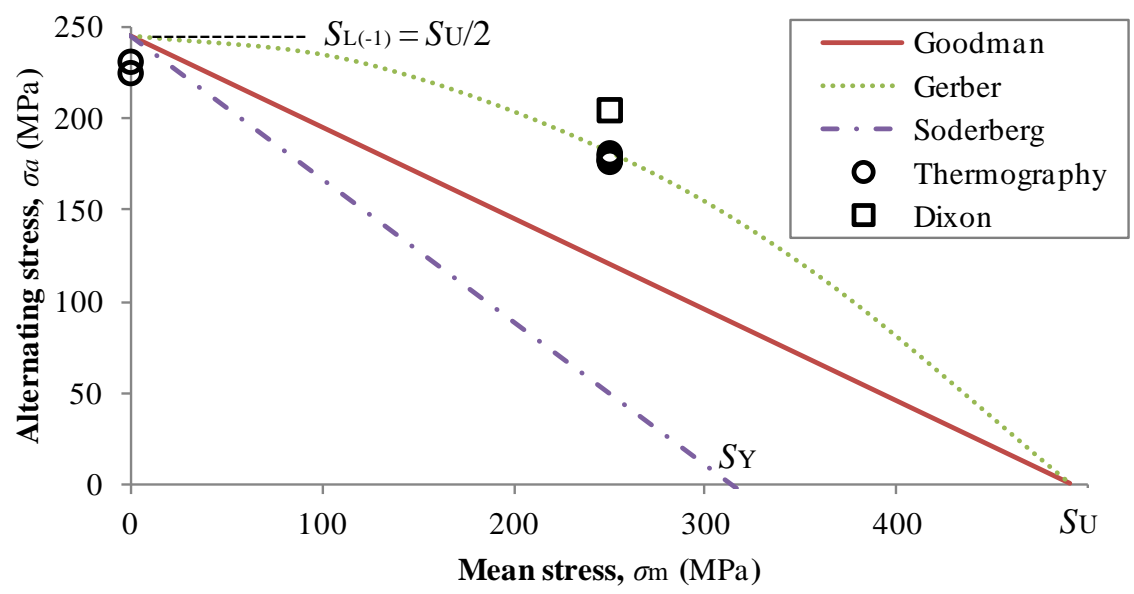

Figure 3.16- $\sigma_{a} \mathrm{x} \sigma_{\mathrm{m}}$ empirical curves and experimental results from Dixon's up-and-down and IR thermography methods for SAE 1020 steel.

It is worth nothing that the fatigue limit $\Delta S_{0.1}$ measured by IR thermography is within the lower and upper boundaries given by Soderberg and Gerber models, respectively, while the value from conventional Dixon's up-and-down method is approximately $14 \%$ higher than that obtained by IR thermography, as shown in Figure 3.16. The lower fatigue limit value obtained by IR thermography could be explained by making an analogy with the existence of a second fatigue limit in the SN diagrams that can be observed for very high cycle fatigue VHFC (generally 
assumed as $N>10^{8}$ ). This phenomenon is more evident in high strength steels, but is also present in low carbon steel [71]. The conventional fatigue limit (up to $10^{6}<$ $N<10^{7}$ ) is related to the slip band crack at the specimen surface, while the second lower fatigue limit (for $N>10^{7}$ ) is attributed to an internal crack initiation mechanism [72]. Since thermography measures the temperature variations associated to the fatigue damage, the fatigue limit measured would involve the initiation and/or propagation of both surface and internal cracks. Therefore, it would be expected a lower value compared to that obtained from Dixon method.

Therefore, since the fatigue limit assessed by IR thermography is associated to a more realistic fatigue damage mechanism, its value will be used for the estimation of the short crack characteristic size and for making predictions by SG model in next chapter. Taking into account all the specimens tested for $R=0.1$, with and without the insulated chamber, the mean value is $\left(\Delta S_{0.1} / 2\right)=178.5 \mathrm{MPa}$.

Moreover, another reason to use IR thermography in the present work was to propose a valid, accurate and fast method to fatigue limit assessment in order to apply it to other non-ferrous materials such as aluminum alloys, whose fatigue limit is defined for a number of cycles much greater than that of steels, so the determination by conventional methods is more complex and expensive. Indeed, aluminum alloys are widely used for the detection of fatigue cracks by nondestructive techniques, e.g. X-ray micro-computed tomography, because of their low density compared to steel, which facilitates the penetration of the X-rays. In the case of dense metals, higher energy X-rays or very small specimens are required, as stated above in Section 2.8.3.

\section{5.}

\section{Short crack characteristic size $a_{0.1}$}

This parameter was computed from the experimentally assessed fatigue properties $\Delta K_{0.1}=10 \mathrm{MPa} \sqrt{\mathrm{m}}$ and $\Delta S_{0.1}=357 \mathrm{MPa}$, using Eq. (2.17). It results in $a_{0.1}=199 \mu \mathrm{m}$. Therefore, it is expected that short fatigue crack sizes in the order of magnitude of this $a_{0.1}$ would be easily detected by optical microscopy techniques, considering ideal conditions: surface cracks or through 1D cracks. 
Since $a_{0.1}$ has been estimated, it can be used in the SG model to predict the fatigue limit and the largest non-propagating short crack, $a_{\max }$, of $\mathrm{C}(\mathrm{T})$-like specimens, as presented in the next chapter. 
4

\section{Experimental verification}

In this chapter, the experimental program for verifying the predictions from the SG model is detailed. To accomplish that, several specimens were testes under constant stress amplitude control and $R=0.1$. Furthermore, several attempts to detect non-propagating short cracks were performed and they are described herein. Among the crack detection techniques, X-ray micro-computed tomography was also used, not only for SAE 1020 steel specimens, but also for a few specimens of Al $6061 \mathrm{~T} 3$ aluminum alloy, since this material presents a lower density (low linear attenuation coefficient), thus is less opaque to the X-ray penetration.

\section{1.}

\section{Geometry and dimensions of the specimen}

$\mathrm{C}(\mathrm{T})$-like specimens were specially designed to induce short cracks at the tip of their elongated notches. These specimens were machined from a $76.2 \mathrm{~mm} \mathrm{x}$ $12.7 \mathrm{~mm}$ flat bar of SAE 1020 low carbon steel, which were tested to verify the predictions from the SG model. These tests were conducted on a $100 \mathrm{kN}$ Instron or on a $25 \mathrm{kN}$ MTS (from the INT Corrosion Laboratory) servo-controlled testing machines. The width and the thickness of the $\mathrm{C}(\mathrm{T})$-like specimens, $W=60 \mathrm{~mm}$ and $t=9 \mathrm{~mm}$, respectively, are shown in Figure 4.1. The depth $b=15 \mathrm{~mm}$ was kept constant and five different tip radii were chosen for the elongated notch, $\rho=$ $\{0.15 ; 0.20 ; 0.35 ; 0.60 ; 1.25\} \mathrm{mm}$, based on a previous work of the author [73]. The total nominal stress range $\Delta \sigma_{\mathrm{n}}$ acting at the notch root of the $\mathrm{C}(\mathrm{T})$-like specimen illustrated in Figure 4.1 can be determined as a sum of the tensile $\Delta \sigma_{\mathrm{n}, N}$ and bending $\Delta \sigma_{\mathrm{n}, M}$ stress contributions caused by a load range $\Delta P$, resulting in Eq. (4.1). The load range is applied perpendicular to the notch and at the center of the holes. 


$$
\begin{aligned}
& \Delta \sigma_{\mathrm{n}}=\Delta \sigma_{\mathrm{n}, N}+\Delta \sigma_{\mathrm{n}, M}=\frac{\Delta P}{t(W-b)}+\frac{6 \Delta P\left(b+\frac{W-b}{2}\right)}{t(W-b)^{2}} \\
& \therefore \Delta \sigma_{\mathrm{n}}=\frac{2 \Delta P(2 W+b)}{t(W-b)^{2}}
\end{aligned}
$$
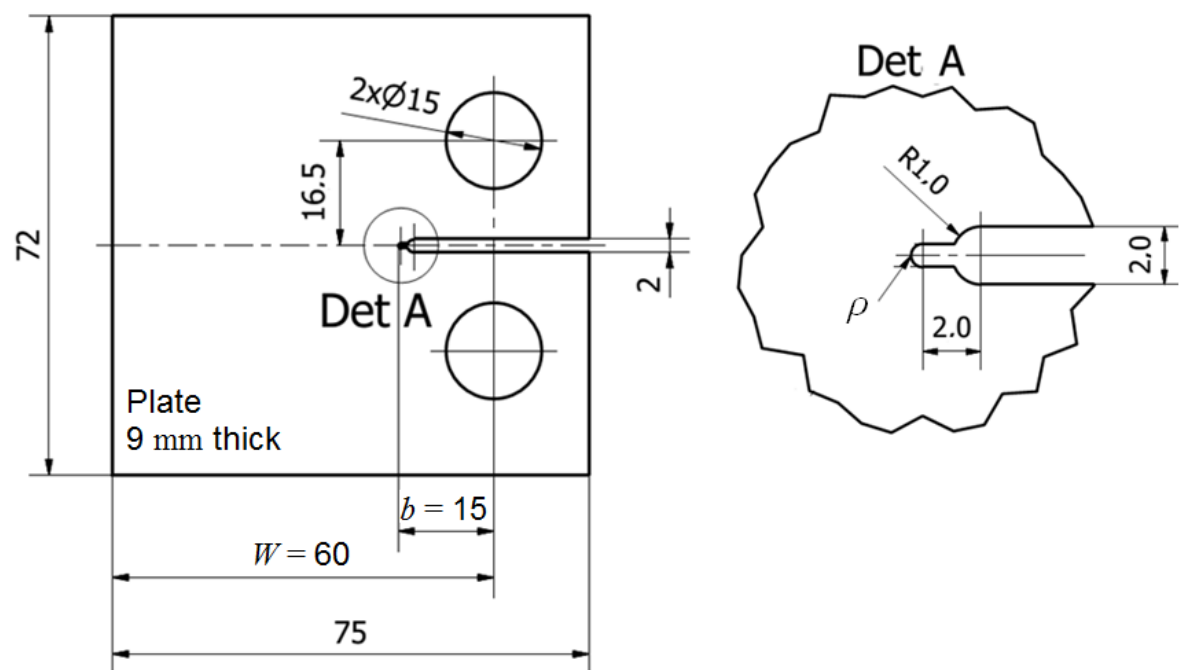

Figure 4.1- Dimensions in mm of the $C(T)$-like specimen used to verify the SG predictions, whose stress concentration factor was calculated by finite elements.

For cracked $\mathrm{C}(\mathrm{T})$ specimens, the SIF range $\Delta K$ can be calculated by Eq. (4.2), according to the ASTM E647 standard.

$$
\Delta K=\frac{\Delta P}{t \sqrt{W}} f_{2}(\lambda)
$$

and

$$
f_{2}(\lambda)=\frac{(2+\lambda)}{(1-\lambda)^{3 / 2}}\left(0.886+4.64 \lambda-13.32 \lambda^{2}+14.72 \lambda^{3}-5.6 \lambda^{4}\right)
$$

where $\lambda=(b+a) / W$ and $a$ is the size of the crack emanating from the notch root.

The stress concentration effect around the notch tip of the $\mathrm{C}(\mathrm{T})$-like specimen in Figure 4.1 was calculated by the finite element method (FEM) and also estimated by the Creager-Paris' (C-P) approach (see section 2.4: Eq. (2.11) for $K_{\mathrm{t}}$, and Eq. (2.24) for the stress distribution). Figure 4.2a shows the SCF $K_{\mathrm{t}}$ distribution along the notch front (z-axis origin at the mid-plane of the specimen), where $z / t=0$ and $z / t= \pm 0.5$ represent the mid-plane and the lateral faces of the 
specimen, respectively. Figure 4.2b and Figure 4.2c shows the typical ratio $f_{1}(x)=$ $\sigma_{y}(x) / \sigma_{\mathrm{n}}$ that describes the stress concentration gradient ahead the notch tip for $\rho=$ $0.15 \mathrm{~mm}$ and $\rho=1.25 \mathrm{~mm}$, respectively. Based on these comparisons, it is possible to conclude that the C-P's approach is a good approximation to estimate the stress concentration for the specimen with the specified geometry and dimensions.

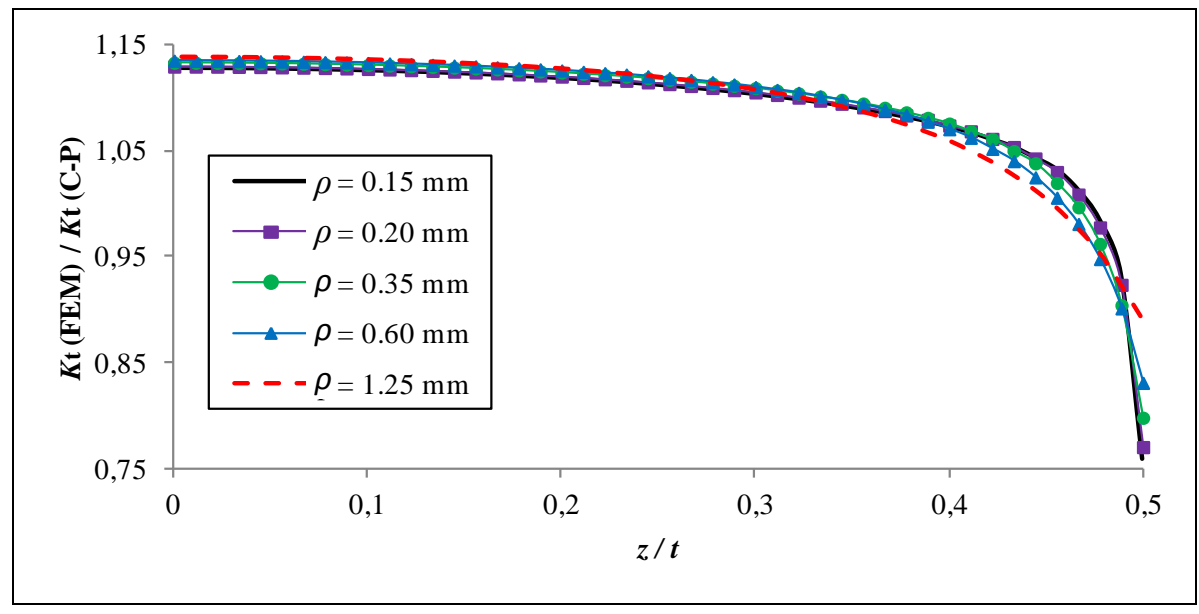

(a)

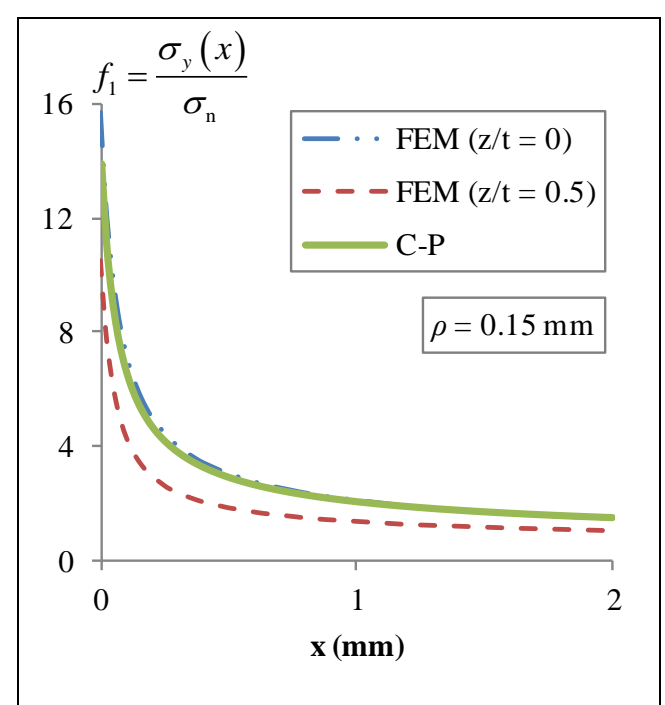

(b)

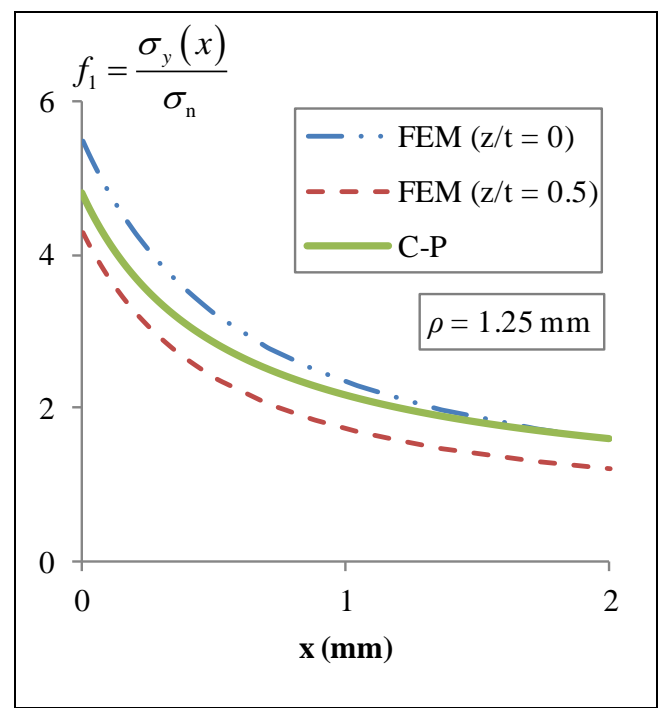

(c)

Figure 4.2- a) $K_{\mathrm{t}}(\mathrm{FEM}) / K_{\mathrm{t}}(\mathrm{C}-\mathrm{P})$ distribution along the notch front. b) and c) are the typical ratio $f_{1}=\sigma_{y}(x) / \sigma_{\mathrm{n}}$ that describes the stress concentration gradient ahead the notch tip.

Therefore, Figure 4.3 plots the functions $f_{1}(x, \rho)$ for five $\rho$ values, estimated using the C-P's approach. The SCF can be estimated at the point $x=0$ as $K_{\mathrm{t}}=f_{1}(x$ $=0, \rho)$. 


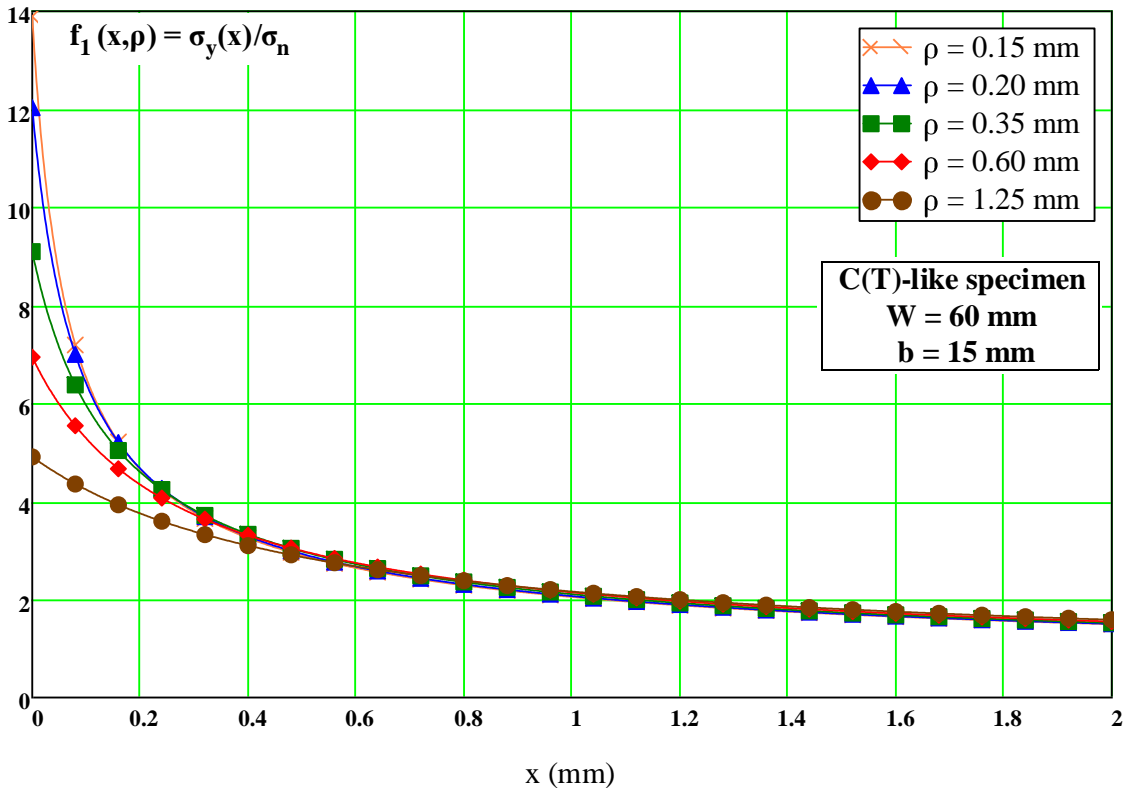

Figure 4.3- Ratio $f_{1}=\sigma_{y}(x) / \sigma_{\mathrm{n}}$ that describes the stress concentration effect ahead the notch tip of a $\mathrm{C}(\mathrm{T})$-like specimen for several $\rho$ values.

\section{2.}

\section{Fatigue limit prediction of the $\mathrm{C}(\mathrm{T})$-like specimen}

In this section, the SG and TCD models are applied to the $\mathrm{C}(\mathrm{T})$-like specimen shown in Figure 4.1.

\subsection{1. SG model}

The application of the SG model to the $\mathrm{C}(\mathrm{T})$-like specimen was explained in Section 2.6.2. Two estimations and one numerical approaches were used to obtain the functions that describe the stress concentration gradient ahead the notch tip, namely: $f_{1, \mathrm{C}-\mathrm{P}}, f_{1, \mathrm{~s}-\mathrm{e}}$, and $f_{\text {Quebra. }}$. The predictions of the SG model will be presented as $\mathrm{SG}_{\mathrm{C}-\mathrm{P}}, \mathrm{SG}_{\mathrm{s}-\mathrm{e}}$, and $\mathrm{SG}_{\text {Quebra }}$, respectively, according to the function used to determine the SIF of a small crack at the notch tip. Figure 4.4a-b plots the estimated and calculated $f_{1}$ and $f$ for the limit values of the notch root radius $\rho=$ $0.15 \mathrm{~mm}$ and $\rho=1.25 \mathrm{~mm}$, respectively.

The SG model can be applied by solving Eq. (2.26), which can be graphically solved by plotting the dimensionless functions $f_{1}$ (when it is estimated), or $f$ (when it is calculated), and the dimensionless function $g$, given by Eq. (2.24) and (2.25), respectively. Considering a specimen with a notch depth $b=$ $15 \mathrm{~mm}$, a notch root radius $\rho=0.15 \mathrm{~mm}$, a stress ratio $R=0.1$, and a Bazant's 
parameter $\gamma=6$, Figure 4.5 shows $f_{1, \mathrm{C}-\mathrm{P}}$ (estimated using the C-P approach) and four $g$ curves as a function of the crack size $a$ to illustrate the determination of the $K_{\mathrm{f}}$ value that fulfills Eq. (2.26). Similar procedures can be applied for $f_{1, \mathrm{~s} \text {-e }}$ (estimated from a semielliptical notch geometry factor) and $f_{\text {Quebra }}$ (calculated by FE in Quebra2D software). Besides, similar procedures can be used for the remaining four $\rho$ values.

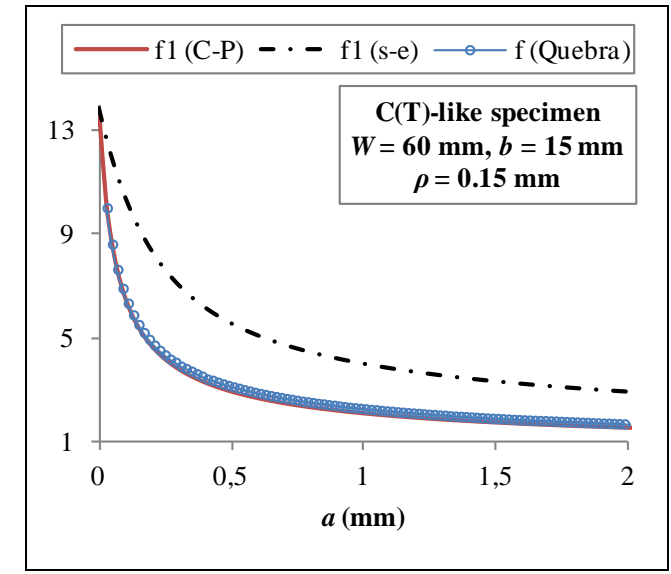

(a)

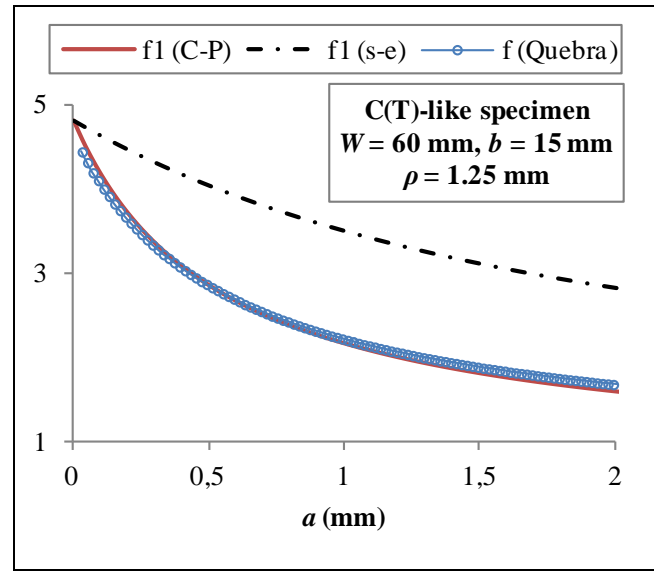

(b)

Figure 4.4- Estimated $\left(f_{1}\right)$ and calculated $(f)$ geometry factor functions of the SIF of short cracks that depart from the notch tip in a $\mathrm{C}(\mathrm{T})$-like specimen ( $W=60 \mathrm{~mm}, b=15 \mathrm{~mm}$ ). Notch root radius a) $\rho=0.15 \mathrm{~mm}$, and b) $\rho=1.25 \mathrm{~mm}$.

As studied before, cracks departing from notch tips of $\mathrm{C}(\mathrm{T})$-like specimens will propagate if $f_{1, \mathrm{C}-\mathrm{P}}>g$. For high applied loads $\Delta \sigma_{\mathrm{n}}, g$ is lower than $f_{1, \mathrm{C}-\mathrm{P}}$ for any $a$, e.g. the lower $g$ curve in Figure 4.5 associated to $\Delta \sigma_{\mathrm{n}}=119 \mathrm{MPa}\left(\Delta S_{0.1} / \Delta \sigma_{\mathrm{n}}\right.$ $=3$ ), so cracks will always start and grow from the notch tip. In the other hand, for low applied $\Delta \sigma_{\mathrm{n}}$, if $g$ is always higher than $f_{1, \mathrm{C}-\mathrm{P}}$, as the upper $g$ curve for $\Delta \sigma_{\mathrm{n}}=$ $25.7 \mathrm{MPa}\left(\Delta S_{0.1} / \Delta \sigma_{\mathrm{n}}=13.9\right)$, cracks will neither start nor grow from the notch tip. For intermediate loads, e.g. when $\Delta \sigma_{\mathrm{n}}=51 \mathrm{MPa}\left(\Delta S_{0.1} / \Delta \sigma_{\mathrm{n}}=7\right)$, at the beginning $f_{1, \mathrm{C}-\mathrm{P}}>g$, thus the crack will start and grow until the curves cross, and the crack arrests and becomes a non-propagating one. The limiting case in this problem occurs for $\Delta \sigma_{\mathrm{n}}=77.4 \mathrm{MPa}\left(\Delta S_{0.1} / \Delta \sigma_{\mathrm{n}}=4.6=K_{\mathrm{f}}\right)$ occurs when $f_{1, \mathrm{C}-\mathrm{P}}$ and $g$ are tangent at a single point ( $a=0.81 \mathrm{~mm}$ in this case). This point corresponds to the largest non-propagating crack $a_{\max }$ that can be tolerated at the notch tip, and the applied $\Delta \sigma_{\mathrm{n}}$ represents the fatigue limit of the $\mathrm{C}(\mathrm{T})$-like specimen analyzed. 


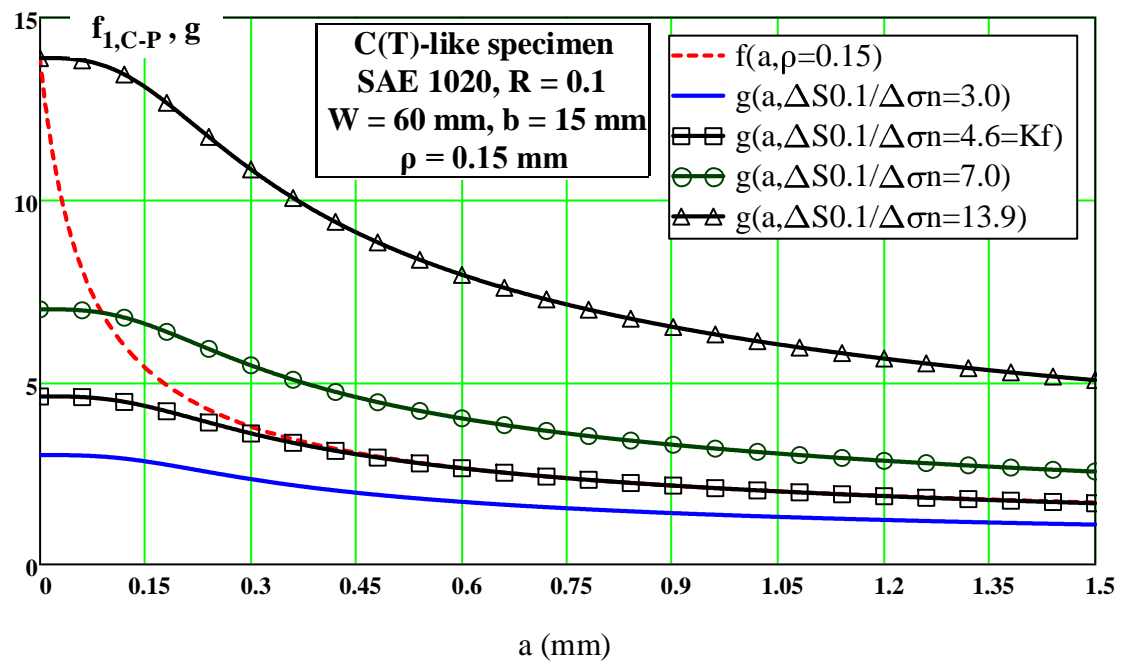

Figure 4.5- Curves of the dimensionless $f_{1, \mathrm{C}-\mathrm{P}}$ and $g$ functions used to calculate $K_{\mathrm{f}}$ for a $\mathrm{C}(\mathrm{T})$ with $b=15 \mathrm{~mm}$ and $\rho=0.15 \mathrm{~mm}$.

On the other hand, the fatigue limit condition is fulfilled when the SIF range of short cracks that depart from notch roots $\Delta K(a)$ (see Eq. (2.23)) and the short crack propagation threshold $\Delta K_{\mathrm{th}}(a)$ (see Eq. (2.20)) are tangent at a single point. At this condition, the applied nominal stress range $\Delta \sigma_{\mathrm{n}}$ is actually the fatigue limit of the $\mathrm{C}(\mathrm{T})$-like specimen and the tangent point is $a=a_{\max }$. The threshold $\Delta K_{\mathrm{th}}(a)$ and the SIFs range $\Delta K(a)$ for five $\rho$ values are plotted in Figure 4.6 as functions of the crack size $a$ emanating at notch root.

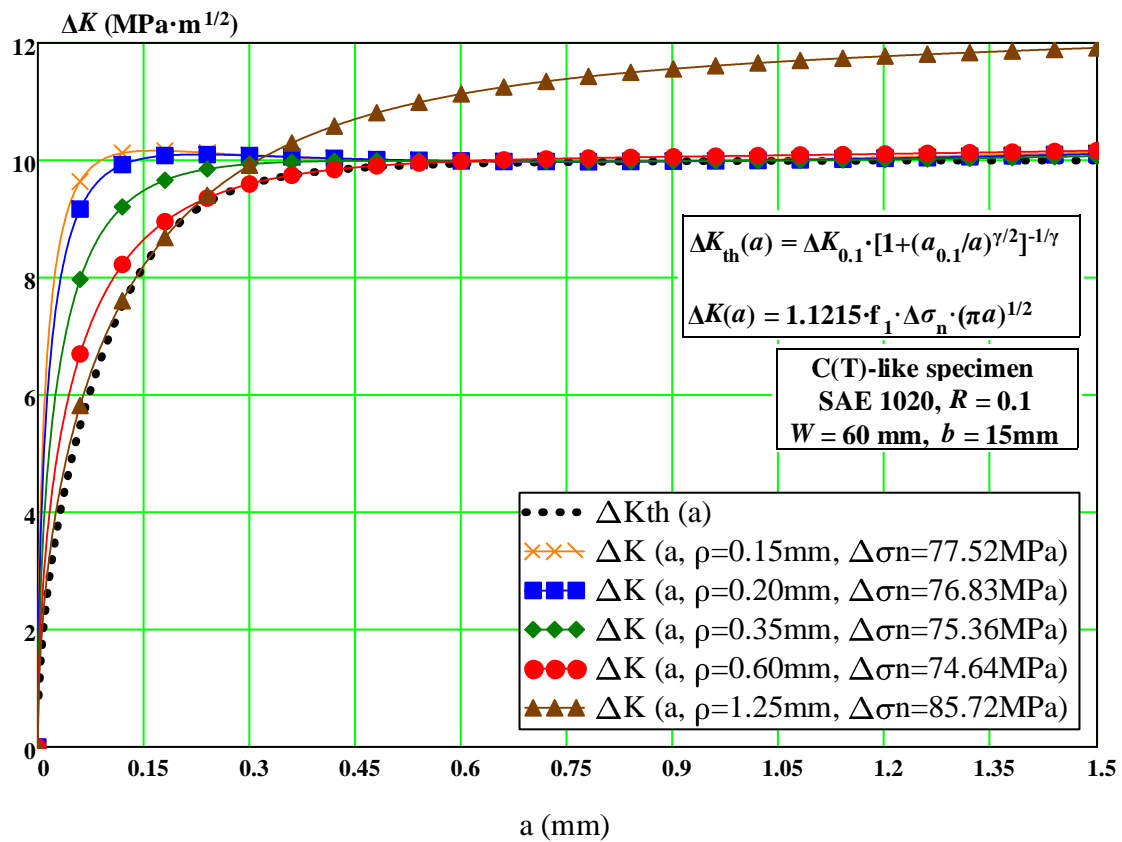

Figure 4.6- The SIF range of short cracks emanating at the notch tip and the short crack propagation threshold $\Delta K_{\mathrm{th}}$ as a function of the crack length $a$ for $\mathrm{SG}_{\mathrm{C}-\mathrm{P}}$ model. 


\subsection{2.}

\section{TCD model}

Based on the fundamentals of TCD model given in Section 2.7 and applying the PM approach, $\Delta \sigma_{\mathrm{y}}(x=L / 2)=\Delta S_{0.1}, K_{\mathrm{f}}$ can be directly estimated from the ratio $f_{1}(x)=\sigma_{y}(x) / \sigma_{\mathrm{n}}$, the LE stress concentration effect ahead of the notch tip. Since $\Delta \sigma_{\mathrm{y}}(x=L / 2)=f(x=L / 2) \cdot \Delta \sigma_{\mathrm{n}}$, thus, $K_{\mathrm{f}}=f(x=L / 2)$. The critical distance parameter for SAE 1020 steel can be calculated using Eq. (2.27), and it results in $L=0.25$ $\mathrm{mm}$. The C-P's approach was demonstrated to be a good approximation to estimate the stress function $f_{1, \mathrm{C}-\mathrm{P}}$ (see Figure 4.2). Therefore, the $f_{1, \mathrm{C}-\mathrm{P}}(x, \rho)$ curves for five $\rho$ values are plotted in Figure 4.7 and $K_{\mathrm{f}}$ is equal to the corresponding value for $x=L / 2=0.125 \mathrm{~mm}$.

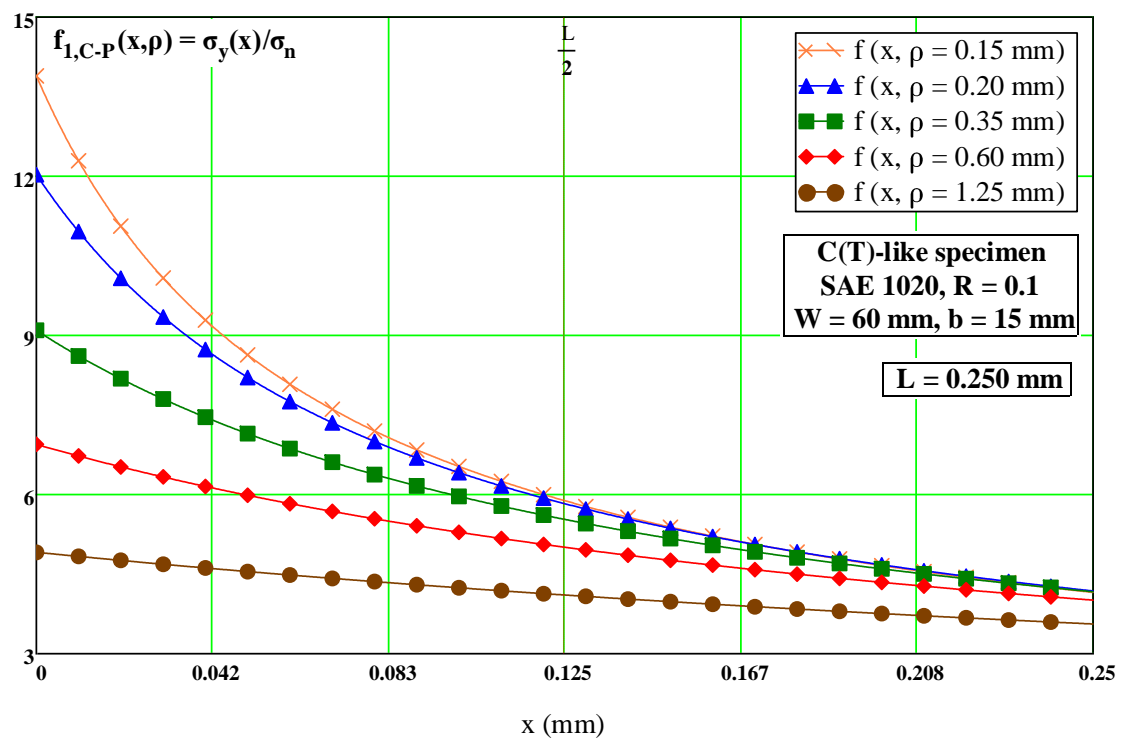

Figure 4.7- Dimensionless ratio $f_{1, \text { C-P }}=\sigma_{y}(x) / \sigma_{\mathrm{n}}$ ahead the notch tip for prediction of $K_{\mathrm{f}}$ by TCD using the Point Method.

The $K_{\mathrm{f}}$ values predicted by TCD-PM and SG models, are summarized in Table 4.1 for the five notch tip radius $\rho$ analyzed. For lower $K_{\mathrm{t}}$ values (blunt notches) the predicted $K_{\mathrm{f}}$ are almost coincident for $\mathrm{SG}_{\mathrm{C}-\mathrm{P}}, \mathrm{SG}_{\mathrm{s} \text {-e }}$ and TCD-PM models. However, for larger $K_{\mathrm{t}}$ values (sharp notches) the predictions of $K_{\mathrm{f}}$ by the SG and TCD-PM models are different. 
Table 4.1- Predictions of the fatigue SCF $K_{\mathrm{f}}$ for a C(T)-like specimen with $W=60 \mathrm{~mm}, b=$ $15 \mathrm{~mm}$ and several notch tip radius $\rho$.

\begin{tabular}{cccccc}
\hline$\rho$ & $K_{\mathrm{t}}$ & \multicolumn{4}{c}{$K_{\mathrm{f}}$ predicted by model } \\
\cline { 3 - 6 }$(\mathrm{mm})$ & $(\mathrm{C}-\mathrm{P})$ & $\mathrm{TCD}-\mathrm{PM}$ & $\mathrm{SG}_{\mathrm{C}-\mathrm{P}}$ & $\mathrm{SG}_{\mathrm{s}-\mathrm{e}}$ & $\mathrm{SG}_{\text {Quebra }}$ \\
\hline 0.15 & 13.89 & 5.88 & 4.61 & 8.91 & 5.0 \\
\hline 0.20 & 12.03 & 5.83 & 4.65 & 8.87 & 5.0 \\
\hline 0.35 & 9.10 & 5.53 & 4.74 & 7.96 & 5.0 \\
\hline 0.60 & 6.95 & 5.01 & 4.78 & 6.55 & 4.8 \\
\hline 1.25 & 4.81 & 4.05 & 4.16 & 4.72 & 4.1 \\
\hline
\end{tabular}

Furthermore, the largest non-propagating short crack $a_{\max }$ predicted by SG model are summarized in Table 4.2, for the three approaches used to obtain the geometry factor of the SIF.

Table 4.2- Predictions of the largest tolerable crack $a_{\max }$ for a $\mathrm{C}(\mathrm{T})$-like specimen with $W=$ $60 \mathrm{~mm}, b=15 \mathrm{~mm}$ and several notch tip radius $\rho$.

\begin{tabular}{ccccc}
\hline$\rho$ & $K_{\mathrm{t}}$ & \multicolumn{3}{c}{$a_{\max }(\mu \mathrm{m})$ predicted by model } \\
\cline { 3 - 5 }$(\mathrm{mm})$ & $(\mathrm{C}-\mathrm{P})$ & $\mathrm{SG}_{\mathrm{C}-\mathrm{P}}$ & $\mathrm{SG}_{\text {s-e }}$ & $\mathrm{SG}_{\text {Quebra }}$ \\
\hline 0.15 & 13.89 & 814 & 561 & 420 \\
\hline 0.20 & 12.03 & 863 & 379 & 480 \\
\hline 0.35 & 9.10 & 919 & 171 & 390 \\
\hline 0.60 & 6.95 & 354 & 119 & 290 \\
\hline 1.25 & 4.81 & 170 & 79 & 160 \\
\hline
\end{tabular}

Since $a_{\max }>379 \mu \mathrm{m}$ for the sharpest notches $(\rho=\{0.15,0.20\} \mathrm{mm})$, according to the predictions of the three approaches of the SG model (see Table 4.2), these non-propagating short cracks should be easily detected on the specimen surface by optical microscopy, at least in theory. However, it is important to point out that the SG model was applied considering an ideal 1D crack propagation, as if it was a through crack since the moment when it is nucleated, a simplification that does not reflect the real 2D or even 3D initial growth of short cracks. Therefore, the detection of non-propagating cracks is a more complex issue.

Following Frost's statement, the difference between the LE and fatigue SCFs, $K_{\mathrm{t}}$ and $K_{\mathrm{f}}$, defines a region where non-propagating short fatigue cracks can be generated [11]. For the considered C(T)-like specimen, $K_{\mathrm{f}}$ predicted by the SG and by the TCD (using the PM method) models are plotted in Figure 4.8a, as a function of the notch tip radius $\rho$ for a constant notch depth $b=15 \mathrm{~mm}$. Moreover, this figure also shows $K_{\mathrm{t}}$ values estimated by the Creager-Paris' approach [18] and 
how they tend to $K_{\mathrm{f}}$ as $\rho$ increases. Therefore, for this specific geometry and material combination, notches with tip radii $\rho \leq 0.5 \mathrm{~mm} \approx 2.5 a_{0.1}$ should be able to generate non-propagating cracks. The $a_{\max }$ values predicted by SG model are presented in Figure $4.8 \mathrm{~b}$ as a function of $\rho$. It can be seen that the maximum of these curve do not correspond with the smallest $\rho$, as it would be expected.

(a)
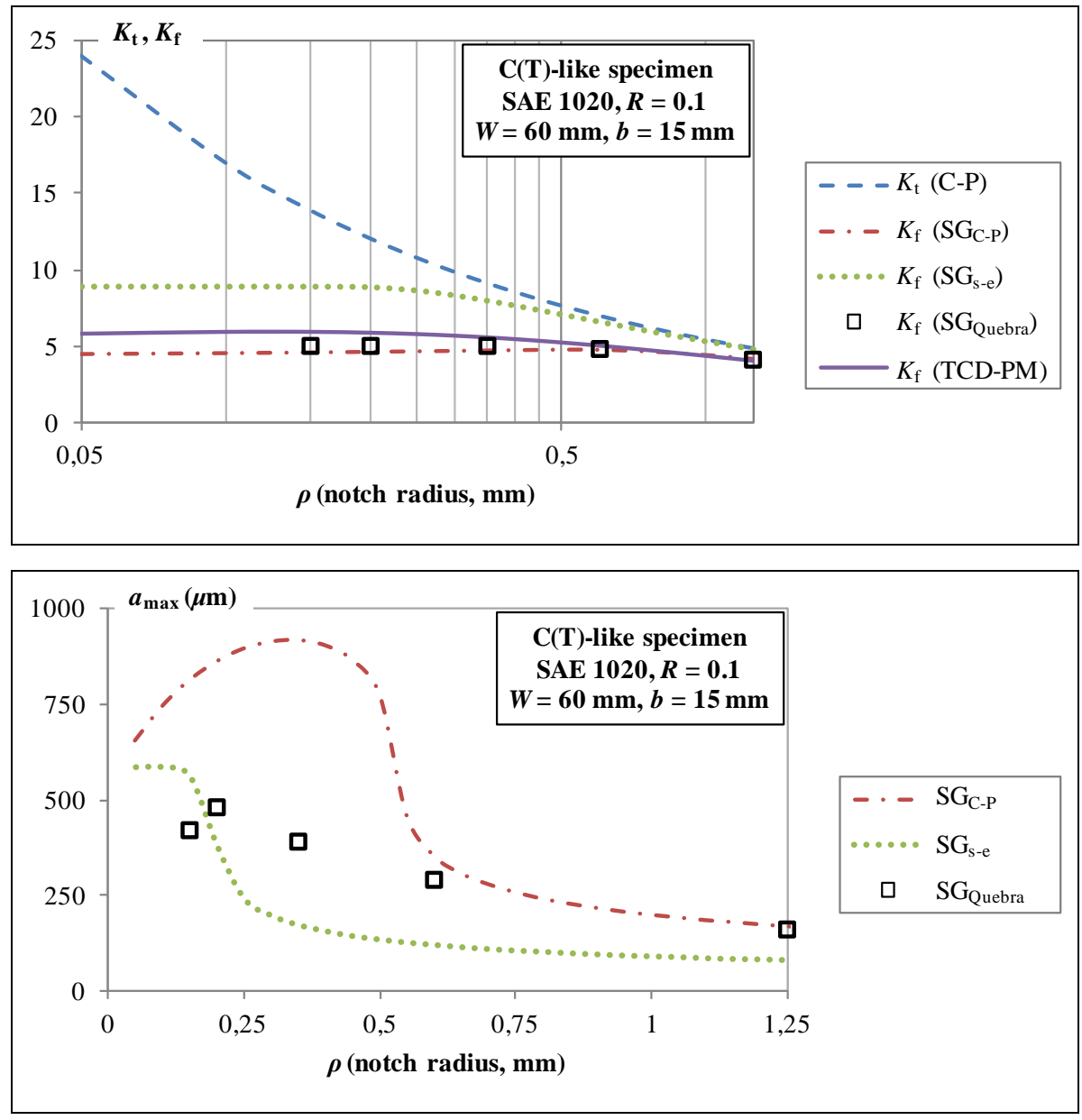

Figure 4.8- a) $K_{\mathrm{t}}$ estimated by the C-P's approach and $K_{\mathrm{f}}$ predicted by the SG and TCDPM models, and b) $a_{\max }$ predicted by the SG model, as a function of the notch radius $\rho$.

\section{3.}

\section{Experimental procedure for $K_{\mathrm{f}}$ assessment}

The $\mathrm{C}(\mathrm{T})$-like specimens were tested under fixed range force-controlled, at a frequency of $40 \mathrm{~Hz}$. Since typical fatigue limits are specified at lives of $10^{6}-10^{7}$ cycles for steels, a life of $3 \cdot 10^{6}$ cycles was used in this work for assessing the fatigue limit of the $\mathrm{C}(\mathrm{T})$-like specimens. An accelerated fatigue test involving step loading was carried out following procedures proposed by Nicholas [61] (see 
Appendix A.1). The initial load level was chosen to cause a local stress at the notch root slightly higher than the smooth specimen fatigue limit $\Delta S_{0.1}$ and it was increased by a small step between $5 \%$ and $12 \%$, depending on the initial stress level. A traveling microscope mounted on a micrometric base (see Figure 4.9) was used to in-situ monitoring the notch root region during the test to detect whether or not a crack is generated. Then, the specimen was removed from the test machine and one of the following non-destructive crack detection techniques was applied: optical microscopy, DIC, and microCT. If no surface cracks were detected, the load was increased by one step as described above. When a surface crack was detected, the criterion to consider it as a propagating one is that its length should be higher than $a_{\max }$, parameter predicted by the SG model. Otherwise, it was considered as a surface non-propagating short crack.

It is well known that the probability of generating non-propagating cracks is higher for sharp notches. Hence, 16 additional specimens with $\rho=0.15 \mathrm{~mm}$ were tested to gain insight about nucleation and growth of short cracks until arrest in the case of non-propagating cracks, or up they become long ones. For these specimens, two techniques for crack detection were used: i) non-destructive surface inspection for the first ten; and ii) destructive subsurface inspection for the last six specimens. In the later, several planes parallel to the specimen surface were polished by proper methods, etched with a $2 \%$ nital solution and examined by optical microscopy. The term "surface cracks" presented herein is related to cracks detected on the external specimen surface, while the expression "subsurface cracks" means internal cracks detected in plans parallel to the surface, along the notch front. 


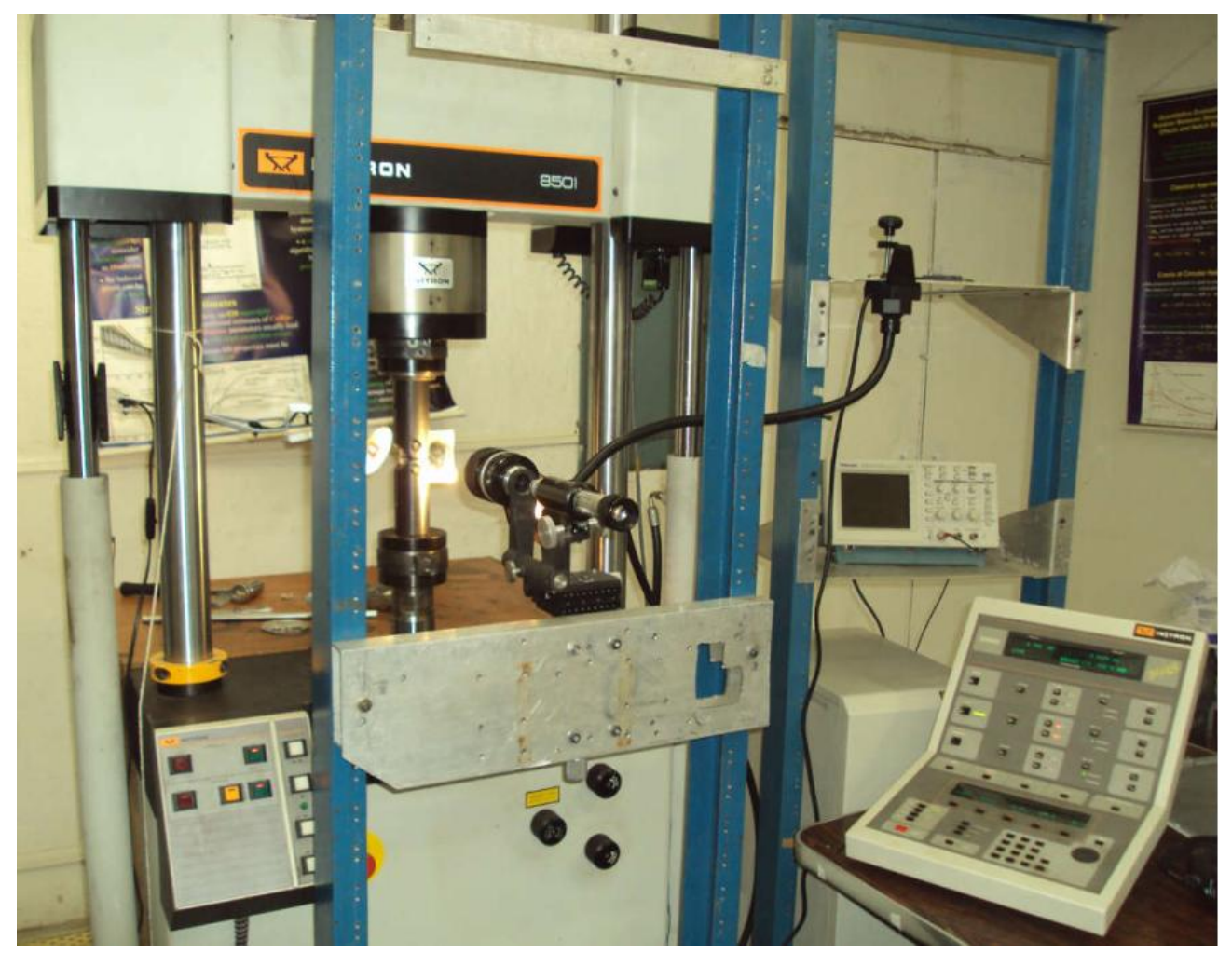

Figure 4.9- $\mathrm{C}(\mathrm{T})$-like notched specimen tested in a servo-hydraulic machine. A traveling microscope is included for in-situ monitoring of the notch root region.

\section{4.}

\section{C(T)-like specimen preparation}

The $\mathrm{C}(\mathrm{T})$-like notched specimens were machined from a rectangular bar in the T-L direction, according to ASTM E399 designation. The notch root was machined via electrical discharge machining (EDM). Since non-propagating short cracks are expected to depart from the notch root, this area was polished to obtain a better surface finish and facilitate their detection by a proper technique. Several sandpaper grits $(240-320-400-600-1200)$ were sequentially used, as indicated in Figure 4.10. Next, the notch tip area was polished using a Dremel rotary tool and a polishing cloth with diamond paste of 6 and $3 \mu \mathrm{m}$, respectively.

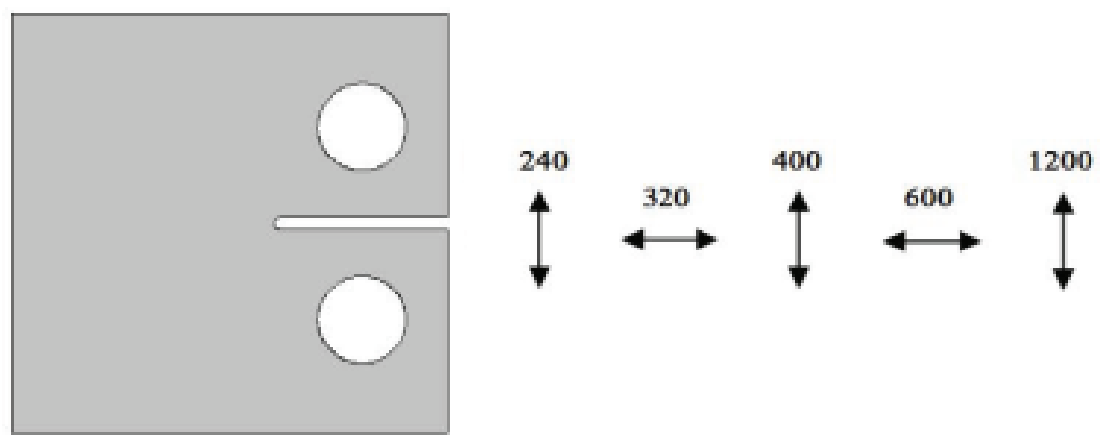

Figure 4.10- Sanding direction and grits used the notch tip area of the specimens. 


\section{5.}

\section{Techniques and equipment for short crack detection}

\subsection{1. Optical microscopy}

A ZEISS Axioplan 2 imaging microscope attached to a computer was used for crack detection at both surfaces of the TS, see Figure 4.11. Magnifications of $5 \mathrm{X}, 10 \mathrm{X}, 20 \mathrm{X}$, and 50X were used. The digital images were captured by a coupled Axio Cam HRc ZEISS camera and the Axio Vision (v. 4.7) software was used.

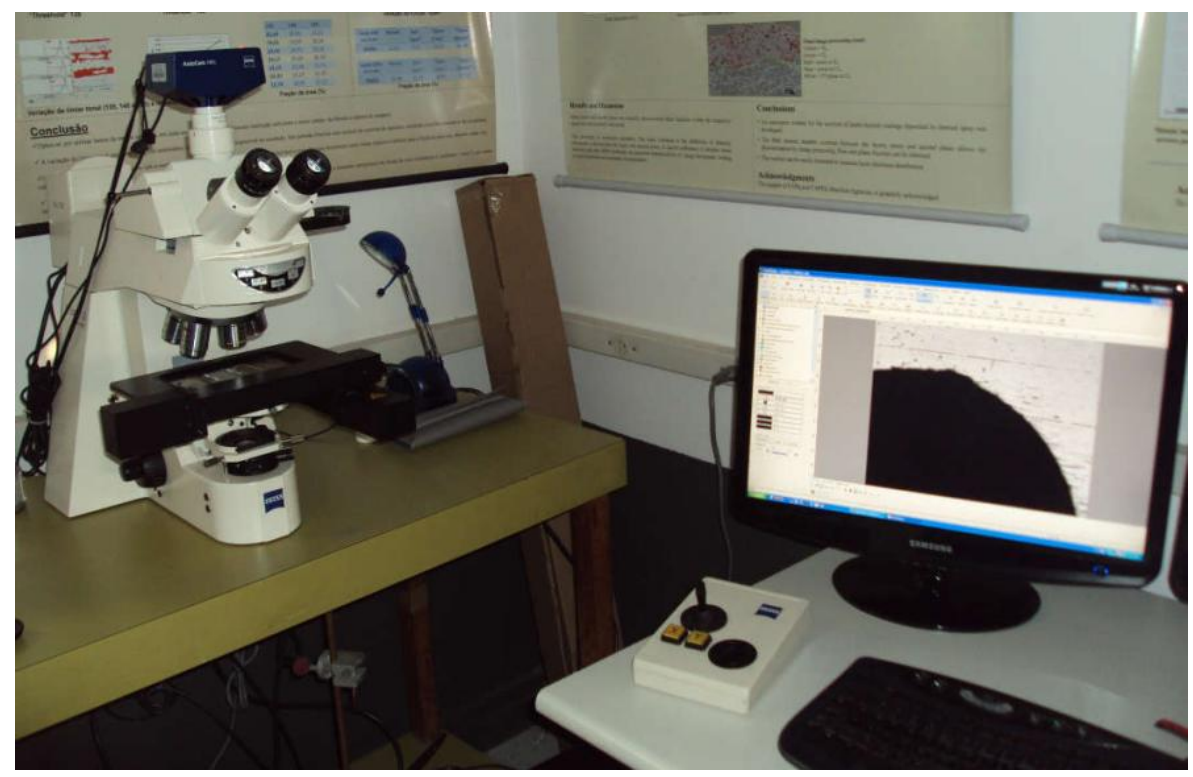

Figure 4.11- Optical microscope for crack detection.

\subsection{2.}

\section{Digital Image Correlation, DIC}

One of the $\mathrm{C}(\mathrm{T})$-like specimen faces was painted with a layer of white paint and then black paint was sprayed over it to get the random fine dot pattern required for the DIC analyses (see Figure 4.12a). The DIC system consists of two high resolution $(2248 \times 2048$ pixels) CCD cameras (Point Grey GRAS-50S5M) with Tamron SP AF180mm F/3.5 lenses, a tripod with supporting hardware, a fiber optic light source, calibration grids, and the software package VIC-3D from Correlated Solutions Inc, as shown in Figure 4.12b. Since at least 20 images are recommended for a reliable calibration [29], 26 images were used in this work.

The notch tip area was monitored by DIC for each level of the step loading procedure. First, the reference image was acquired at the unloaded stage and the deformed images were obtained during two cycles of load at a reduced load 
frequency of $0.01 \mathrm{~Hz}$ and at a rate of 1 image/sec. These deformed images were recorded at the beginning, during, and at the end of the block of cycles $\left(3 \cdot 10^{6}\right)$.

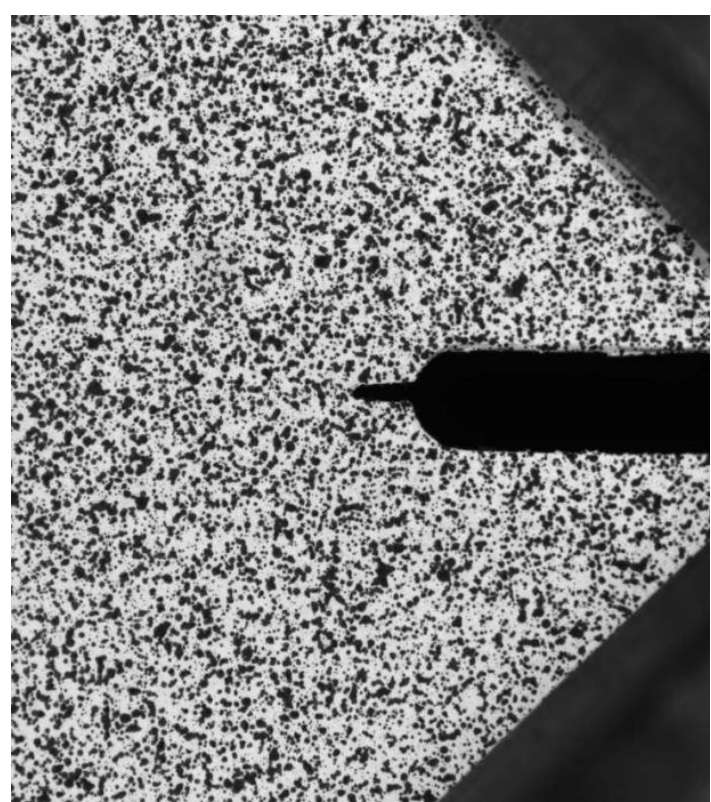

(a)

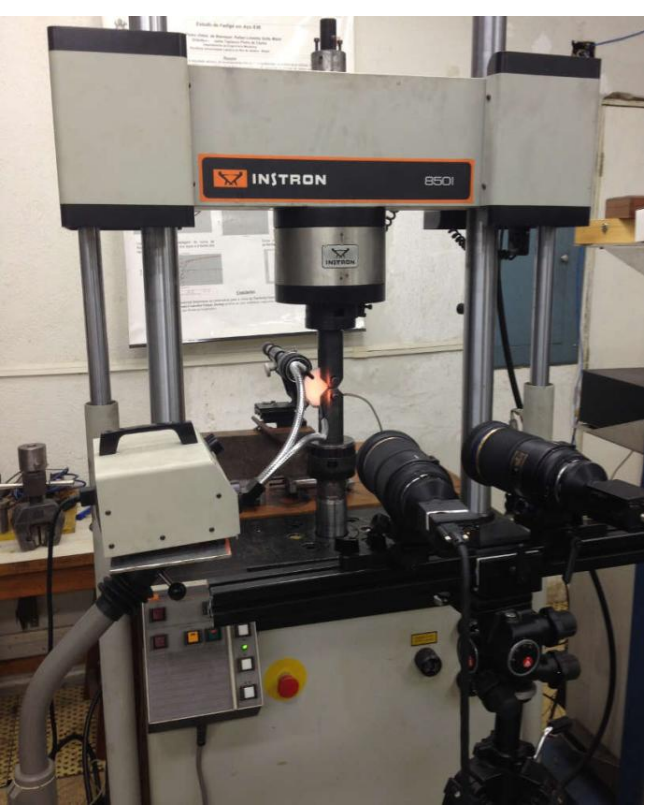

(b)

Figure 4.12- a) Notch root area of the painted face of the $\mathrm{C}(\mathrm{T})$-like specimen analyzed by DIC, and b) DIC system for crack detection.

\subsection{3. \\ X-ray micro-computed tomography}

Attempts to detect short cracks were also carried out using a ZEISS Xradia 510 Versa microtomographer (see Figure 4.13), consisting of a microfocus X-ray tube source. The characteristics of this system are presented in Table 4.3.

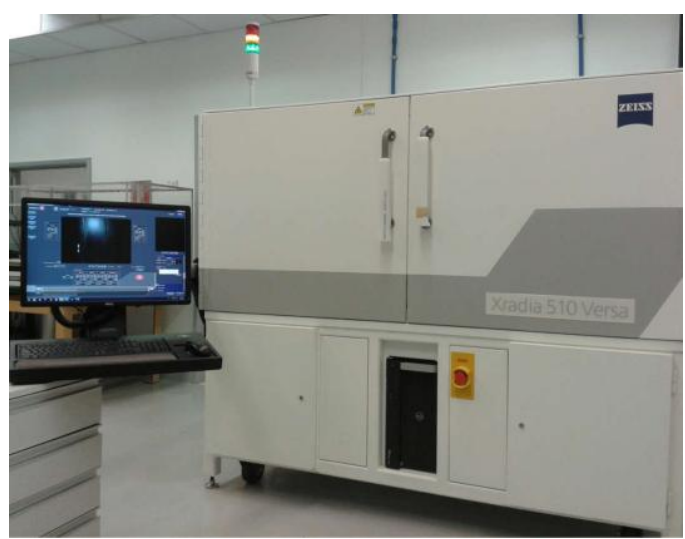

(a)

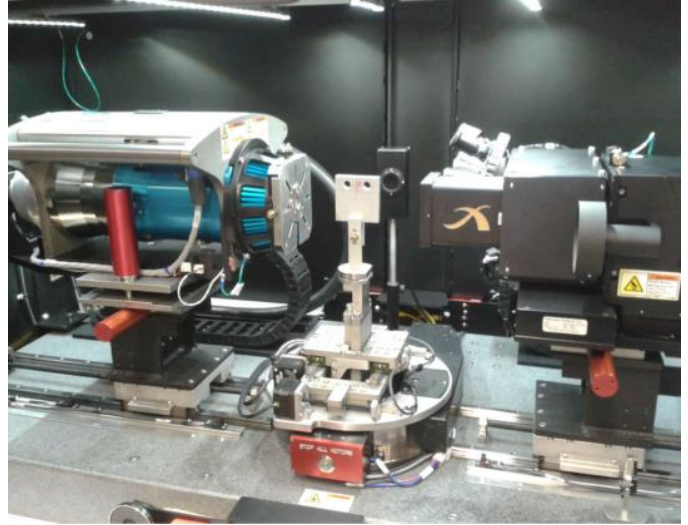

(b)

Figure 4.13- a) External and b) internal configurations of ZEISS Xradia 510 Versa microtomograph. X-ray source (left), specimen (middle) and detector (right). 
The acquisition conditions were: $140 \mathrm{kV}$ voltage and $10 \mathrm{~W}$ power. For each specimen, 1601 projections over $360^{\circ}$ were obtained, with an exposure time of 2 seconds per projection. The pixel size obtained in the particular geometrical configuration of source and using a $0.4 \mathrm{X}$ lens was $11.5 \mu \mathrm{m}$.

Table 4.3- Characteristic of ZEISS Xradia 510 Versa system.

\begin{tabular}{cccccc}
\hline $\begin{array}{c}\text { Spatial } \\
\text { resolution }\end{array}$ & $\begin{array}{c}\text { Typicalvolt } \\
\text { age }\end{array}$ & $\begin{array}{c}\text { Maximum } \\
\text { Power }\end{array}$ & $\begin{array}{c}\text { Objectives } \\
\text { lenses }\end{array}$ & $\begin{array}{c}\text { Maximum } \\
\text { specimen size }\end{array}$ & Capacity \\
\hline $0.7 \mu \mathrm{m}$ & $30-160 \mathrm{kV}$ & $10 \mathrm{~W}$ & $\begin{array}{c}0.4 \mathrm{X}, 4 \mathrm{X}, \\
20 \mathrm{X}, 40 \mathrm{X}\end{array}$ & $300 \mathrm{~mm}$ & $15 \mathrm{~kg}$ \\
\hline
\end{tabular}

Al6061T3 aluminum alloy C(T)-like specimens $(W=56 \mathrm{~mm}, b=16 \mathrm{~mm}, \rho$ $=0.62 \mathrm{~mm}, t=10 \mathrm{~mm}$ ) were also analyzed by X-ray microCT. This alloy composition is presented in Table 4.4.

Table 4.4- Chemical composition of Al6061T3 aluminum alloy.

\begin{tabular}{ccccccccc}
\hline Element & $\mathrm{Si}$ & $\mathrm{Mg}$ & $\mathrm{Fe}$ & $\mathrm{Cr}$ & $\mathrm{Cu}$ & $\mathrm{Mn}$ & $\mathrm{Zn}$ & $\mathrm{Ti}$ \\
\hline $\mathrm{wt} \%$ & 0.65 & 1.01 & 0.24 & 0.18 & 0.30 & 0.09 & 0.2 & 0.2 \\
\hline
\end{tabular}

The same analysis by SG model previously applied to SAE 1020 steel was used into this material and geometry combination to predict the fatigue limit and $a_{\max }$. The representative mechanical properties and the calculations are detailed in Appendix A.2. These predictions are summarized in Table 4.5.

Table 4.5- Mechanical properties from the literature, including $K_{\mathrm{f}}$ and $a_{\max }$ predicted by SG model applied to an Al6061T3 C(T)-like specimen.

\begin{tabular}{cccrrc}
\hline$\Delta S_{0.1}$ & $\Delta K_{\mathrm{th}}$ & $a_{0.1}$ & $K_{\mathrm{t}}$ & $K_{\mathrm{f}}$ & $a_{\max }$ \\
\hline $167 \mathrm{MPa}$ & $3.9 \mathrm{MPa} \sqrt{\mathrm{m}}$ & $139 \mu \mathrm{m}$ & 6.5 & 5.1 & $160 \mu \mathrm{m}$ \\
\hline
\end{tabular}


5

\section{Results and discussions}

This chapter presents the experimentally assessed fatigue limit of $\mathrm{C}(\mathrm{T})$-like notched specimens, as well as some images of the attempts conducted to detect short cracks in the notch root area, using the techniques explained in the previous chapter. In order to better explain and discuss these results, the specimens were coded as described in Table 5.1.

Table 5.1- C(T)-like specimens codification based on their notch root radius $\rho$.

\begin{tabular}{|c|c|c|c|c|c|c|c|c|}
\hline $\begin{array}{c}\text { Specimen } \\
\text { code }\end{array}$ & $\begin{array}{c}\rho \\
(\mathrm{mm})\end{array}$ & $\mathrm{TM}$ & $\mathrm{OM}$ & DIC & TOM & DMA & $\begin{array}{c}\text { Internal } \\
\text { NPSC }\end{array}$ & $\begin{array}{c}\text { Surface } \\
\text { NPSC }\end{array}$ \\
\hline CT-0.15 & 0.15 & $\mathrm{X}$ & $\mathrm{X}$ & & & & & \\
\hline CT-0.20 & 0.20 & $\mathrm{X}$ & $\mathrm{X}$ & & & & & \\
\hline CT-0.35 & 0.35 & $\mathrm{X}$ & $\mathrm{X}$ & & & & & \\
\hline CT-0.60 & 0.60 & $\mathrm{X}$ & $\mathrm{X}$ & & & & & \\
\hline CT-1.25 & 1.25 & $\mathrm{X}$ & $\mathrm{X}$ & & & & & \\
\hline CT-0.15-1 & 0.15 & $\mathrm{X}$ & $\mathrm{X}$ & & & & & \\
\hline CT-0.15-2 & 0.15 & $\mathrm{X}$ & $\mathrm{X}$ & & & & & \\
\hline CT-0.15-3 & 0.15 & $\mathrm{X}$ & $\mathrm{X}$ & & & & & \\
\hline CT-0.15-4 & 0.15 & $\mathrm{X}$ & $\mathrm{X}$ & $\mathrm{X}$ & & & & \\
\hline CT-0.15-5 & 0.15 & $\mathrm{X}$ & $\mathrm{X}$ & & $\mathrm{X}$ & & & $\mathrm{X}$ \\
\hline CT-0.15-6 & 0.15 & $\mathrm{X}$ & $\mathrm{X}$ & & & & & $\mathrm{X}$ \\
\hline CT-0.15-7 & 0.15 & $\mathrm{X}$ & $\mathrm{X}$ & & & & & \\
\hline CT-0.15-8 & 0.15 & $\mathrm{X}$ & $\mathrm{X}$ & & & & & $\mathrm{X}$ \\
\hline CT-0.15-9 & 0.15 & $\mathrm{X}$ & $\mathrm{X}$ & & & & & \\
\hline CT-0.15-10 & 0.15 & $\mathrm{X}$ & $\mathrm{X}$ & & & & & \\
\hline CT-0.15-11 & 0.15 & $\mathrm{X}$ & $\mathrm{X}$ & $\mathrm{X}$ & & $\mathrm{X}$ & $\mathrm{X}$ & \\
\hline CT-0.15-12 & 0.15 & $\mathrm{X}$ & $\mathrm{X}$ & & & $\mathrm{X}$ & $\mathrm{X}$ & \\
\hline CT-0.15-13 & 0.15 & $\mathrm{X}$ & $\mathrm{X}$ & & & $\mathrm{X}$ & $\mathrm{X}$ & \\
\hline CT-0.15-14 & 0.15 & $\mathrm{X}$ & $\mathrm{X}$ & & & $\mathrm{X}$ & $\mathrm{X}$ & \\
\hline CT-0.15-15 & 0.15 & $\mathrm{X}$ & $\mathrm{X}$ & & & $\mathrm{X}$ & $\mathrm{X}$ & \\
\hline CT-0.15-16 & 0.15 & $\mathrm{X}$ & $\mathrm{X}$ & & & $\mathrm{X}$ & $\mathrm{X}$ & \\
\hline CT-0.60-AI* & 0.60 & $\mathrm{X}$ & & & $\mathrm{X}$ & & & $\mathrm{X}$ \\
\hline
\end{tabular}

TM (traveling microscope), OM (optical microscope), TOM (tomography), DMA (destructive metallographic analysis), NPSC (non-propagating short crack), * Al6061T3 C(T)-like specimen

\section{1.}

\section{Fatigue limit assessment of the $\mathrm{C}(\mathrm{T})$-like specimen}

The Frost diagram depicted in Figure 5.1 was built using the smooth specimen fatigue limit $\Delta S_{0.1}$, the linear SCF $K_{\mathrm{t}}$ (estimated by Creager-Paris' approach), the fatigue SCF $K_{\mathrm{f}}$ (predicted by the SG and by the TCD-PM models). The applied nominal stress range $\Delta \sigma_{\mathrm{n}}$ is plotted versus $K_{\mathrm{t}}$ values, which depends on the notch root radius $\rho$. This diagram shows the region where non-propagating 
cracks should be generated, whose lower and upper limits are obtained dividing $\Delta S_{0.1}$ by $K_{\mathrm{t}}$ and $K_{\mathrm{f}}$, respectively. Five C(T)-like specimens with different notch root radii were tested and surface non-propagating cracks were not detected. "O" marks in Figure 5.1 represent the first levels of the step-up loading applied on the specimen where no surface cracks were detected, while " $\mathrm{X}$ " marks correspond to the final level where surface propagating cracks were detected. Since several specimens with $\rho=0.15 \mathrm{~mm}$ were tested, the "X" mark in Figure 5.1 corresponds to the average value of the "X" marks in Figure 5.2.

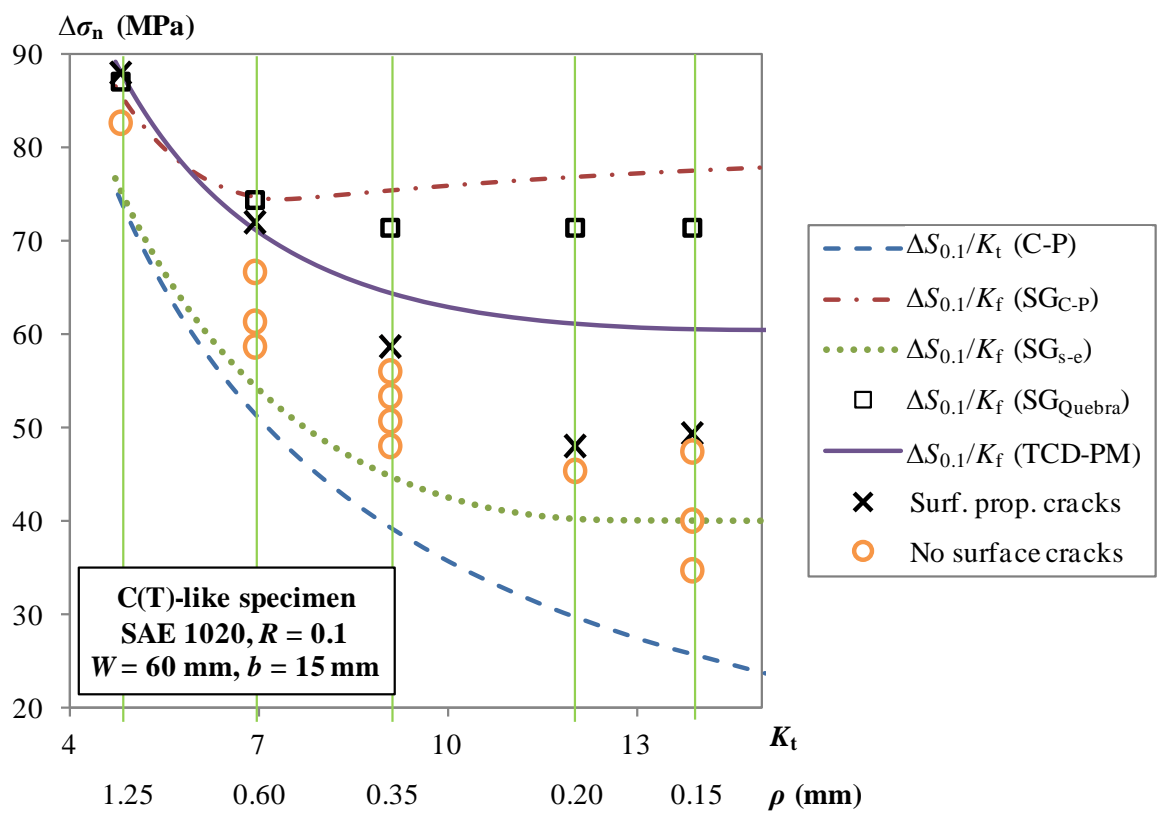

Figure 5.1- Frost diagram for five $\mathrm{C}(\mathrm{T})$-like specimens with different notch root radii $\rho$. The upper limit for non-propagating cracks is defined by the curve of each model and the lower limit is defined by $\Delta S_{0.1} / K_{\mathrm{t}}$ ratio.

Since the non-propagation region in the Frost diagram increases when the SCF $K_{\mathrm{t}}$ increases, a deeper analysis was carried out for additional $16 \mathrm{C}(\mathrm{T})$-like specimens with $\rho=0.15 \mathrm{~mm}$, as stated before, and the applied nominal stress range $\Delta \sigma_{\mathrm{n}}$ for each specimen is presented in Figure 5.2, including the specimen CT-0.15 already presented in Figure 5.1. It is worth noting that the existence of surface NPSCs has been reported in the literature mainly for negative $R$ values [47,74], while few works describe the generation of NPSCs at $R$ values larger than zero. Generally, positive $R$ values do not give rise to surface NPSCs and the cases reported in the literature are considered as an abnormal behavior [43]. The 
experimental results of this work demonstrate that surface NPSC can be generated for $R=0.1$, and the optical micrographs images are shown in Section 5.2.1.

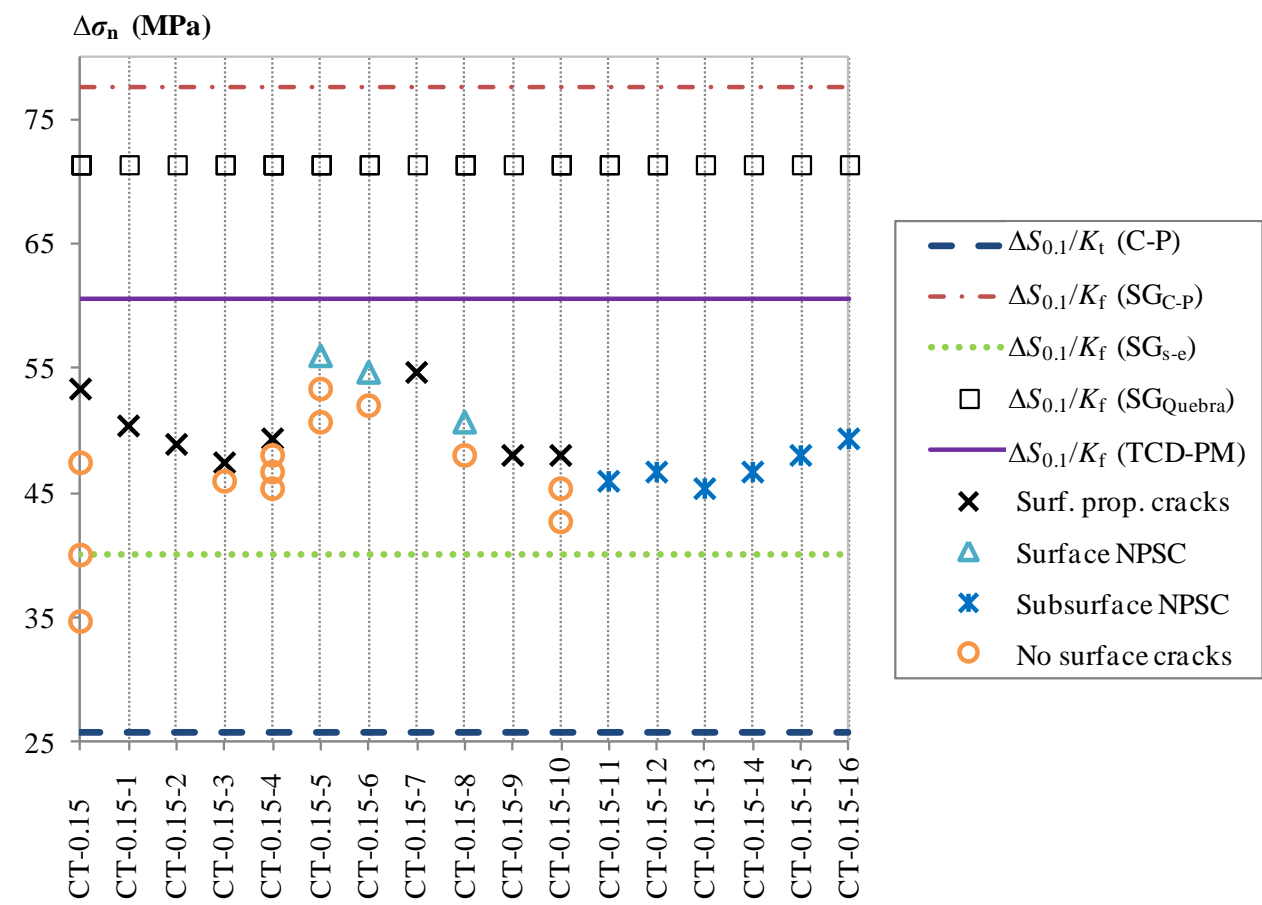

Figure 5.2- Frost diagram for $17 \mathrm{C}(\mathrm{T})$-like specimens with notch root radius $\rho=0.15 \mathrm{~mm}$. (NPSC: non-propagating short cracks).

During the step loading procedure, the first specimen with $\rho=0.15 \mathrm{~mm}$ presented in Figure 5.2 was tested under an initial step $\Delta \sigma_{\mathrm{n}}=35 \mathrm{MPa}$, because NPSCs should be generated under this condition in accordance to Frost diagram (see Figure 5.1). The following step increments in $\Delta \sigma_{\mathrm{n}}$ were in the range of $10-13 \%$ up to a propagating crack was detected at $\Delta \sigma_{\mathrm{n}}=53 \mathrm{MPa}$. Therefore, next specimens were subjected to an initial step load slightly lower than $\Delta \sigma_{\mathrm{n}}=53 \mathrm{MPa}$ and the step increments were smaller than $6 \%$. Due to the fact that these step increments caused the transition from no-crack to propagating crack condition without arrest on the specimen surface (specimens CT-0.15, CT-0.15-1 - CT0.15-4, CT-0.15-7, CT-0.15-9, and CT-0.15-10 in Figure 5.2), the hypothesis that subsurface cracks could be already generated in the actual or even previous load steps is reasonable. For this reason, the specimens CT-0.15-11 - CT-0.15-16 were subjected to an initial step $\Delta \sigma_{\mathrm{n}}$ lower than those applied in previous tested specimens (CT-0.15, CT-0.15-1 - CT-0.15-10), where surface cracks were already detected and the hypothesis of the existence of subsurface NPSCs was verified under these conditions by metallographic analysis, see section 5.2.3. 


\section{2.}

\section{Attempts for short cracks detection}

All the attempts for crack detection were carried out in SAE 1020 C(T)-like specimens with a notch root radius $\rho=0.15 \mathrm{~mm}$ and thickness $t=9 \mathrm{~mm}$. Solely two Al6061T3 C(T)-like specimens were analyzed by X-ray microCT.

\subsection{1.}

\section{Optical microscopy}

The optical micrographs of the detected NPSCs on the face of three C(T)like specimens (CT-0.15-5, CT-0.15-6, CT-0.15-8) are shown in Figure 5.3. It can be seen that the length of these cracks are smaller than the predicted $a_{\max }$ and slightly higher than the grain size, so the macroscopic assumptions of the SG model are fulfilled. However, the length values are not constant, revealing the random nature of the fatigue short cracks especially at the initial stage of nucleation and propagation.

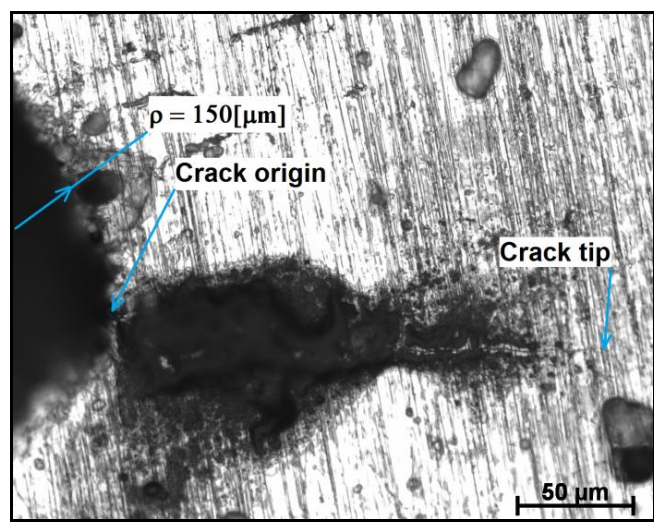

(a) CT-0.15-5, $a \approx 213 \mu \mathrm{m}$

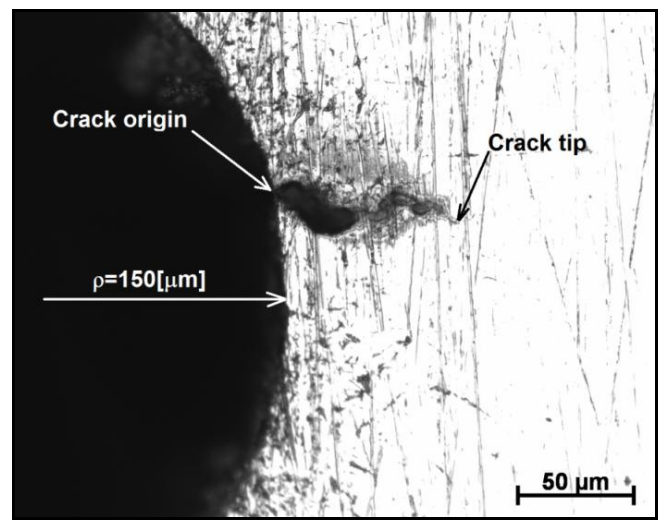

(b) CT-0.15-6, $a \approx 81 \mu \mathrm{m}$

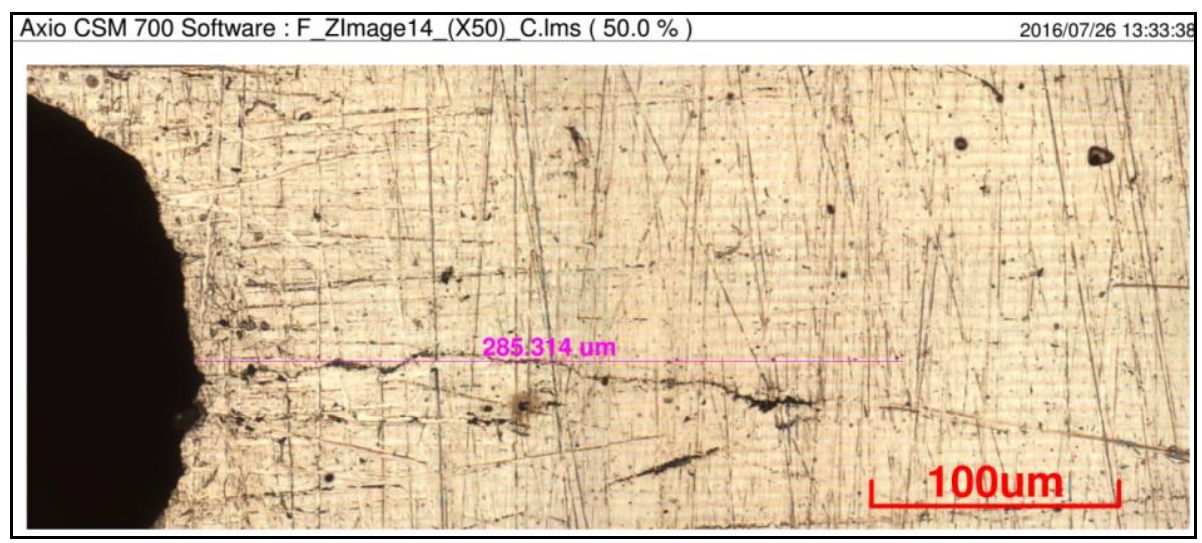

(c) CT-0.15-8, $a \approx 285 \mu \mathrm{m}$

Figure 5.3- Optical micrographs for the three surface NPSCs detected. 


\subsection{2.}

\section{Digital Image Correlation, DIC}

This non-destructive technique for crack detection was applied in CT-0.15-4 and CT-0.15-11 specimens. The former was subjected to four levels in the step loading method, with nominal stress ranges $\Delta \sigma_{\mathrm{n}}=\{45.3,46.7,48.0,49.3\} \mathrm{MPa}$. The plots of the nominal stress at the notch tip $\sigma_{\mathrm{n}}$ as a function of the notch opening displacement (NOD) at a distance ranging between $0.5 \mathrm{~mm}$ to $1 \mathrm{~mm}$ from the notch root are shown in Figure 5.4a-d for these four load levels, respectively. For the first three levels, no cracks were detected at the end of the block and a linear behavior $\sigma_{\mathrm{n}} \mathrm{x}$ NOD was confirmed by the corresponding plots, while Figure $5.4 \mathrm{~d}$ shows a non-linear behavior from the beginning of the fourth level $\left(\Delta \sigma_{\mathrm{n}}=\right.$ $49.3 \mathrm{MPa}$ ) and a propagating (long) crack $a \approx 1.5 \mathrm{~mm}$ was detected at the end of the block.

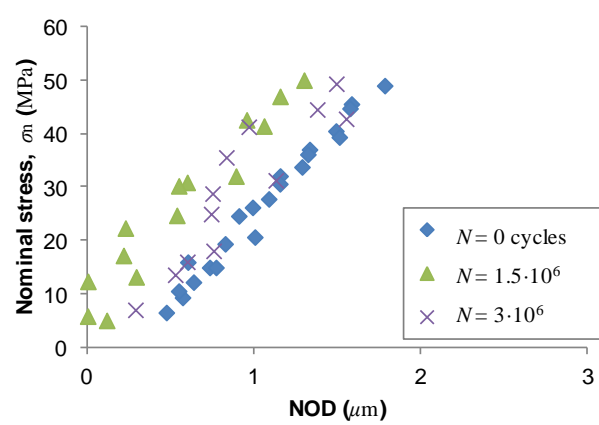

(a) $\Delta \sigma_{\mathrm{n}}=45.3 \mathrm{MPa}$, no crack detected

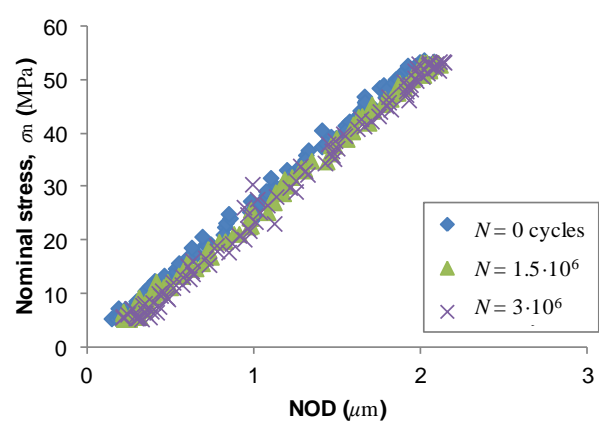

(c) $\Delta \sigma_{\mathrm{n}}=48.0 \mathrm{MPa}$, no crack detected

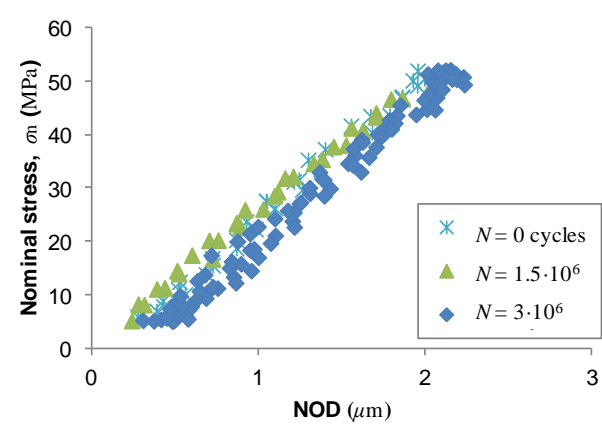

(b) $\Delta \sigma_{\mathrm{n}}=46.7 \mathrm{MPa}$, no crack detected

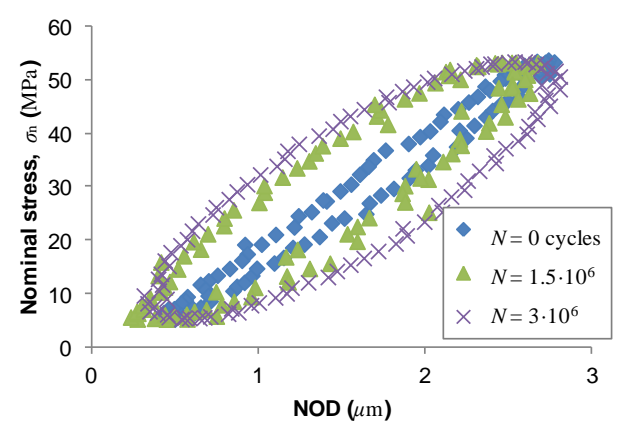

(d) $\Delta \sigma_{\mathrm{n}}=49.3 \mathrm{MPa}, a \approx 1.5 \mathrm{~mm}$

Figure 5.4- Stress-displacement plots for CT-0.15-4 specimen

Since no crack was detected for the first three load levels, and a long crack was obtained at the end of the fourth level, it was assumed that an internal crack was nucleated previously. Therefore, the new CT-0.15-11 specimen was subjected to the first two load levels, $\Delta \sigma_{\mathrm{n}}=\{45.3,46.7\} \mathrm{MPa}$, and monitored by DIC in a 
new attempt. These results are shown in Figure 5.5 and no cracks were detected at the end of those load levels, nor any non-linearity in the $\sigma_{\mathrm{n}} \mathrm{x}$ NOD curves.

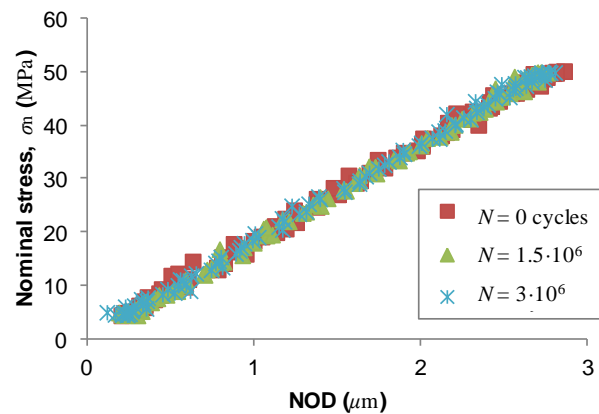

(a) $\Delta \sigma_{\mathrm{n}}=45.3 \mathrm{MPa}$, no crack detected

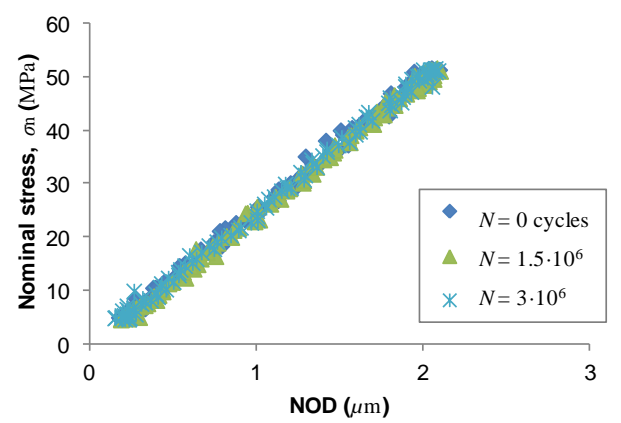

(b) $\Delta \sigma_{\mathrm{n}}=46.7 \mathrm{MPa}$, no crack detected

Figure 5.5- Stress-displacement plots for CT-0.15-11 specimen.

Since no effect of a NPSC presence was detectable by DIC in these two $\mathrm{C}(\mathrm{T}) \mathrm{s}$ tested, the CT-0.15-11 specimen was subjected to a destructive metallographic analysis by sectioning the $\mathrm{C}(\mathrm{T})$ in planes parallel to their faces. This result is shown in the next section.

\subsection{3.}

\section{Destructive metallographic analysis}

Six specimens were sectioned and subjected to a destructive metallographic analysis, as shown in Figure 5.2. Two representative images obtained by optical microscopy are presented in Figure 5.6. The first one corresponds to CT-0.15-11 specimen, which was previously monitored by DIC and no surface crack was detected. However, an internal crack was observed at a plane located at $2 \mathrm{~mm}$ from the (lateral) face, as shown in Figure 5.6a.

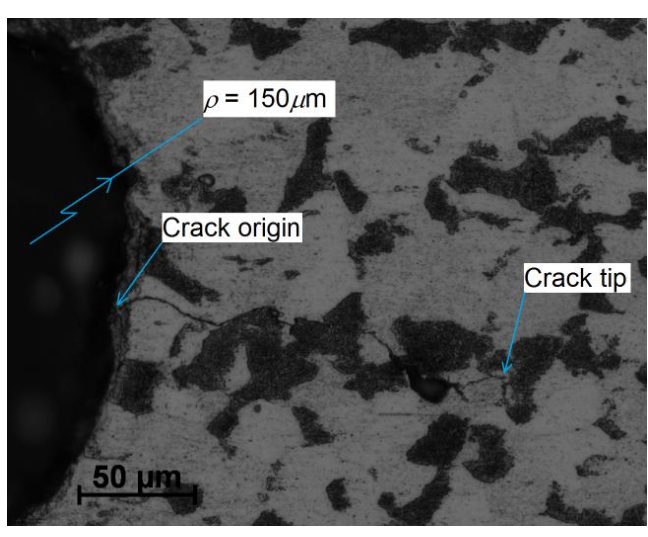

(a) CT-0.15-11, $a \approx 168 \mu \mathrm{m}$

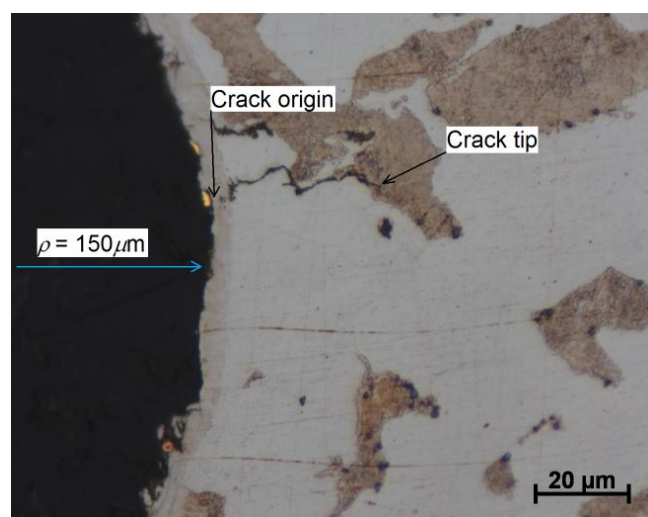

(b) CT-0.15-15, $a \approx 37 \mu \mathrm{m}$

Figure 5.6- Optical images of subsurface (internal) NPSC. Plane located at a) $2 \mathrm{~mm}$ and b) $3.5 \mathrm{~mm}$ from the face of the $\mathrm{C}(\mathrm{T})$. 
Note that the sizes of surface $(81-285 \mu \mathrm{m})$ and subsurface (up to $168 \mu \mathrm{m}$ ) short cracks were considerable shorter than those values predicted by the Stress Gradient model $\left(a_{\max }=814 \mu \mathrm{m}\right)$.

\subsection{4.}

\section{X-ray micro-computed tomography}

From an experimental point of view, $\mathrm{C}(\mathrm{T})$ specimens are the most used in fatigue crack studies due to the low amount of test material required to evaluate the crack growth behaviour. However, C(T) specimens presents some limitations for microtomography inspection, mainly due to its aspect ratio. Indeed, when the longest dimension of the SAE 1020 specimen $(72 \mathrm{~mm})$ is oriented parallel to the X-ray beam, the intensity of the transmitted X-ray beam is strongly attenuated and the contrast is not enough to detect a crack. The acceptable X-ray transmission rate $\left(I / I_{0}\right)$, from Eq. (2.31), should be in the range of $0.2-0.8$, with an optimal value of $\sim 0.5$ [31]. Considering the $\mathrm{C}(\mathrm{T})$ dimensions, the density of the material $\rho$, and the mass attenuation coefficient $\mu_{1} / \rho$ (obtained from [75]) at the applied voltage $(140 \mathrm{kV})$, the $\left(I / I_{0}\right)$ rate was computed for the two limit positions: with the specimen face perpendicular (thickness direction) and parallel (height direction) to the incident X-ray beam. These values are presented in Table 5.2.

Table 5.2- X-ray transmission rate for SAE 1020 and Al6061T3 C(T)-like specimen.

\begin{tabular}{ccccc}
\hline Material & $\begin{array}{c}\mu_{1} / \rho \\
\left(\mathrm{cm}^{2} / \mathrm{g}\right)\end{array}$ & $\begin{array}{c}\rho \\
\left(\mathrm{g} / \mathrm{cm}^{3}\right)\end{array}$ & $\begin{array}{c}I / I_{0} \\
\text { (thickness direction) }\end{array}$ & $\begin{array}{c}I / I_{0} \\
\text { (height direction) }\end{array}$ \\
\hline SAE 1020 & 0.196 & 7.85 & 0.25 & $1.5 \cdot 10^{-5}$ \\
\hline A16061T3 & 0.138 & 2.70 & 0.70 & $8.2 \cdot 10^{-2}$ \\
\hline
\end{tabular}

Based on $\left(I / I_{0}\right)$ rates, the critical dimension is the height direction, as expected, where the transmitted X-ray beam was highly attenuated. For this reason, it was not possible to detect any short crack into the bulk for both materials. Furthermore, short cracks present small opening, mainly because of the unloaded condition in which the examination by microCT was conducted. This renders the detection even more complicated. Hence, the Al6061T3 specimen was tested under fatigue loads until a long crack was generated at the notch tip. This crack was visible to the naked eye, but it was not imaged by microCT. Therefore, this crack was forced to be opened through the application of an external load by a wedge introduced in the notch and the images are presented in Figure 5.7. 


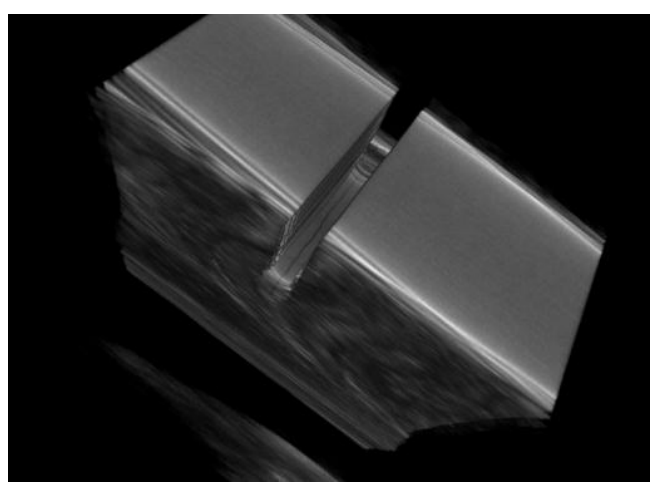

(a)

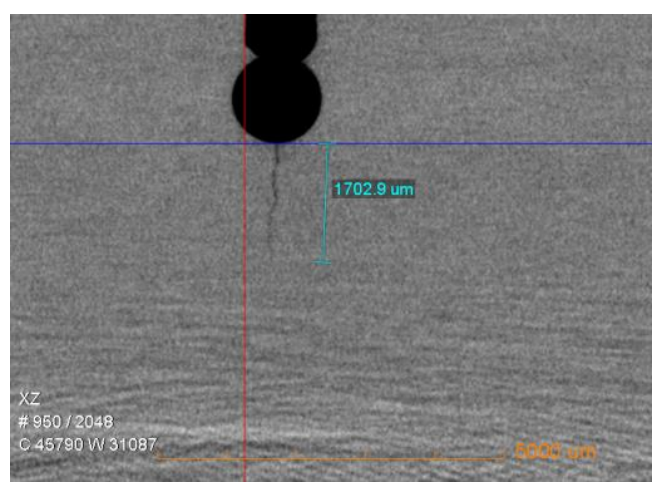

(b)

Figure 5.7- Images obtained by $\mathrm{X}$-ray microCT examination. a) 3D notch tip region and b) plane located at $4 \mathrm{~mm}$ from the face of the Al6061T3 C(T)-like specimen.

It is important to point out that 3D studies of short fatigue crack nucleation and propagation are commonly carried out using synchrotron X-ray microCT, due to the high spatial resolution of this technique. The monitoring of the specimen within "the bulk" is generally conducted during in-situ fatigue tests performed at synchrotron facilities, where small fatigue testing machines are especially designed to be coupled to microCT system [33]. Regarding to the size and shape of the specimens for studying crack nucleation and propagation, miniature specimens in the range of $0.35 \mathrm{~mm}$ in diameter [76], as well as, cylindrical and plate specimens with diameter of $\sim 3 \mathrm{~mm}$ and thickness of $2 \mathrm{~mm}$, respectively [77,78], have been reported in the literature as preferred geometries. Moreover, conventional ASTM C(T) specimens with miniature dimensions in the range of 2 to $2.7 \mathrm{~mm}$ thick and the residual ligament $(W-b)=25.4 \mathrm{~mm}$, have also been used for synchrotron X-ray microCT examination of crack closure $[79,80]$, but not for initiation and propagation stages of short cracks. Note that when miniature fatigue specimens are designed, the use of sophisticated equipments and techniques, such as focused ion beam (FIB), could be necessary to machine fine notches [81].

Among the materials usually employed for X-ray microCT investigations, cast aluminum alloys (Aluminum alloy $\mathrm{AC} 4 \mathrm{CH}$ [78]; $\mathrm{Al}-\mathrm{Si7}-\mathrm{Mg} 03$, called as AS7G03 [77]; Al-Li based on AA5091 alloy [81]), titanium alloys Ti-6Al-4V [33], ductile cast iron [76], magnesium [82] are the most studied. These materials exhibit low linear attenuation coefficients (with the exception of cast iron) and, therefore, less X-ray absorption. 
One strategy to detect short cracks is the tracking of microstructural features, for instance, pores in cast aluminum alloys or graphite nodules/pores in ductile cast iron, since the majority of fatigue cracks initiates from defects [83]. Therefore, these microstructural defects act as natural markers and allow identifying the evolution of short fatigue cracks within the bulk metal, as depicted in Figure A.2a in the case of cast aluminum alloy AC4CH [78] (Appendix A.3). The gauge volume of the specimen presented in Figure A.2b corresponding to a ductile cast iron specimen is shown at Figure A.2c, while a magnified view of this region was sectioned to show a fatigue crack nucleated from a pore is indicated in Figure A.2d [76].

Other X-ray microCT studies have been performed to elucidate the interaction between short cracks and grain boundaries. Since grain boundaries are not normally visible by conventional attenuation tomography, decoration techniques such as gallium infiltration have been applied in aluminum alloy specimens [84]. Due to the fact that gallium exhibits an X-ray attenuation coefficient higher than aluminum, the gallium layers formed at grain boundaries can be detected by absorption microCT. However, the infiltration process leads to complete loss of mechanical strength of the material and, consequently, this decoration technique is considered as a destructive one, which can be used merely at the end of the fatigue test [85].

Regarding to titanium alloys, such as Ti-6246, one of the advantages of these materials is that offer enough contrast to visualize microstructure/crack interactions directly, as reported by Birosca et al. [86].

It is important to mention that only a few works describe the application of conventional X-ray microCT for the microstructural analysis of steels. These works are mainly based on the detection of inhomogeneities (inclusions with sizes less than $30 \mu \mathrm{m}$ and micropores) and the results have been encouraging [87]. Therefore, conventional X-ray microCT is a promissory technique for the detection of short fatigue cracks using equipments available a laboratory scale, but still it has to overcome certain shortcomings, as those founded in the present work. These limitations could be overcome by the proper combination of the following factors: i) the material selection based on the linear attenuation 
coefficient $\left(\mu_{\mathrm{m}} / \rho\right)$ and microstructure (porosity or inclusions are favorable to the initiation and tracking of short cracks); ii) geometry and dimensions of the specimen (since the specimen must be rotated, cylindrical shapes are preferred). The range of the spatial resolution can be estimated from (diameter/2000) to (diameter/1000). For example, for a $3 \mathrm{~mm}$ diameter specimen the resolution would be in the range of $1.5 \mu \mathrm{m}$ to $3 \mu \mathrm{m}$, and iii) configuration of microCT system, since geometrical and optical magnifications also affect the resolution. Smaller source-specimen distances give rise to high magnifications and therefore, the spatial resolution is increased. The use of objective lenses can be also considered for that purpose.

In the case of ASTM C(T)-like specimens, the main concern is with the largest dimension of this geometry $(1.2 W)$. Since the $\mathrm{X}$-ray transmission rate should be in the range $0.2<I / I_{0}<0.8$, Figure 5.8 shows the limit values of $1.2 \mathrm{~W}$ for low carbon steels and aluminum $\mathrm{C}(\mathrm{T})$ specimens. Accordingly, cracks in $\mathrm{C}(\mathrm{T})$ specimens can be properly detected by microCT when $1.2 \mathrm{~mm}<W<8.7 \mathrm{~mm}$ for steels and $5 \mathrm{~mm}<W<36 \mathrm{~mm}$ for aluminum, at a source voltage of $150 \mathrm{kV}$. The thickness can be scaled according to ASTM recommendations. It is worth noting that the $W$ values obtained for steels are too small for real applications, which corroborates the fact that no cracks were detected in SAE 1020 specimens.

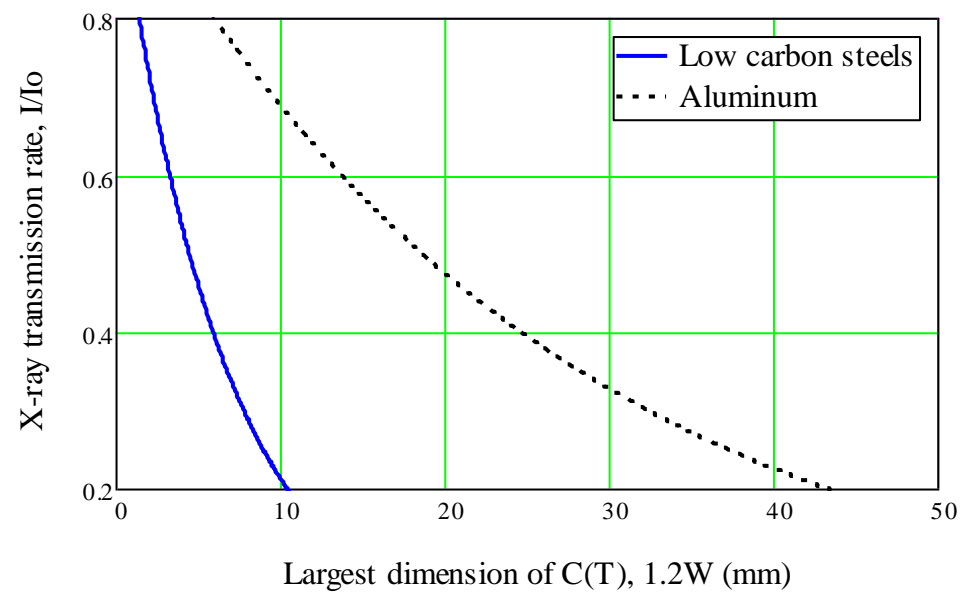

Figure 5.8- X-ray transmission rate as a function of the largest dimension of low carbon steel and aluminum $\mathrm{C}(\mathrm{T})$ specimen, when the voltage of the source is $150 \mathrm{kV}$.

Finally, it can be noted that Al6061T3 alloy, also employed in this work, is a promissory material for X-ray microCT studies using conventional system due 
to the fact that its microstructure contains two types of particles: Fe-rich and $\mathrm{Mg}_{2} \mathrm{Si}$ intermetallics. Agawarl et al. [88] demonstrated that damage due to cracking and void growth around Fe-rich intermetallics is significant while that of $\mathrm{Mg}_{2} \mathrm{Si}$ intermetallics is practically negligible. Therefore, these microstructural defects can be beneficial for crack detection. Furthermore, a study of thermal treatments of this alloy would be performed to determine the conditions that allow obtaining the best microstructural features for detection of short cracks.

\section{3.}

\section{Discussion}

\subsection{1.}

\section{$K_{\mathrm{f}}$ predictions}

The SG and the TCD models were used to predict the fatigue SCF $K_{\mathrm{f}}$, which is related to the fatigue limit of the notched $\mathrm{C}(\mathrm{T})$-like specimen. In the SG model, three approaches were used to obtain the geometry factor of the SIF of a short crack at the notch root. Accordingly, this model was called as $\mathrm{SG}_{\mathrm{C}-\mathrm{P}}, \mathrm{SG}_{\mathrm{s-e}}$, and

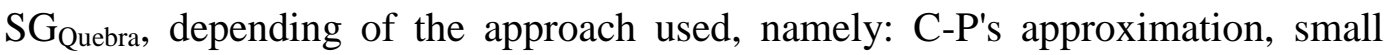
crack at a semielliptical notch, and FE analysis by Quebra2D software. On the other hand, the TCD model was applied by using the PM method. All of these predictions were applied considering LE stress fields ahead the notch tip.

The $K_{\mathrm{f}}$ predicted by the $\mathrm{SG}_{\mathrm{C}-\mathrm{P}}$ (estimated geometry factor $f_{1, \mathrm{C}-\mathrm{P}}$ ) and by the $\mathrm{SG}_{\text {Quebra }}$ (calculated geometry factor $f_{\text {Quebra }}$ ) model are very similar. This similarity was expected, since the C-P's approach was demonstrated by FE analysis to be a good approximation of the stress distribution ahead of a notch tip (see Figure 4.2). For blunt notches $(\rho>0.60 \mathrm{~mm})$, these predictions present a good agreement with the experimental observations (see Figure 5.1), which means that a LE analysis is appropriate to model those notches. However, for sharp notches $(\rho \leq 0.60 \mathrm{~mm})$, the predicted $K_{\mathrm{f}}$ is less than the experimental one, i.e. the predicted fatigue limit is greater than the experimental one, up to $\sim 60 \%$ for $\mathrm{SG}_{\mathrm{C}-\mathrm{P}}$ and up to $\sim 49 \%$ (for $\rho=$ $0.15 \mathrm{~mm})$. This disagreement increases as $\rho$ decreases. These non-conservative predictions compared to the experiments can be justified as a consequence of the use of LE analysis, which could underestimate the SIF, especially in sharp notches that can causes high localized stresses. This explanation also is valid for the 
predictions by the TCD-PM model, since it requires a LE stress distribution to estimate the fatigue limit.

On the other hand, the predictions by the $\mathrm{SG}_{\mathrm{s}-\mathrm{e}}$ (estimated geometry factor $\left.f_{1, \mathrm{~s}-\mathrm{e}}\right)$ are conservatives compared to the experimental data, even for blunt notches. The disagreement between predictions and experimental also increases as $\rho$ decreases (up to $\sim 24 \%$ for $\rho=0.15 \mathrm{~mm}$ ). Since $f_{1, \mathrm{~s} \text {-e }}$ was estimated from the expression for a semielliptical notch under constant nominal tensile stress (see Figure 2.8), a possible justification can be associated to the fact that in a $\mathrm{C}(\mathrm{T})$ specimen, the nominal tensile stress decreases as the crack increases, due to the decrement of the bending stress (see Eq. (4.1)).

To close this section, it is worth mentioning that both models used in the current work do not include 3D stress fields nor plasticity effects ahead of the notch root. However, their predictions can be considered as a first simplified approximation whose accuracy can be improved by including notch effects, a complex problem that usually involves the use of FEM to determine an entire 3D solution.

\subsection{2.}

\section{$a_{\max }$ predictions and short cracks detection}

According to ASTM-E112 standard, the grain size $g r$ for the SAE 1020 steel used in the present work is No. G 7.0, corresponding to an average diameter de $\sim 32 \mu \mathrm{m}$. On the other hand, the largest non-propagating crack $a_{\max }$ predicted by the three approaches of the SG model were greater than $79 \mu \mathrm{m}$, and the estimated short characteristic size for a stress ratio $R=0.1, a_{0.1} \approx 200 \mu \mathrm{m}$. Therefore, these cracks can be modeled by LEFM, since $a>g r$.

Figure $4.8 \mathrm{~b}$ shows how the $a_{\max }$ predicted by the SG model varies as the notch root radius $\rho$ increases. In general, the predicted $a_{\max }$ increases as $\rho$ decreases, but for values $\rho<\sim 10 g r, a_{\max }$ decreases with $\rho$, possibly due to the fact that a notch tends to a crack as $\rho \rightarrow 0$. The same trend between the predictions of the fatigue limit of the three approaches of the SG model was maintained for the case of $a_{\max }$ predictions, i.e. $a_{\max }\left(\mathrm{SG}_{\mathrm{C}-\mathrm{P}}\right)>a_{\max }\left(\mathrm{SG}_{\mathrm{Quebra}}\right)>a_{\max }\left(\mathrm{SG}_{\mathrm{s}-\mathrm{e}}\right)$, at least for $\rho>\sim 8 g r$. 
Finally, the experimentally measured $a_{\max }$ are much smaller than those predicted by SG model. This difference could be related to the 3D behaviour of a real crack, since in this work the crack was considered as 1D. According to Figure 4.2, the SCF $K_{\mathrm{t}}$ is maximum at the middle plane of the $\mathrm{C}(\mathrm{T})$, along the notch front. So, a small crack will be able to nucleate at this point and then it will propagate as a $2 \mathrm{D}$ crack, along and ahead the notch front. In that way, the size of the crack measured at the lateral face of the $\mathrm{C}(\mathrm{T})$ will be the lowest one, while the corresponding size at the middle of the notch front could already had exceeded the maximum tolerable $a_{\max }$. This fact can support the need to use a 3D system for insitu monitoring of the crack front development. 
6

\section{Conclusions and future works}

\section{1.}

\section{Conclusions}

In this work, the effect of short fatigue cracks departing from elongated notch tips on the fatigue limit was assessed by the application of the Stress Gradient model. The experimental verification of this model was carried out using specimens of a SAE 1020 low carbon steel, which was selected based on both, the estimated short characteristic size $a_{0}$ and the commercial availability in the local market. The ASTM C(T)-like geometry was selected according to their versatility for the study of the behavior of crack propagation. The predicted and experimentally measured fatigue limits and non-propagation short crack sizes were compared and the following conclusions were drawn:

The fatigue limit of the material $\left(\Delta S_{0.1} / 2\right)$ measured by Dixon's up-and-down method was $\sim 15 \%$ greater than that measured by IR thermography (178.5 MPa). Since the fatigue limit assessed by IR thermography is associated to a more realistic fatigue damage mechanism, its value was used for the estimation of the short crack characteristic size $a_{0.1}=199 \mu \mathrm{m}$.

The SG and the TCD models were used to predict the fatigue SCF $K_{\mathrm{f}}$ (or the fatigue limit). Besides, the SG model also allows to predict the maximum tolerable crack $a_{\max }$. Three forms of the SG model was applied, namely: $\mathrm{SG}_{\mathrm{C}-\mathrm{P}}$, $\mathrm{SG}_{\mathrm{s}-\mathrm{e}}$, and $\mathrm{SG}_{\mathrm{Quebra}}$; depending on the approach used to obtain the geometry factor of the SIF. It was demonstrated that the fatigue limit predicted by the $\mathrm{SG}_{\mathrm{C}-\mathrm{P}}$, $\mathrm{SG}_{\text {Quebra, }}$ and TCD models are almost coincident for blunt notches $(\rho=\{0.60$, $1.25\} \mathrm{mm}$ ) and in turn, they present a good agreement with experimental observations. In the case of sharp notches, these predictions are greater than the experiments, with differences up to $\sim 60 \%, \sim 49 \%$, and $\sim 28 \%$, respectively. On the other hand, the predictions by the $\mathrm{SG}_{\mathrm{s} \text {-e }}$ model are less than experiments (up to $\sim 24 \%$ ), even for blunt notches. 
The differences between the predictions and the experimental data can be partially explained from the fact a LE analysis was used in this work. In general, LE stress field can lead to underestimate the SIF, especially in sharp notches where even low nominal applied stresses can causes high localized stresses. Another reason could be the use of the simplified 1D model to describe the crack in this work, since a real crack has a 3D behavior and it was demonstrated by FEM that the SCF $K_{\mathrm{t}}$ presents a maximum value at the middle plane of the C(T) specimen analyzed.

Several attempts were used for in-situ monitoring and post-test detection of short cracks at the notch tip region, but the existence of surface non-propagating cracks was only verified by optical microscopy on the face of $\mathrm{C}(\mathrm{T})$-like specimen of SAE 1020 steel (for $\rho=0.15 \mathrm{~mm}$ under $R=0.1$ ). Subsurface non-propagating cracks were also detected by destructive metallographic technique for the sharpest notched specimens tested. The sizes of surface $(81-285 \mu \mathrm{m})$ and subsurface (up to $168 \mu \mathrm{m}$ ) short cracks were considerable shorter than those values predicted by the SG model: $a_{\max }\left(\mathrm{SG}_{\mathrm{C}-\mathrm{P}}\right)=814 \mu \mathrm{m}, a_{\max }\left(\mathrm{SG}_{\mathrm{s}-\mathrm{e}}\right)=561 \mu \mathrm{m}, a_{\max }\left(\mathrm{SG}_{\text {Quebra }}\right)=420$ $\mu \mathrm{m}$. Since the grain size of the SAE 1020 steel used in this work is $g r \approx 32 \mu \mathrm{m}$, the use of the macroscopic properties in the SG model is justified.

DIC and X-ray microCT techniques did not allow the detection of short cracks. Boundary problems are associated to the DIC technique, while the high attenuation coefficient of the low carbon steel along with the geometry and dimensions of the $\mathrm{C}(\mathrm{T})$ specimen are the main limitations related to microCT.

\section{2.}

\section{Future works}

Based on the results and conclusions arising from this thesis, suggestions for future works are presented as follows:

Improvement of the SG model by including another parameter instead of the LE SIF to take into account plasticity effects on the analysis of notches, especially the sharp ones. Furthermore, the variation of the $K_{\mathrm{t}}$ through the specimen thickness should be considered to better describe the propagation of a crack, i.e. the entire 3D stress field around the notch tip. 
Increase the number of cycles of the fatigue limit concept, in such a way that the assessed fatigue limit can be obtained from more realistic conditions.

Design of new specimens with suitable geometry/material combinations to induce non-propagating short cracks, which can be detected by X-ray microCT conventional systems and compare these results with those obtained by high resolution synchrotron systems.

Development of a configuration system composed of a fatigue testing machine and a crack detecting equipment for in-situ monitoring surface and subsurface cracks during the test. 
7

\section{References}

[1] SURESH, S.; RITCHIE, R. O. Propagation of short fatigue cracks. International Metals Reviews, v.29, n.6, pp. 445-475, 1984.

[2] GUIU, F.; STEVENS, R.N. The nucleation and growth of short fatigue cracks both at plain surfaces and notches. Fatigue \& Fracture of Engineering Materials \& Structures, v.13, n.6, pp. 625-635, nov. 1990.

[3] CHAPETTI, M.D. et al. Two small-crack extension force concept applied to fatigue limit of blunt notched components. International Journal of Fatigue, v.21, n.1, pp. 77-82, jan. 1999.

[4] El HADDAD, M. H.; TOPPER, T. H.; SMITH, K. N. Prediction of nonpropagating cracks. Engineering Fracture Mechanics, v.11, n.3, pp. 573-584, 1979.

[5] MegGiolaro, M. A.; MiRAndA, A. C.O.; CASTRO, J. T. P. Short crack threshold estimates to predict notch sensitivity factors in fatigue. International Journal of Fatigue, v.29, n.9-11, pp. 2022-2031, sep.-nov. 2007.

[6] PIPPAN, R. et al. Non-propagation conditions for fatigue cracks and fatigue in the very high-cycle regime. Fatigue \& Fracture of Engineering Materials \& Structures, v.25, n.8-9, pp. 805-811, sep. 2002.

[7] INGLIS, C. Stress in a plate due to the presence of cracks and sharp corners. Philosophical Transactions of the Royal Society series A, v.215, pp. 119-233, 1913.

[8] TADA, H.; PARIS, P. C.; IRWIN, G. R. The Stress Analysis of Cracks Handbook. St. Louis: Del Research, 1985.

[9] DOWLING, N. Mechanical Behavior of Materials. Upper Saddle River: Prentice Hall, 2007.

[10] VERREMAN, Y.; LIMODIN, N. Fatigue notch factor and short crack propagation. Engineering Fracture Mechanics, v.75, n.6, pp. 1320-1335, apr. 2008.

[11] FROST, N. E.; MARSH, K. J.; POOK, L. P. Metal Fatigue. Oxford: Clarendon Press, 1974. [Reprinted. New York: Dover; 1999].

[12] WILLIAMS, M. L. On the stress distribution at the base of a stationary crack. Journal of Applied Mechanics, v.24, n.1, pp. 109-114, 1957.

[13] IRWIN, G. R. Analysis of stresses and strains near the end of a crack traversing a plate. Journal of Applied Mechanics, v.24, pp. 361-364, sep.1957. 
[14] CASTRO, J. T. P.; MEGGIOLARO, M. A. Fadiga: Técnicas e Práticas de Dimensionamento Estrutural sob Cargas Reais de Serviço. Rio de Janeiro: Create Space, 2009.

[15] DUGDALE, D. S. Yielding of sheets containing slits. Journal of the Mechanics and Physics of Solids, v.8, n.2, pp.100-104, may 1960.

[16] TOLMAN, R. C. The principle of similitude. Physical Review, v.3, n.4, pp. 244-255, apr. 1914.

[17] MILLER, K. J. The behaviour of short fatigue cracks and their initiation Part I - A review of two recent books. Fatigue \& Fracture of Engineering Materials \& Structures, v.10, n.1, pp. 75-91, jan. 1987.

[18] CREAGER, M.; PARIS, P. C. Elastic field equations for blunt cracks with reference to stress corrosion cracking. International Journal of Fracture Mechanics, v.3, n.4, pp. 247-252, dec. 1967

[19] KITAGAWA, H.; TAKAHASHI, S. Applicability of fracture mechanics to very small crack or cracks in the early stage. Proceedings of the 2nd International Conference on Mechanical Behavior of Materials, pp. 627-631, ASM 1976.

[20] YU, M. T.; DUQUESNAY, D. L. ; TOPPER, T. H. Notch fatigue behavior of 1045 steel. International Journal of Fatigue, v.10, n.2, pp. 109-116, apr. 1988.

[21] BAZANT, Z. P. Scaling of quasibrittle fracture: asymptotic analysis. International Journal of Fracture, v.83, pp. 19-40, jan. 1997.

[22] CASTRO, J. T. P. et al. Prediction of notch sensitivity effects in fatigue and in environmentally assisted cracking. Fatigue \& Fracture of Engineering Materials \& Structures, v.38, n.2, pp. 161-179, feb. 2015.

[23] MIRANDA, A. C. O. et al. Fatigue crack propagation under complex loading in arbitrary 2d geometries. ASTM STP 1411, v.4, pp. 120-46, jan. 2002.

[24] TAYLOR, D. Geometrical effects in fatigue: a unifying theoretical model. International Journal of Fatigue, v.21, n.5, pp. 413-420, may 1999.

[25] BELLETT, D. et al. The fatigue behaviour of three-dimensional stress concentrations. International Journal of Fatigue, v.27, n.3, pp. 207-221, mar. 2005.

[26] SUSMEL, L. The theory of critical distances: a review of its applications in fatigue. Engineering Fracture Mechanics, v.75, n.7, pp. 1706-1724, may 2008.

[27] FROST, N. E.; DUGDALE, D. S. Fatigue tests on notched mild steel with measurements of fatigue cracks. Journal of the Mechanics and Physics of Solids, v.5, n.3, pp. 182-192, 1957.

[28] AMIRI, M.; MODARRES, M. Short fatigue crack initiation and growth modeling in aluminum 7075-T6. Proceedings of the Institution of Mechanical Engineers, Part C: Journal of Mechanical Engineering Science, v.229, n.7, pp.1206-1214, aug. 2014. 
[29] GONZÁLES, G. L. G. et al. Strains in Shallow and Deep Notches Using Two DIC Algorithms. In Advancement of Optical Methods in Experimental Mechanics, v.3, pp. 281-294, 2016.

[30] LANDIS, E. N.; KEANE, D. T. X-ray microtomography. Materials Characterization, v.61, n.12, pp. 1305-1316, dec. 2010.

[31] LI, T. et al. Three-dimensional observation of nonmetallic inclusion clusters in Solid Metal by X-ray Micro-CT, The Iron and Steel Institute of Japan, vol.16, n.11, pp. 1989-1995, jul. 2016.

[32] BABOUT, L. X-ray tomography imaging: a necessary tool for materials science. Automatyka, v.10, n.3, pp. 117-124, 2006.

[33] NAKAMURA, T. et al. Detection of small internal fatigue cracks in Ti-6Al$4 \mathrm{~V}$ by using synchrotron radiation $\mu \mathrm{CT}$ imaging. Bulletin of the JSME Mechanical Engineering Letters, v.2, pp. 1-8, apr. 2016.

[34] CHAPPARD, C.; BASILLAIS, A.; BENHAMOU, L. Bone microarchitecture from synchrotron radiation and conventional $\mathrm{x}$-ray. Medical Physics, v.33, n.9, pp. 3568-3577, sep. 2006.

[35] BERNHARDT, R. et al. Analysis of osteointegration with microtomography. European Cells and Materials, v.7, pp. 42-51, 2004.

[36] FESER, M. et al. Sub-micron resolution CT for failure analysis and process development. Measurement Science and Technology, v.19, pp. 1-8, 2008.

[37] FAN, F.; KALNAUS, S.; JIANG, Y. Modeling of fatigue crack growth of stainless steel 304L. Mechanics of Materials, v.40, n.11, pp. 961-973, nov. 2008.

[38] GATES, N.; FATEMI, A. Fatigue crack growth behavior in the presence of notches and multiaxial nominal stress states. Engineering Fracture Mechanics, v.165, pp. 24-38, oct. 2016.

[39] MENEGHETTI, G.; CAMPAGNOLO, A.; BERTO, F. Assessment of tensile fatigue limit of notches using sharp and coarse linear elastic finite element models. Theoretical and Applied Fracture Mechanics, v.84, pp. 106-118, aug. 2016.

[40] DOWLING, N. E. Notched member fatigue life predictions combining crack initiation and propagation. Fatigue \& Fracture of Engineering Materials \& Structures, v.2, n.2, pp. 129-138, sep. 1979.

[41] CAMERON, A. D.; SMITH, R. A. Fatigue life prediction for notched members. International Journal of Pressure Vessels and Piping, v.10, n.3, pp. 205-217, may 1982.

[42] SHIN, C. S.; SMITH, R. A. Fatigue crack growth from sharp notches. International Journal of Fatigue, v.7, n.2, pp. 87-93, apr. 1985.

[43] TANAKA, K.; NAKAI, Y. Propagation and non-propagation of short fatigue cracks at a sharp notch. Fatigue \& Fracture of Engineering Materials \& Structures, v.6, n.4, pp. 315-327, 1983.

[44] SMITH, R. A.; MILLER, K. J. Prediction of fatigue regimes in notched components. International Journal of Mechanical Sciences, v.20, n.4, pp. 201-206, 1978. 
[45] HAMMOUDA, M. M.; SMITH, R. A.; MILLER, K. J. Elastic-plastic fracture mechanics for initiation and propagation of notch fatigue cracks. Fatigue \& Fracture of Engineering Materials \& Structures, v.2, n.2, pp. 139-54, sep. 1979.

[46] DONG, P.; HONG, J. K.; CAO, Z. Stresses and stress intensities at notches: 'anomalous crack growth' revisited. International Journal of Fatigue, v.25, n.9-11, pp. 811-825, sep.-nov. 2003.

[47] DING, F.; FENG, M., JIANG, Y. Modeling of fatigue crack growth from a notch. International Journal of Plasticity, v.23, n.7, pp. 1167-1188, jul. 2007.

[48] SADANANDA, K.; VASUDEVAN, A. K. Short crack growth and internal stresses. International Journal of Fatigue, v.19, n.93, pp. 99-108, jun. 1997.

[49] BENEDETTI, M. et al. The effect of notch plasticity on the behaviour of fatigue cracks emanating from edge-notches in high-strength $\beta$-titanium alloys. Engineering Fracture Mechanics, v.75, n.2 , pp. 169-187, jan. 2008

[50] PIPPAN, R.; BERGER, M.; STÜWE, H. P. The influence of crack length on fatigue crack growth in deep sharp notches. Metallurgical Transactions A, v.18, n.3, pp. 429-435, mar. 1987.

[51] PETERSON, R. E. Notch sensitivity. In: Metal fatigue. New York: MacGraw-Hill, 1959. p. 293-306.

[52] NEUBER, H. Kerbspannungslehre. Vienna: Springer-Verlag, 1987. [Reprinted in translation as Theory of notch stresses. Berlin: Springer Publishers, 1958.].

[53] HEYWOOD, R. E. Designing against fatigue. London: Chapman and Hall, 1962.

[54] TAYLOR D. The Theory of Critical Distances: a new perspective in fracture mechanics. Oxford: Elsevier, 2007.

[55] CASTRO, J. T. P. et al. Prediction of fatigue crack initiation lives at elongated notch roots using short crack concepts. International Journal of Fatigue, v.42, pp. 172-182, sep. 2012.

[56] NEWMAN, J. C.; YAMADA, Y. Compression precracking methods to generate near-threshold fatigue-crack-growth-rate data. International Journal of Fatigue, v.32, n.6, pp. 879-885, jun. 2010.

[57] TAKAHASHI, Y. et al. Fatigue limit investigation of 6061-T6 aluminum alloy in giga-cycle regime. Materials Science \& Engineering: A, v.614, n.22, pp. 243-249, sep. 2014.

[58] DIXON, W. J.; MOOD, A. M. A method for obtaining and analyzing sensitivity data. Journal of the American Statistical Association, v.43, n.241, pp. 109-126, mar. 1948.

[59] DIXON, W. J. The Up-and-Down Method for Small Samples. Journal of the American Statistical Association, v.60, n.312, pp. 967-978, dec. 1965. 
[60] JUVINALL, R. C.; MARSHEK, K. M. Fundamentals of Machine Component Design. 4th ed. Wiley, 2005.

[61] NICHOLAS, T. High Cycle Fatigue: A Mechanics of Material Perspective. Oxford: Elsevier Ltd., 2006. 656 p.

[62] KALETA, J.; BLOTNY, R.; HARIG, H. Energy stored in a specimen under fatigue limit loading conditions. Journal of Testing and Evaluation, v.19, n.4, pp. 326-333, jul. 1991.

[63] RISITANO, A.; RISITANO, G. L.'importanza del Parametro Energetico Temperatura per la Caratterizzazione Dinamica dei Materiali. Frattura ed Integrità Strutturale, v.9, pp. 113-24, 2009.

[64] La ROSA, G.; RISITANO, A. Thermographic methodology for rapid determination of the fatigue limit of materials and mechanical components. International Journal of Fatigue, v.22, n.1, pp. 65-73, jan. 2000.

[65] FARGIONE, G. et al. Rapid determination of the fatigue curve by the thermographic method. International Journal of Fatigue, v.24, n.1, pp. 11-19, jan. 2002.

[66] CURA, F.; CURTI, G.; SESANA, R. A new iteration method for the thermographic determination of fatigue limit in steels. International Journal of Fatigue, v.27, n.4, pp. 453-459, apr. 2005.

[67] De FINIS, R. et al. Fatigue limit evaluation of various martensitic stainless steels with new robust thermographic data analysis. International Journal of Fatigue, v.74, pp. 88-96, may 2015.

[68] LIPSKI, A. Accelerated determination of the fatigue limit and the S-N curve by means of the thermographic method for X5CrNi18-10 steel. Acta mechanica et automatic, v.10, n.1, pp. 22-27, feb. 2016.

[69] CHARLES, J. A.; APPL, F. J.; FRANCIS, J. E. Using the scanning infrared camera in experimental fatigue studies. Experimental Mechanics, v.15, n.4, pp. 133-138, 1975.

[70] LUONG, M. P. Infrared thermographic scanning of fatigue in metals. Nuclear Engineering and Design, v.158, n.2-3, pp. 363-376, sep. 1995.

[71] BATHIAS, C; PARIS, P. C. Gigacycle fatigue in mechanical practice. New York: Marcel Dekker, 2005.

[72] SAKAI, T. et al. A review on fatigue fracture modes of structural metallic materials in very high cycle regime. International Journal of Fatigue, v.93, n.2, pp. 339-351, dec. 2016.

[73] GUAMÁN, M. V. Previsão do efeito das trincas curtas em componentes estruturais. 2012. 93 f. Dissertação (Mestrado) Departamento de Engenharia Mecânica, Pontifícia Universidade Católica do Rio de Janeiro, Rio de Janeiro, 2013.

[74] AHMAD, H. Y.; YATES, J. R. An elastic-plastic model for fatigue crack growth at notches. Fatigue \& Fracture of Engineering Materials \& Structures, v.17, n.6, pp. 651-660, jun. 1994.

[75] NIST: XAAMDI, X-ray Attenuation and Absorption for Materials of Dosimetric Interest Database, NIST, Gaithersburg, MD, 2013. 
[76] MARROW, T. J. et al. High resolution X-ray tomography of short fatigue crack nucleation in austempered ductile cast iron. International Journal of Fatigue, v.26, n.7, pp. 717-725, jul. 2004.

[77] BUFFIÈRE, J-Y. et al. Experimental study of porosity and its relation to fatigue mechanisms of model $\mathrm{Al}-\mathrm{Si} 7 \mathrm{Mg} 0.3$ cast $\mathrm{Al}$ alloys. Materials Science and Engineering: A, v.316, n.1-2, pp. 115-126, nov. 2001.

[78] TODA, H. et al. Statistical assessment of fatigue crack initiation from subsurface hydrogen micropores in high-quality die-cast aluminum. Acta Materialia, v.59, n.12, pp. 4990-4998, jul. 2011.

[79] IGNATIEV, K. I. et al. Phase contrast stereometry: fatigue crack mapping in 3D. In: Developments in X-Ray Tomography IV, 2004, Bellingham-WA, Proceedings of SPIE, v.5535, pp. 253-260, 2004.

[80] STOCK, S. R. X-ray microtomography of materials. International Materials Reviews, v.44, n.4, pp. 141-164, 1999.

[81] FERRIÉ, E. et al. Fatigue crack propagation: In situ visualization using Xray microtomography and $3 \mathrm{D}$ simulation using the extended finite element method. Acta Materialia, v.54, n.4, pp. 1111-1122, feb. 2006.

[82] KING, A. et al. Three-dimensional in situ observations of short fatigue crack growth in magnesium. Acta Materialia, v.59, n.17, pp. 6761-6771, oct. 2011.

[83] LIMODIN, N. et al. Influence of closure on the 3D propagation of fatigue cracks in a nodular cast iron investigated by X-ray tomography and 3D volume correlation. Acta Materialia, v.58, n.8, pp. 2957-2967, may. 2010.

[84] WITHERS, P. J.; PREUSS, M. Fatigue and damage in structural materials studied by X-ray tomography. Annual Review of Materials Research, v.42, pp. 81-103, may. 2012.

[85] LUDWING, W. et al. Study of the interaction of a short fatigue crack with grain boundaries in a cast Al alloy using X-ray microtomography. Acta Materialia, v.51, n.3, pp. 585-598, feb. 2003.

[86] BIROSCA, S. et al. Three-dimensional characterization of fatigue cracks in Ti-6246 using X-ray tomography and electron backscatter diffraction. Acta Materialia, v.57, n.19, pp. 5834-5847, nov. 2009.

[87] HARRER, B. et al. On the detection of inhomogeneities in steel by computed tomography. In: 17th World Conference on Nondestructive Testing, 2008, Shangai, China.

[88] AGARWAL, H. et al. Void growth in 6061-aluminum alloy under triaxial stress state. Materials Science and Engineering: A, v.341, n.1-2, pp. 35-42, jan. 2003.

[89] NICHOLAS, T. Step loading for very high cycle fatigue. Fatigue \& Fracture of Engineering Materials \& Structures, v.25, n.8-9, pp. 861-869, sep. 2002.

[90] BELLOWS, R.S.; MUJU, S.; NICHOLAS, T. Validation of the Step Test Method for Generating Haigh Diagrams for Ti-6Al-4V. International Journal of Fatigue, v.21, n.7, pp. 687-697, aug. 1999. 


\section{A Appendices}

\section{A.1. Step-up loading procedure}

Nicholas [89] describes a step-up test that uses constant stress amplitude blocks of $N_{\mathrm{b}}$ cycles for each step, starting below the estimated fatigue limit. After each block, the stress amplitude is increased by approximately 5\% until failure occurs at the $i$-th block. The fatigue limit is then determined by a linear interpolation given in Eq. (A.1).

$$
S_{\mathrm{L}}=\sigma_{a(i-1)}+\Delta \sigma_{i}\left(\frac{n_{i}}{N_{\mathrm{b}}}\right)
$$

where $\sigma_{a(\mathrm{i}-1)}$ is the larger stress amplitude that did not result in failure, $\Delta \sigma_{\mathrm{i}}$ is the step increase in the $i-$ th load, and $n_{\mathrm{i}}$ is the number of cycles to failure at $\left[\sigma_{a(\mathrm{i}-1)}+\right.$ $\left.\Delta \sigma_{\mathrm{i}}\right]$. Successive tests may start closer to the previously measured $S_{\mathrm{L}}$. This method was verified testing specimens of the titanium alloy $\mathrm{Ti}-6 \mathrm{Al}-4 \mathrm{~V}$ and the results were in agreement with those obtained by conventional SN methods [90].

\section{A.2.}

\section{Application of SG model to an Al6061T3 C(T)-like specimen}

The basic mechanical properties for Al6061T3 aluminum alloy are obtained from [14] and are presented in Table A.1.

Table A.1- Basic mechanical properties of Al6061T3 aluminum alloy.

\begin{tabular}{cccc}
\hline$E(\mathrm{GPa})$ & $S_{\mathrm{Y}}(\mathrm{MPa})$ & $S_{\mathrm{U}}(\mathrm{MPa})$ & $\Delta K_{\mathrm{th}}(\mathrm{MPa} \sqrt{\mathrm{m}})$ \\
\hline 75 & 276 & 310 & 3.9 \\
\hline
\end{tabular}

The short crack characteristic size for $R=0.1, a_{0.1}$, can be estimated from $\Delta K_{\text {th }}$ and $\Delta S_{0.1}$, the long crack propagation threshold and the smooth specimen 
fatigue limit, using the Eq. (2.17). The fatigue limit $\Delta S_{0.1}$ was estimated from the fatigue limit for fully reversed load condition $(R=-1)$ given by Juvinall [60]: $\Delta S_{-1}\left(5 \cdot 10^{8}\right)=0.8 S_{U}$ for aluminum alloys; then, the equivalent value $\Delta S_{0.1}$ was computed via Goodman approach: $\Delta S_{0.1}=166.6 \mathrm{MPa}$. Hence, $a_{0.1}=139 \mu \mathrm{m}$.

The application of the SG model to the Al $6061 \mathrm{~T} 3$ aluminum alloy $\mathrm{C}(\mathrm{T})$ like specimen is graphically shown by plotting the dimensionless $f$ and $g$ functions. Taking into account the specimen dimensions: width $W=56 \mathrm{~mm}$, thickness $t=10 \mathrm{~mm}$, notch depth $b=16 \mathrm{~mm}$, notch root radius $\rho=0.62 \mathrm{~mm}$, and assuming a Bazant's parameter $\gamma=6$, Figure A.1 shows $f$ and three $g$ curves as a function of the crack size $a$ to illustrate the determination of $K_{\mathrm{f}}$, when $f=g$ and $\mathrm{d} f / \mathrm{d} a=\mathrm{d} g / \mathrm{d} a$. Accordingly, $K_{\mathrm{f}} \approx 5.1$ and the tangent point corresponds to the largest non-propagating crack $a_{\max } \approx 160 \mu \mathrm{m}$ for the applied $\Delta \sigma_{\mathrm{n}}=32.7 \mathrm{MPa}$ which represents the fatigue limit of the $\mathrm{C}(\mathrm{T})$-like specimen analyzed.

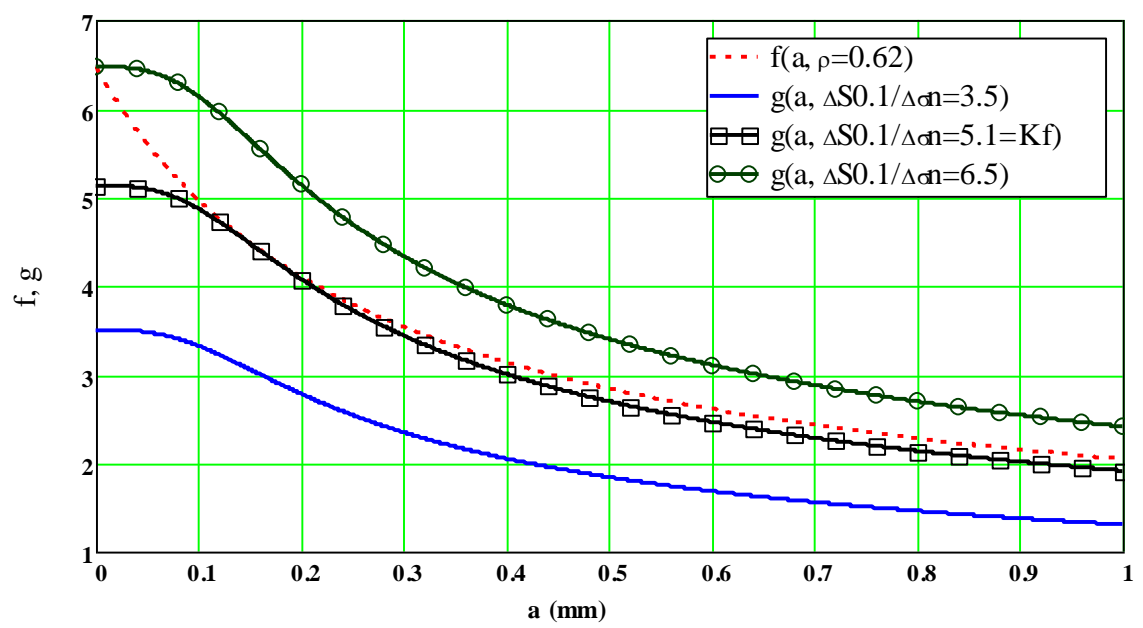

Figure A.1- Curves of the dimensionless $f$ and $g$ functions to calculate $K_{\mathrm{f}}$ for a Al6061T3 aluminum alloy $\mathrm{C}(\mathrm{T})$ specimen with $W=56 \mathrm{~mm}, t=10 \mathrm{~mm}, b=16 \mathrm{~mm}$, and $\rho=0.62 \mathrm{~mm}$. 


\section{A.3.}

\section{X-ray microCT 3D images from literature}

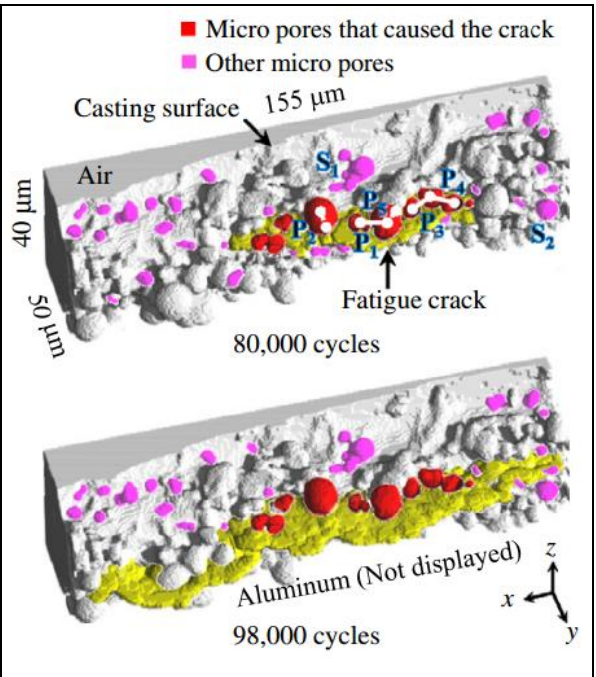

(a)

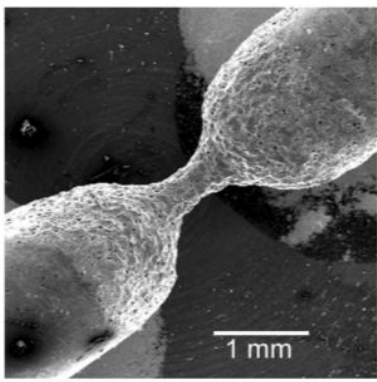

(b)

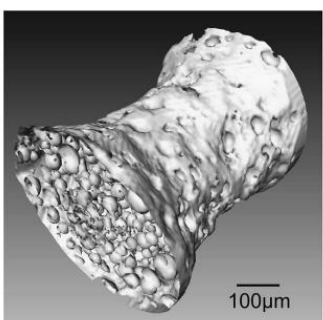

(c)

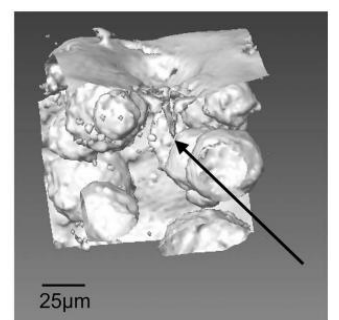

(d)

Figure A.2- a) 3D view of magnified fatigue crack initiation behavior in cast aluminum alloy specimens with internal micropores [78], b) miniature fatigue specimen with a gauge diameter of $0.35 \mathrm{~mm}, \mathrm{c}$ ) gauge volume of the specimen, and d) magnified region of the gauge volume, where a crack initiated form a pore is indicated by the arrow [76]. 